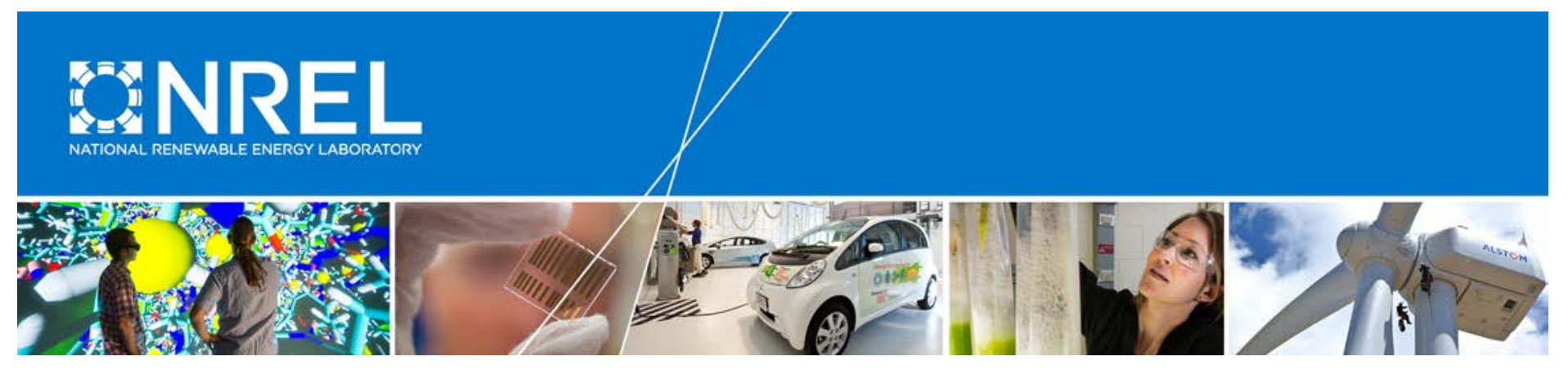

\title{
Water and Climate Impacts on Power System Operations: The Importance of Cooling Systems and Demand Response Measures
}

Jordan Macknick, Ella Zhou, Matthew O'Connell, and Gregory Brinkman National Renewable Energy Laboratory

Ariel Miara

The City College of New York; CUNY Advanced Science Research Center: Environmental Sciences Initiative

Eduardo Ibanez

GE Energy Connections

Marissa Hummon

Tendril

NREL is a national laboratory of the U.S. Department of Energy Office of Energy Efficiency \& Renewable Energy Operated by the Alliance for Sustainable Energy, LLC

This report is available at no cost from the National Renewable Energy Laboratory (NREL) at www.nrel.gov/publications.

Technical Report

NREL/TP-6A20-66714

December 2016

Contract No. DE-AC36-08GO28308 


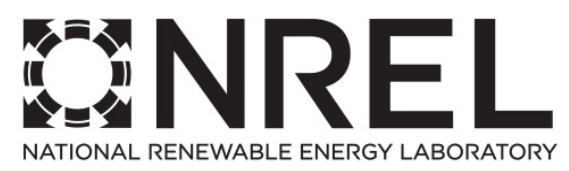

\section{Water and Climate Impacts on Power System Operations: The Importance of Cooling Systems and Demand Response Measures}

Jordan Macknick, Ella Zhou, Matthew O'Connell, and Gregory Brinkman National Renewable Energy Laboratory

Ariel Miara

The City College of New York; CUNY Advanced Science Research Center: Environmental Sciences Initiative

Eduardo Ibanez

GE Energy Connections

Marissa Hummon

Tendril

Prepared under Task Nos. EPSA.Z140, EP41.0101

NREL is a national laboratory of the U.S. Department of Energy Office of Energy Efficiency \& Renewable Energy Operated by the Alliance for Sustainable Energy, LLC

This report is available at no cost from the National Renewable Energy Laboratory (NREL) at www.nrel.gov/publications.

National Renewable Energy Laboratory 15013 Denver West Parkway Golden, CO 80401

303-275-3000 • www.nrel.gov
Technical Report

NREL/TP-6A20-66714

December 2016

Contract No. DE-AC36-08G028308 


\section{NOTICE}

This report was prepared as an account of work sponsored by an agency of the United States government. Neither the United States government nor any agency thereof, nor any of their employees, makes any warranty, express or implied, or assumes any legal liability or responsibility for the accuracy, completeness, or usefulness of any information, apparatus, product, or process disclosed, or represents that its use would not infringe privately owned rights. Reference herein to any specific commercial product, process, or service by trade name, trademark, manufacturer, or otherwise does not necessarily constitute or imply its endorsement, recommendation, or favoring by the United States government or any agency thereof. The views and opinions of authors expressed herein do not necessarily state or reflect those of the United States government or any agency thereof.

This report is available at no cost from the National Renewable Energy Laboratory (NREL) at www.nrel.gov/publications.

Available electronically at SciTech Connect http:/www.osti.gov/scitech

Available for a processing fee to U.S. Department of Energy and its contractors, in paper, from:

U.S. Department of Energy

Office of Scientific and Technical Information

P.O. Box 62

Oak Ridge, TN 37831-0062

OSTI http://www.osti.gov

Phone: 865.576.8401

Fax: 865.576.5728

Email: reports@osti.gov

Available for sale to the public, in paper, from:

U.S. Department of Commerce

National Technical Information Service

5301 Shawnee Road

Alexandria, VA 22312

NTIS http://www.ntis.gov

Phone: 800.553 .6847 or 703.605 .6000

Fax: 703.605.6900

Email: orders@ntis.gov 


\section{Acknowledgments}

This work was supported by the U.S. Department of Energy Office of Energy Policy and Systems Analysis under Contract No. DE-AC36-08GO28308 with the National Renewable Energy Laboratory as well as the National Science Foundation Water Sustainability and Climate grant No. 1360445. The authors wish to thank John Agan, Diana Bauer, Joe Bryson, Judi

Greenwald, Sean Ramach, Bob Rose, and Jenah Zweig for their review of this work. We are also indebted to Aaron Bloom, David Mooney, and Adam Warren for their thoughtful comments, input, and review of the document in its various stages. We also wish to thank Kathy Cisar, Karin Haas, and Billy Roberts for their editorial and graphics support. 


\section{Acronyms and Abbreviations}

CWA

DR

ELCC

FrAMES

GW

GWh

LOLE

NREL

PLEXOS

REPRA

TP2M

TWh

WBM
Clean Water Act

demand response

effective load-carrying capability

Framework for Aquatic Modeling in the Earth

System

gigawatt

gigawatt-hour

loss of load expectation

National Renewable Energy Laboratory

PLEXOS Integrated Energy Model

Renewable Energy Probabilistic Resource

Assessment

Thermoelectric Power and Thermal Pollution terawatt-hour

Water Balance Model 


\section{Abstract}

The U.S. electricity sector is highly dependent upon water resources; changes in water temperatures and water availability can affect operational costs and dispatch decisions of power systems. Despite the importance of water for power system operations, the effects of changes in water temperature and availability on the generators in a power system are generally not modeled. Moreover, demand response measures, which can change the magnitude and timing of loads and can have beneficial impacts on power system operations, have not yet been evaluated in the context of water-related power sector vulnerabilities. This effort provides a first comprehensive assessment of cost, dispatch, and vulnerability issues associated with waterdriven impacts on a modeled power system and the potential for demand response measures to alleviate negative effects. This study uniquely combines outputs and inputs of a water and power plant system model, electricity production cost model, and relative capacity value model to look at variations in cooling systems, policy-related thermal-induced curtailments, and demand response measures to characterize costs and vulnerability for a test power system. Scenario results show that the dispatch of generation technologies and system costs can greatly be affected by the inclusion of water- and temperature-related impacts on power plant heat rates, the types of cooling systems employed, whether or not policy-related thermal-induced curtailments are included, and whether demand response measures are implemented. This effort also highlights inherent limitations and suggests opportunities for improving power system modeling in the context of water and climate-related vulnerabilities to improve the applicability of results. 


\section{Executive Summary}

The electricity sector is highly dependent on reliable supplies of water for operation. Changes in the temperature of water or other ambient conditions can affect the heat rates and the ability of generators to meet loads, due to both engineering and policy factors. The fuel type and cooling system type of generators have a role in determining how much water is required by a generator and how it is affected by changes in water resources. Over the past decade, there have been more than three dozen incidents where thermal power plants have been forced to curtail generation or shut down due to water-related temperature and availability issues (Figure ES - 1).

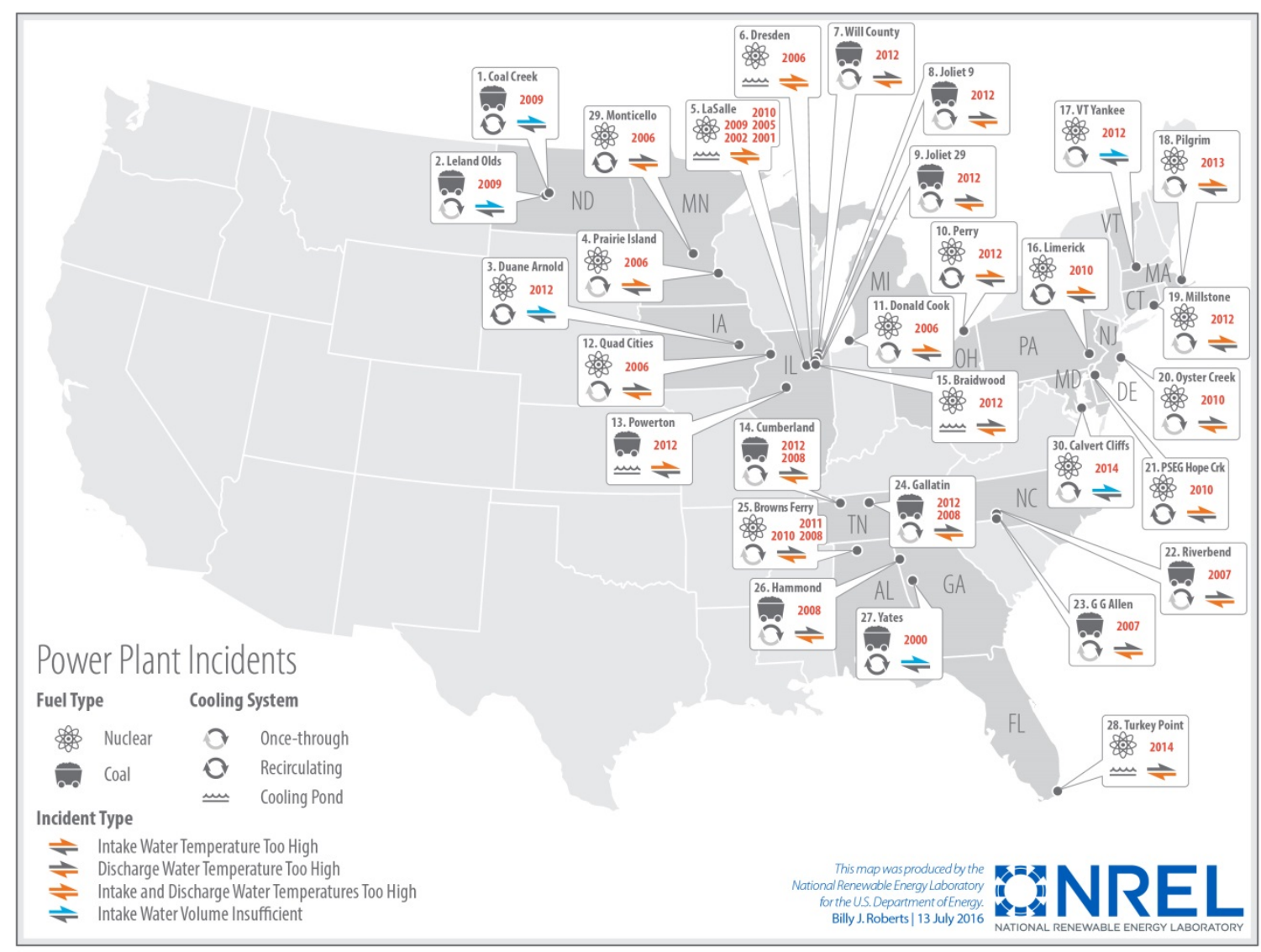

Figure ES - 1. Location of recent thermal power plant curtailments and shut downs due to waterrelated causes

Despite the importance of cooling system types as well as climate and water resource conditions on individual power plant performance, most studies of power plant operations using electricity production cost models do not consider these factors. This means that key characteristics are omitted that could affect power plant heat rates, power plant availability, system production costs, and generation technology dispatch decisions. This study builds and improves upon existing literature by providing the first comprehensive assessment of cooling system characteristics and water temperature characteristics on the operations of a power system, both in terms of costs and system performance. We evaluate changes in cooling system combinations as 
well as the inclusion of water-related policy constraints that can force power plants to reduce generation.

In addition, we examine the potential for demand response (DR) measures to provide services that aid in the efficient management of the power system and quantify any additional benefits related to water-related vulnerabilities. Historically, applications for DR measures have been limited and used primarily for emergencies and peak shaving. We provide a dual unique contribution by considering the impacts that air temperatures, humidity, and water temperatures can have on power plant performance and power system operations, while also considering how DR measures can offset these weather and climate-driven conditions.

This study uniquely combines outputs and inputs of a water and power plant system model (Thermoelectric Power and Thermal Pollution Model), production cost model (PLEXOS Integrated Energy Model), and relative capacity value model (Renewable Energy Probabilistic Resource Assessment tool) to consider variations in cooling systems, policy-related thermal curtailments, and DR measures to characterize costs and vulnerability for a test power system.

A $25 \mathrm{GW}$ (producing $78 \mathrm{TWh}$ annually) test case was analyzed in PLEXOS for one calendar year that roughly corresponds to the generation mix in the Eastern United States in 2010. Twenty-five scenarios in total were analyzed. In the baseline scenario, no climate- and waterrelated impacts on generation are considered and DR resources are not available. The remaining scenarios include representations of additional determinants to better reflect how power systems operate in reality. These determinants include: (1) inclusion of climate- and water-related impacts on efficiencies and curtailments, (2) inclusion of demand response measures, and (3) the choice of cooling system.

Four unique takeaways result from this work, highlighting ways in which production cost modeling activities could be improved:

1. The inclusion of water and air temperature characteristics and cooling system configurations can substantially alter production costs and dispatch decisions

2. Enforcing water-related thermal limits for power plants can have large impacts on system level operations and costs

3. Demand response measures can reduce annual system costs and reduce demands during peak periods for water-impacted systems

4. The impacts of demand response measures on water-related vulnerabilities are subtle.

These four takeaways are described in more detail below.

The inclusion of water and air temperature characteristics and cooling system configurations can substantially alter technology dispatch decisions and system production costs

Although most electricity production cost models do not consider the impacts of water and air temperature characteristics, the inclusion of these elements on electric generators leads to substantial changes in annual generation dispatch decisions, with noticeable trends related to which cooling system types are employed. Compared with the baseline scenario (which does not include water-related impacts or cooling system configurations), all scenarios and all cooling 
system configurations show differences in annual electricity dispatch decisions. Annual generation value differences from the baseline scenario for individual technologies ranged from a $21 \%$ reduction to a $17 \%$ increase. Table ES - 1 highlights the technology-specific changes in annual generation from the baseline scenario that result from including water-related impacts on the test region with and without DR resources.

Table ES - 1. Changes in Annual Generation from Baseline Scenario due to the Inclusion of WaterRelated Impacts

\begin{tabular}{|lll|}
\hline Technology & $\begin{array}{l}\text { Generation difference } \\
\text { ranges in scenarios } \\
\text { without DR compared with } \\
\text { the baseline }\end{array}$ & $\begin{array}{l}\text { Generation difference } \\
\text { ranges in scenarios with } \\
\text { DR compared with the } \\
\text { Baseline }\end{array}$ \\
\hline NGCC & $-1 \%$ to $10 \%$ & $-5 \%$ to $8 \%$ \\
\hline NGCT & $-16 \%$ to $9 \%$ & $1 \%$ to $17 \%$ \\
\hline Coal & $-3 \%$ to $1 \%$ & $0 \%$ to $3 \%$ \\
\hline Nuclear & -21 to $0 \%$ & $-20 \%$ to $0 \%$ \\
\hline NGCC=natural gas combined cycle; & NGCT=natural gas combustion turbine; DR=demand response
\end{tabular}

Changes in dispatch due to water-related factors and cooling system characteristics also lead to changes in system level costs. In general, compared to the baseline, production costs are higher for scenarios that include water-related impacts and cooling system characteristics, which take into consideration efficiency losses. There are two exceptions to this trend. First, when there are no thermal curtailments considered, scenarios with high penetrations of once-through technologies can show lower production costs due to the superior performance of power plants that are once-through cooled with favorable water temperature conditions. Second, scenarios that include DR measures have consistently lower costs than scenarios without DR measures, and many of these have lower costs than the baseline scenario. On an annual basis, production costs from scenarios that do not include DR measures could be as much as $4.9 \%$ higher than the baseline scenario costs, with summer monthly costs as large as $22 \%$ higher. Production costs from scenarios that do include DR measures could be as much as $4.3 \%$ higher than the baseline scenario costs, with summer monthly costs as large as $21 \%$ higher. This indicates that demand response measures can reduce modeled production costs, even when cooling system characteristics are taken into consideration. Table ES - 2 highlights the changes in annual and summer month production costs from the baseline scenario that result from including waterrelated impacts on the test region and whether DR impacts are included. 
Table ES - 2. Changes in Annual Production Costs from Baseline Scenario due to the Inclusion of Water-Related Impacts

\begin{tabular}{|lll|} 
Timeframe & $\begin{array}{l}\text { Cost difference ranges in } \\
\text { scenarios without DR } \\
\text { compared with the } \\
\text { baseline }\end{array}$ & $\begin{array}{l}\text { Cost difference ranges in } \\
\text { scenarios with DR } \\
\text { compared with the } \\
\text { baseline }\end{array}$ \\
\hline Annual & $-0.1 \%$ to $4.9 \%$ & $-1.4 \%$ to $4.3 \%$ \\
\hline June & $-1.6 \%$ to $2.7 \%$ & $-2.8 \%$ to $0.2 \%$ \\
\hline July & $1.2 \%$ to $22.3 \%$ & $0.9 \%$ to $20.7 \%$ \\
\hline August & $1.2 \%$ to $21.2 \%$ & $0.6 \%$ to $19.7 \%$ \\
\hline
\end{tabular}

The ranges in both annual costs as well as summer month costs indicate that the inclusion of water-related impacts and cooling system characteristics can have a meaningful impact on production cost analyses. Climate- and water-related impacts can be especially important when regulatory thermal limits are enforced.

\section{Enforcing water-related thermal limits for power plants can have large impacts on system level operations}

Water-related thermal limits are the primary driver of power plant curtailments shown in Figure ES - 1. Clean Water Act (CWA) regulations set limits on the impacts that power plants can have on water body temperatures, either as a maximum temperature or a maximum allowable increase in water temperature. These limits are based on water quality standards developed by each state to protect aquatic life and human health in the receiving waterbody as required by the CWA. In this analysis we assume strict adherence to CWA thermal regulations to evaluate the impacts that regulations can have on system level costs and operations. Figure ES - 2 highlights the changes in annual generation that result from enforcement of water-related thermal limits for different penetrations of once-through cooling systems, where positive values indicate technologies that generate more due to the enforced curtailments, and negative values indicate less. 

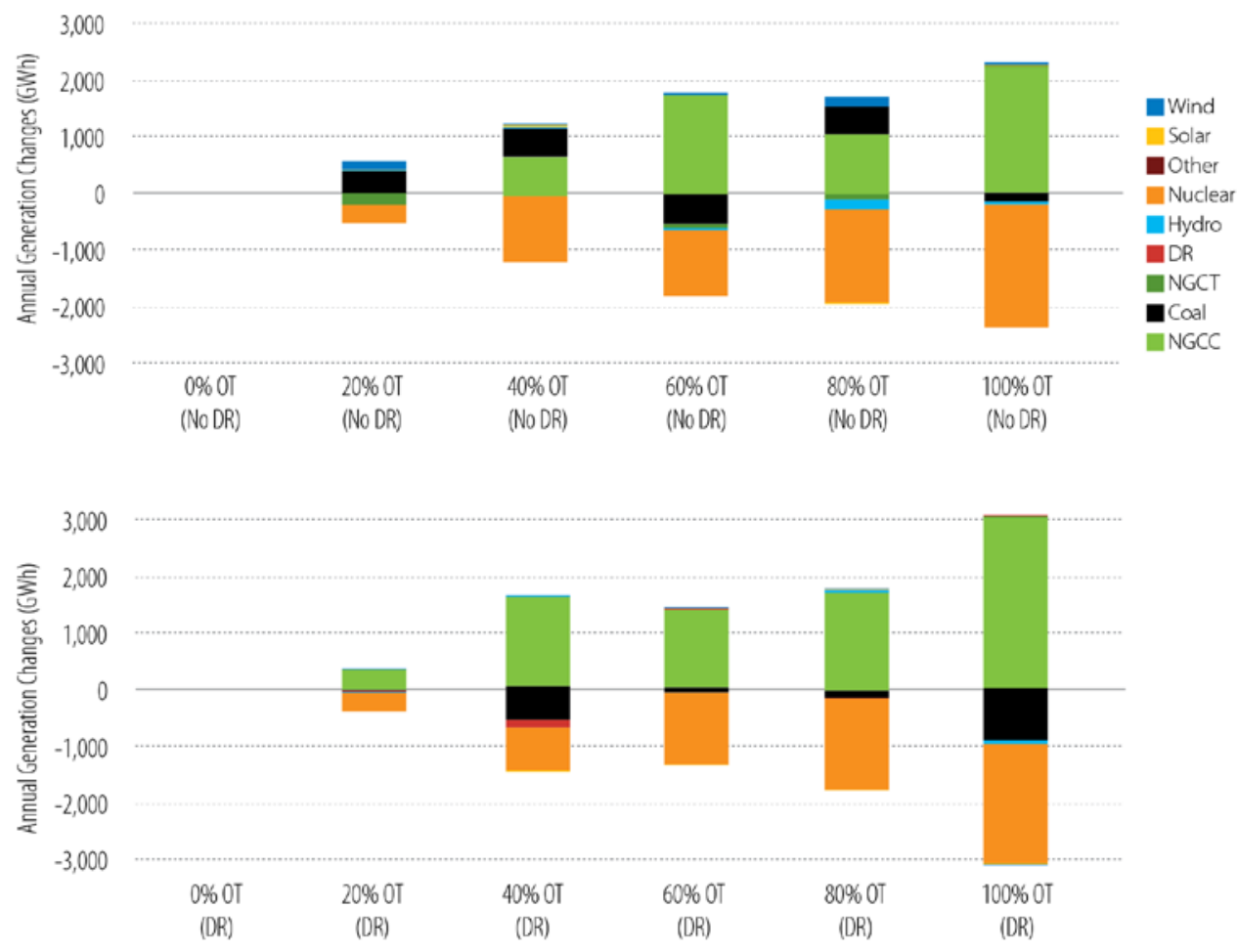

Figure ES - 2. Total annual generation differences for scenarios with thermal curtailments minus scenarios without thermal curtailments in cases without DR (top) and with DR (bottom)

$\mathrm{OT}=$ once-through cooling; $\mathrm{NGCC}=$ natural gas combined cycle; $\mathrm{NGCT}=$ natural gas combustion turbine; $\mathrm{DR}=$ demand response

In the analysis performed on the test system, CWA thermal regulations tend to affect oncethrough cooled facilities more than recirculating cooled facilities, and in this study as the percentage of once-through cooled technologies increases, the magnitude of dispatch changes in annual generation increases. When there are no once-through cooled generators in the system $(0 \%$ OT), the enforcement of thermal limits has no impact on technology dispatch. When all thermal generators are cooled with once-through technologies (100\% OT), scenarios with thermal limits enforced lead to $13 \%$ more natural gas combined cycle generation, $21 \%$ less nuclear generation, and 3\% less coal generation than scenarios without thermal limits enforced. Natural gas combined cycle generation increases in nine of the 12 comparative cases, reflecting its higher efficiency, its ability to ramp up and down to make up for lost generation from nuclear and coal technologies, and it often being the cheapest marginal generator during times when other generators are affected.

When thermal limits are enforced, there is a clear trend in production cost increases. As the share of once-through cooling technologies increases in the fleet, production costs increase due to the baseload generators being curtailed and higher cost yet more flexible generation technologies being dispatched. Table ES - 3 shows production cost increase trends on the test system based on the types of cooling systems deployed. 
Table ES - 3. Annual Production Cost Changes Resulting from Thermal Limit Enforcement

\begin{tabular}{|ll|}
\hline Cooling type & Range of annual production cost changes \\
\hline $\mathbf{0} \%$ Once-through & No change \\
\hline $\mathbf{2 0} \%$ Once-through & $-1.4 \%$ to $0.0 \%$ \\
\hline $\mathbf{4 0} \%$ Once-through & $0.4 \%$ to $1.1 \%$ \\
\hline $\mathbf{6 0} \%$ Once-through & $2.4 \%$ to $3.0 \%$ \\
\hline $\mathbf{8 0} \%$ Once-through & $2.3 \%$ to $2.4 \%$ \\
\hline $\mathbf{1 0 0} \%$ Once-through & $3.5 \%$ to $4.9 \%$ \\
\hline
\end{tabular}

\section{Demand response measures can reduce annual system costs and reduce demands during peak periods for water-impacted systems}

As demand response measures largely target peak electricity demands, they have the effect of reducing generation from generators that follow load, such as natural gas combined cycle, across all scenarios. As some loads are also shifted to other times of the day when loads can be met by baseload generation, they also lead to greater levels of coal and nuclear generation under the assumptions considered. Note that this work gave no consideration to carbon prices, the U.S. Environmental Protection Agency's Clean Power Plan, state or regional greenhouse gas regulations, or to sensitivities associated with natural gas price assumptions; adding in these elements could further alter the dispatch decisions.

DR measures were implemented in PLEXOS in two ways: sheddable and schedulable load resources. In total, the DR included in the study amounts to an annual cumulative availability of $374.17 \mathrm{GWh}$, or $0.4 \%$ of the total electricity use to provide energy and operating reserves. DR measures, despite representing a small percentage of generation and capacity, can substantially alter the dispatch of technologies in an entire system, often leading to reductions in costs. Table ES - 4 highlights the range of generation impacts that DR measures had on the scenarios considered.

Table ES - 4. Impacts of Demand Response Measures on Annual Electricity Generation by Technology Type

\begin{tabular}{|ll|}
\hline Technology & $\begin{array}{l}\text { Range of changes in annual } \\
\text { generation resulting from DR } \\
\text { measures }\end{array}$ \\
\hline NGCC & $-8 \%$ to $0 \%$ \\
\hline Nuclear & $-3 \%$ to $26 \%$ \\
\hline Coal & $-2 \%$ to $4 \%$ \\
\hline
\end{tabular}

NGCC=natural gas combined cycle; NGCT=natural gas combustion turbine; $\mathrm{DR}=$ demand response

Importantly, DR measures often lead to lower generation levels of natural gas combined cycle technologies and higher generation levels of nuclear and coal technologies, counteracting the 
annual generation trends caused by water-related impacts. DR measures also counteract the cost increases that result from water-related impacts, often leading to reductions in system costs from the baseline scenario as well as scenarios that do not include DR measures. Figure ES - 3 shows the annual system costs for scenarios with and without DR measures.

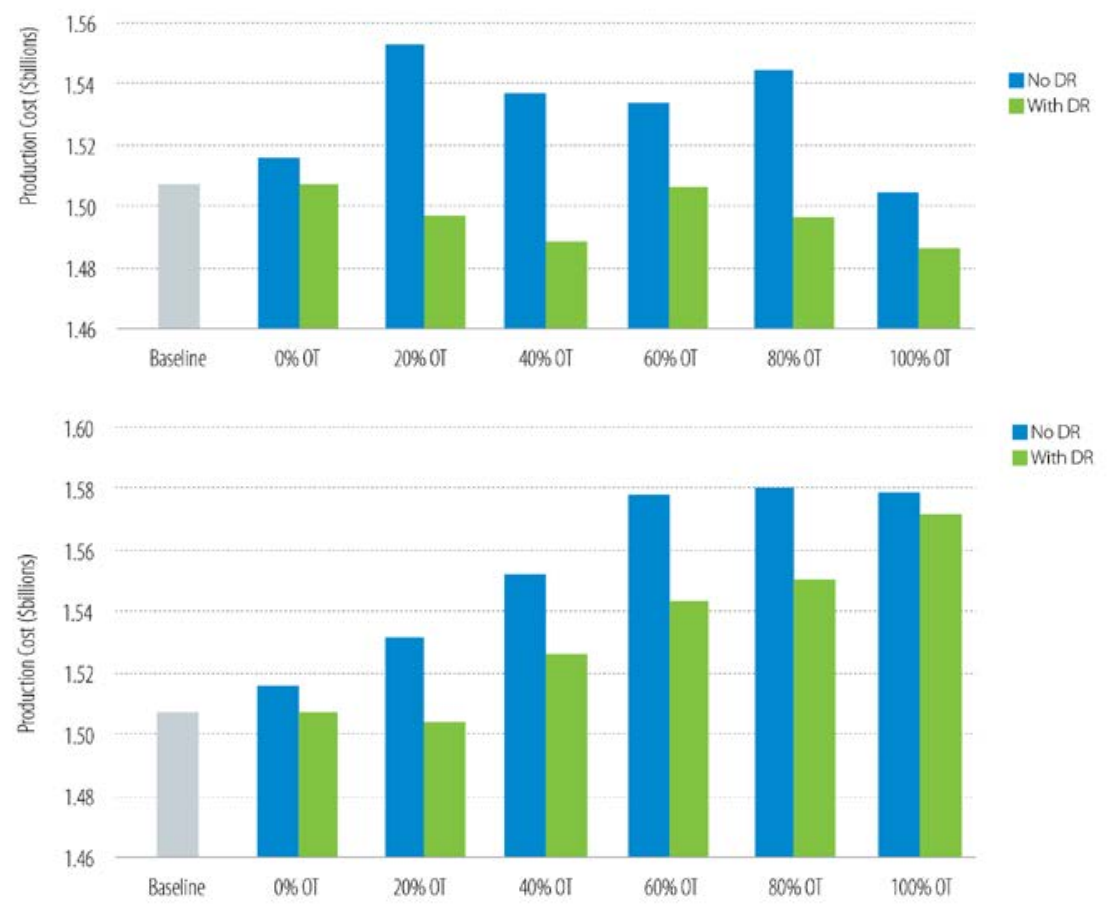

Figure ES - 3. Impacts of demand response measures on electricity generation costs without water-related thermal curtailments (top) and with curtailments (bottom)

$\mathrm{OT}=$ once-through cooling; $\mathrm{DR}=$ demand response

For any given case of once-through cooling penetration, scenarios with DR have lower costs than scenarios without DR. In many scenarios, DR scenarios have lower costs than the baseline scenario. For scenarios that include water-related thermal curtailments (bottom of Figure ES - 3), DR measures tend to lessen the cost increases that result from curtailments.

\section{The impacts of demand response on water-related vulnerabilities are subtle}

DR measures were found to lessen the negative impacts of water-related thermal curtailments on the effective load-carrying capability (ELCC) of the system compared with scenarios without DR. Evaluating the ELCC for these scenarios can clearly show the impacts of cooling systems, curtailments, and demand response measures on system reliability. The reduction in ELCC is most drastic when comparing cases with and without curtailments. Both the with-demand response and the no-demand response cases show that including curtailments leads to a reduction in ELCC of approximately 1.2\%. The effects of including cooling system characteristics on the system leads to a change in ELCC of approximately $0.5 \%$ for the no-curtailment case and $1.6 \%$ for the curtailment case. Including demand response measures leads to an increase of ELCC of approximately $0.2 \%$ over scenarios that do not include demand response measures. Figure ES - 4 highlights changes in ELCC for two scenarios. 

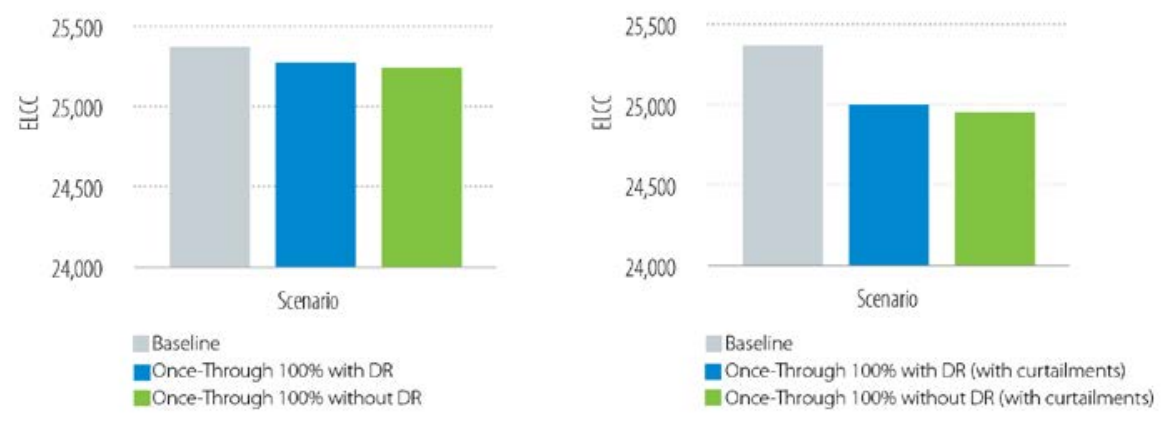

Figure ES - 4. Comparison of effective load-carrying capability for $100 \%$ once-through cooling system scenarios without curtailment (left) and with curtailment (right) for the baseline scenario and scenarios with and without demand response

$E L C C=$ effective load-carrying capability; $D R=$ demand response

Despite improving ELCC metrics, DR measures can lead to slight increases in system level water withdrawal and consumption values on an annual basis, due to the reduction in generation from natural gas combined cycle technologies, and the increase in generation from the higher water withdrawing and consuming coal and nuclear technologies. Water withdrawal impacts ranged from a $0.1 \%$ decrease to a $5.9 \%$ increase on a system level and water consumption impacts ranged from a $0.3 \%$ decrease to a $1.9 \%$ increase.

Results from this work suggest that water resource considerations can substantially affect the performance of individual electricity generators, technology dispatch decisions, total energy system costs, and system reliability. Demand response measures can play a role in reducing system costs, changing the magnitude and type of generators dispatched, and can also have a subtle role in improving system reliability in the context of water-related vulnerabilities. The novel modeling framework used here, which links inputs and outputs from a climate-hydrology and power plant operations model, an electricity production cost model, and a capacity value model, enables a comprehensive assessment of multiple energy sector characteristics that are affected by water resource considerations. Specifically, this effort highlights the importance of water resource and climate considerations in energy system modeling related to cooling system characteristics, water policies and regulations, and demand-side energy management, while also providing a foundation upon which future production cost modeling efforts can expand and improve. 


\section{Table of Contents}

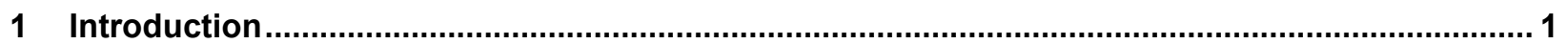

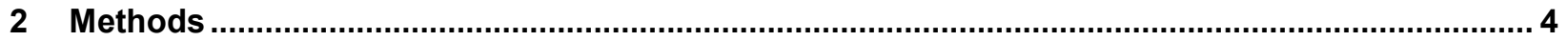

2.1 Climate, Hydrology, and Power Plant Performance .............................................................. 4

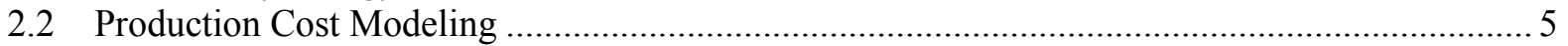

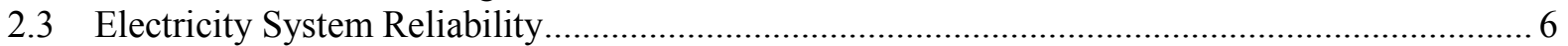

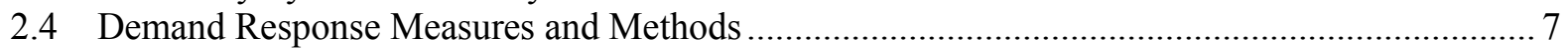

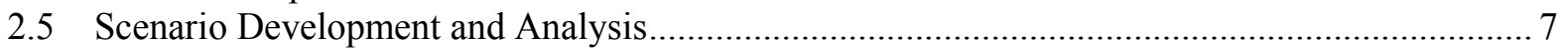

2.6 Water Withdrawal and Consumption Impacts ....................................................................... 9

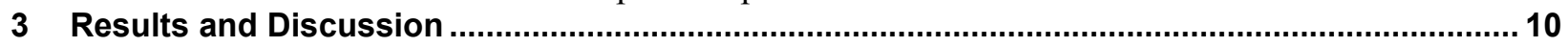

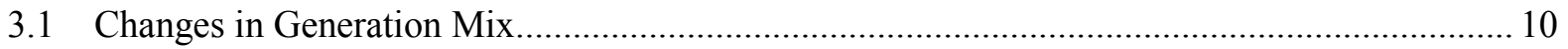

3.1.1 Comparisons of Generation Results with Baseline Scenario ........................................ 11

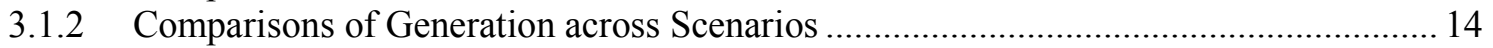

3.1.3 Summary of Changes in System Generation by Technology Type .............................. 16

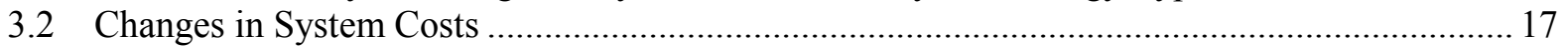

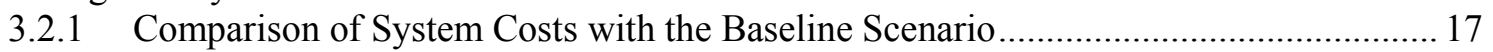

3.2.2 Comparisons of System Costs across Scenarios ........................................................ 18

3.2.3 Summary Impacts on System Level Costs ............................................................. 19

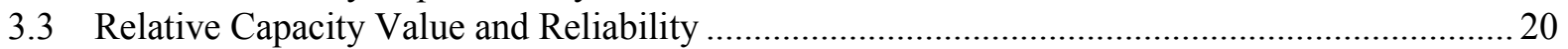

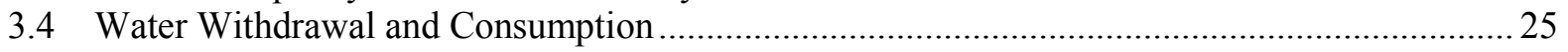

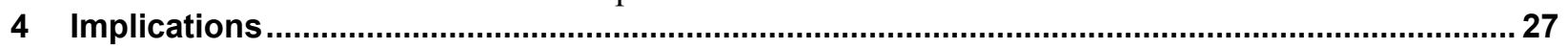

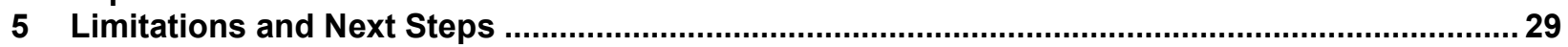

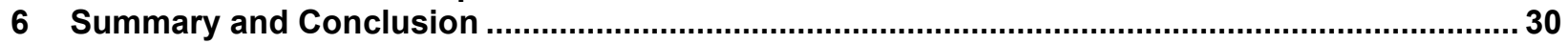

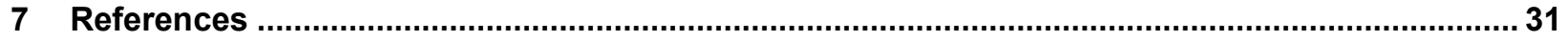

Appendix A. Detail on Water-Related Power Plant Curtailments ....................................................... 36

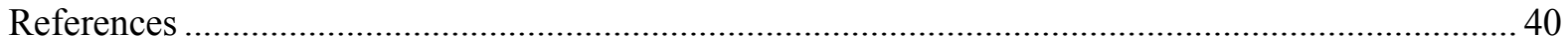

Appendix B. TP2M Results on Technology Efficiencies........................................................... 42

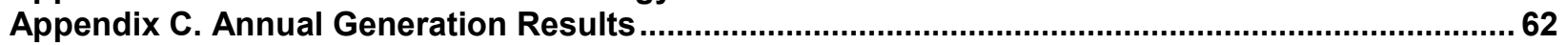

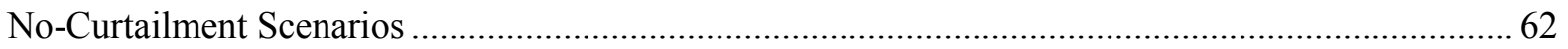

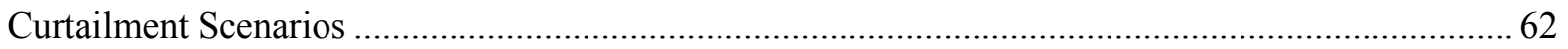

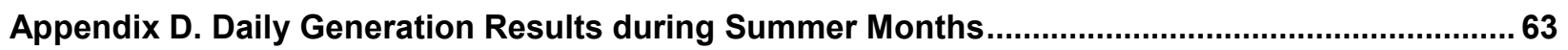

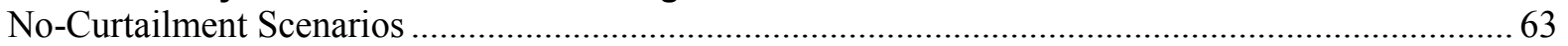

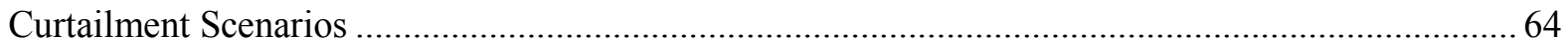

\section{Figures and Tables}

Figure ES - 1. Location of recent thermal power plant curtailments and shut downs due to water-related causes .................................................................................................................... vi

Figure ES - 2. Total annual generation differences for scenarios with thermal curtailments minus scenarios without thermal curtailments in cases without DR (top) and with DR (bottom) ..... $\mathrm{x}$

Figure ES - 3. Impacts of demand response measures on electricity generation costs without water-related thermal curtailments (top) and with curtailments (bottom) ............................................... xii

Figure ES - 4. Comparison of effective load-carrying capability for 100\% once-through cooling system scenarios without curtailment (left) and with curtailment (right) for the baseline scenario and scenarios with and without demand response .....................................................................ii

Figure 1. Location of recent power plant curtailments and shut downs due to water-related causes ........... 1

Figure 2. Schematic of models and data flows in analysis ................................................................. 4

Figure 3. Daily power plant efficiencies for different fuel and cooling system technologies from TP2M...5

Figure 4. Overview of scenarios considered in this analysis ............................................................... 8

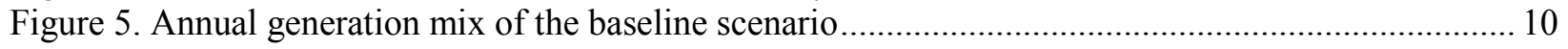

Figure 6. Summer generation dispatch stack of the baseline scenario $(\mathrm{GWh})$........................................ 10 
Figure 7. Change in annual generation $(\mathrm{GWh})$ from baseline scenario for scenarios without water-related thermal regulations and without demand response (top) and including demand response (bottom).

Figure 8. Change in annual generation $(\mathrm{GWh})$ from baseline scenario for scenarios with water-related thermal regulations and without demand response (top) and including demand response (bottom)

Figure 9. Comparison of annual generation mix for water-related curtailment scenarios minus noncurtailment scenarios (GWh) without demand response (top) and with demand response (bottom).

Figure 10. Impacts of demand response measures on electricity generation mixes across scenarios without water-related curtailments (top) and with water-related curtailments (bottom).................... 15

Figure 11. Total annual production costs across no-water-related curtailment scenarios and the baseline 17

Figure 12. Total annual production costs across water-related curtailment scenarios and the baseline ..... 18

Figure 13. Impacts of including demand response measures on production costs across scenarios without water-related curtailments (top) and those with water-related curtailments (bottom) ........... 19

Figure 14. Comparison of daily capacity and maximum daily load for $0 \%$ once-through cooling (left) and $100 \%$ once-through (right) for scenarios with no water-related curtailment .......................... 21

Figure 15. Comparison of daily capacity and maximum daily load for $100 \%$ once-through cooling system scenarios without water-related curtailment (left) and with water-related curtailment (right)22

Figure 16. Comparison of daily capacity and maximum daily load for $100 \%$ once-through cooling system scenarios with water-related curtailment that do not include demand response (left) and that

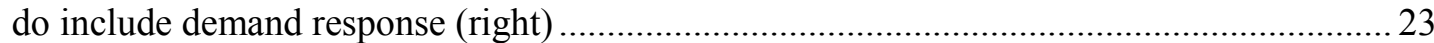

Figure 17. Comparison of daily capacity and maximum daily load for $100 \%$ once-through cooling system scenarios without water-related curtailment (left) and with water-related curtailment (right) for systems without demand response......

Figure 18. Comparison of effective load-carrying capability for $100 \%$ once-through cooling system scenarios without water-related curtailment (left) and with water-related curtailment (right)24

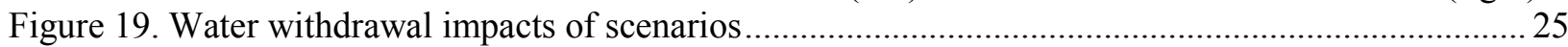

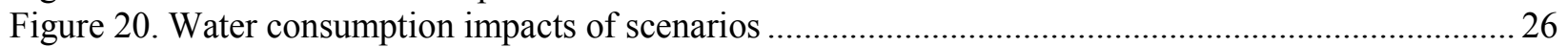

Figure D - 1. Comparison of generation mixes on an hourly basis for summer months (June, July, and August) for $100 \%$ recirculating cooling thermal systems (top) and $100 \%$ once-through cooling systems (bottom) with no curtailments compared with the baseline scenario

Figure D - 2. Comparison of generation mixes on an hourly basis for summer months (June, July, and August) for $100 \%$ recirculating cooling thermal systems (top) and 100\% once-through cooling systems (bottom) with curtailments compared with the baseline scenario

Table ES - 1. Changes in Annual Generation from Baseline Scenario due to the Inclusion of WaterRelated Impacts..................................................................................................................viii

Table ES - 2. Changes in Annual Production Costs from Baseline Scenario due to the Inclusion of Water-

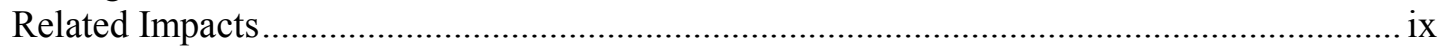

Table ES - 3. Annual Production Cost Changes Resulting from Thermal Limit Enforcement ................... xi

Table ES - 4. Impacts of Demand Response Measures on Annual Electricity Generation by Technology

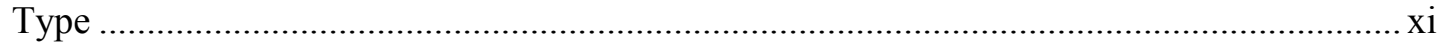

Table 1. Demand Response Products and Physical Requirements ........................................................ 2

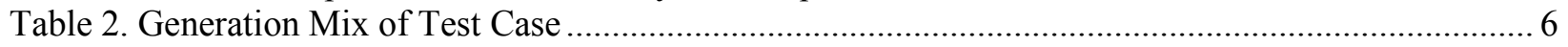

Table 3. Changes in Annual Generation from Baseline Scenario due to the Inclusion of Water-Related

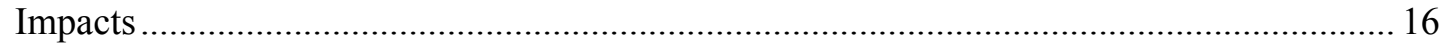

Table 4. Impacts of Demand Response Measures on Annual Electricity Generation by Technology

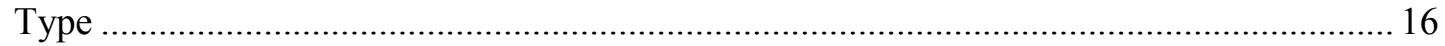

Table 5. Changes in Annual Production Costs from Baseline Scenario due to the Inclusion of Water-

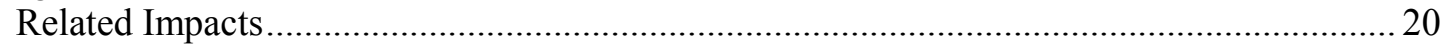


Table 6. Annual Production Cost Changes Resulting from Water-Related Thermal Regulation

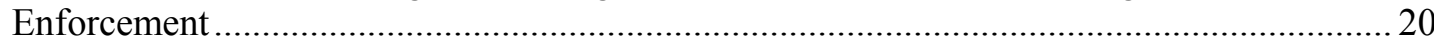

Table A - 1. Detail on Water-Related Power Plant Curtailments............................................................. 36

Table B - 1. Daily Power Plant Efficiency Multipliers by Technology Type for Scenarios with No Curtailments

Table B - 2. Daily Power Plant Efficiency Multipliers by Technology Type for Scenarios with Curtailments

Table C - 1. Annual Generation from Technologies under Scenarios with No Curtailments (GWh) ........ 62

Table C - 2. Annual Generation from Technologies under Scenarios with Curtailments (GWh) 


\section{Introduction}

The electricity sector is highly dependent upon the availability of water resources for operation and is responsible for $41 \%$ of national freshwater withdrawals (Maupin et al. 2014). This dependency on water resources, both in terms of quantity available and appropriate temperatures for operating power plants to comply with thermal permit limits (EPA 2009), has led to instances where power plants have had to curtail generation or shut down when water resources are inadequate (Averyt et al. 2013; Rogers et al. 2013; McCall et al. 2016). Figure 1 highlights recent power plant curtailments and shut downs that have resulted from water-related causes.

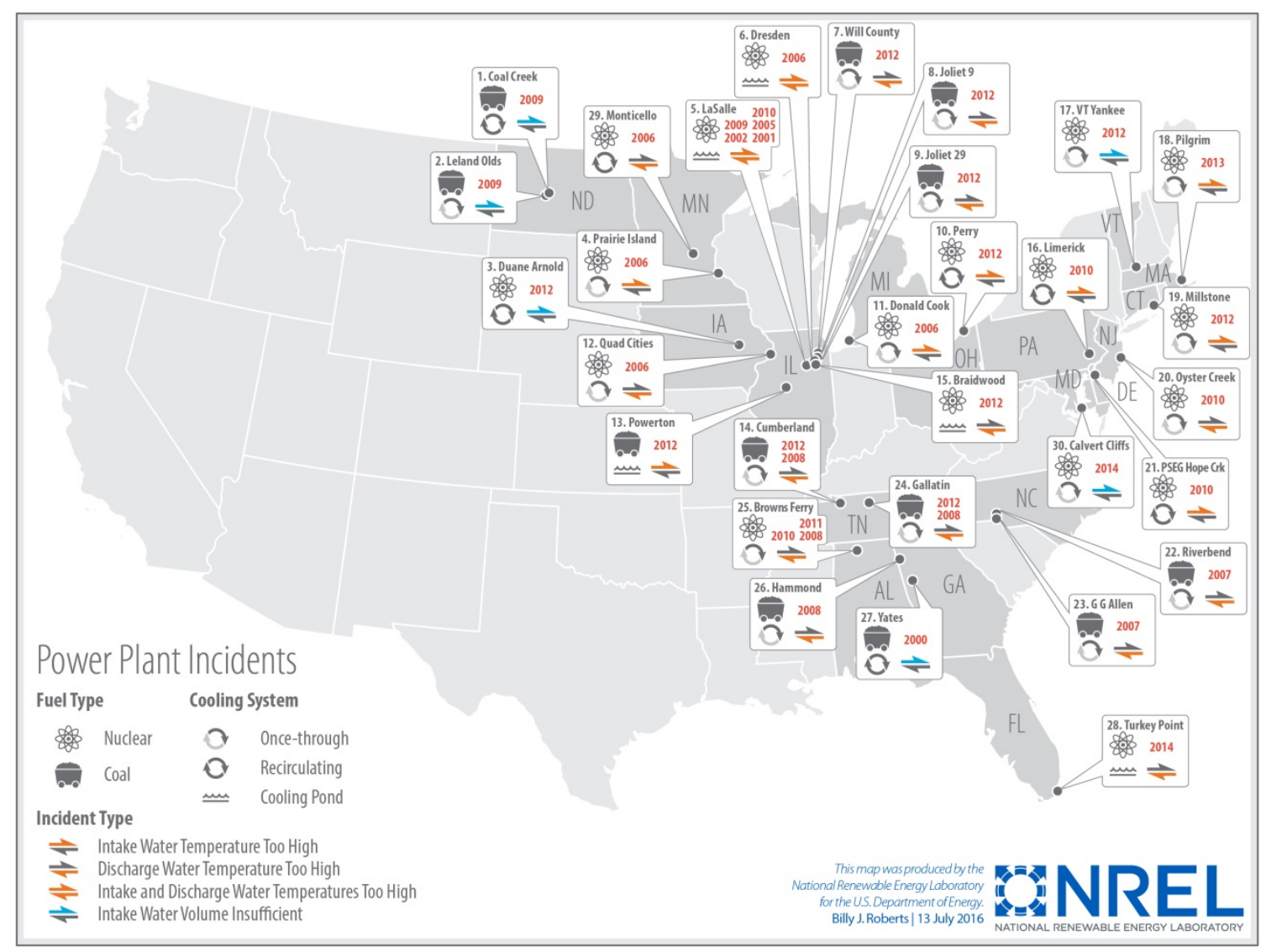

Figure 1. Location of recent power plant curtailments and shut downs due to water-related causes

Additional information on water-related power plant curtailments is found in Appendix A. Further detail on historical power plant curtailment and shutdown incidents, including contributing factors leading to curtailments and adaptation methods adopted by power plant operators, are described in a companion study (McCall et al. 2016).

Increases in air and water temperatures can lead to reductions in power plant efficiencies and capacities before curtailments are necessary, lessening the ability of those generators to meet load (NETL 2008). Given global climate trends and projections, many regions in the United States will experience increases in average air temperatures as well as changes in the magnitude 
and seasonality of precipitation (Kundzewicz et al. 2008). These climate-induced changes could affect electricity demand as well as the performance and capabilities of generators to meet load, as increases in temperatures are likely to occur during the hottest part of the day when load is already at its highest (Sullivan et al. 2015).

One effective mechanism for reducing peak demands and stress on generators is a suite of programs called demand response (DR) (Albadi and El-Saadany 2008; Palensky and Dietrich 2011; Cappers et al. 2010). DR mechanisms can reduce demand during key times through automated or manual shifting or shut downs of loads (Palensky and Dietrich 2011; Torriti et al. 2010; Aghaei and Alizadeh 2013; Paulus and Borggrefe 2011; Sæle and Grande 2011). A variety of products that DR measures can provide are shown in Table 1, along with a description of their physical requirements (Olsen et al. 2013).

Table 1. Demand Response Products and Physical Requirements

\begin{tabular}{|c|c|c|c|c|c|}
\hline \multicolumn{2}{|r|}{ Products } & \multicolumn{4}{|c|}{ Physical Requirements } \\
\hline $\begin{array}{l}\text { Product } \\
\text { Type }\end{array}$ & General Description & $\begin{array}{l}\text { How fast to } \\
\text { respond }\end{array}$ & $\begin{array}{l}\text { Length of } \\
\text { response }\end{array}$ & $\begin{array}{l}\text { Time to fully } \\
\text { respond }\end{array}$ & How often called \\
\hline Regulation & $\begin{array}{l}\text { Response to random } \\
\text { unscheduled deviations } \\
\text { in scheduled net load } \\
\text { (bidirectional) }\end{array}$ & 30 seconds & $\begin{array}{l}\text { Energy } \\
\text { neutral in } 15 \\
\text { minutes }\end{array}$ & 5 minutes & $\begin{array}{l}\text { Continuous } \\
\text { within specified } \\
\text { bid period }\end{array}$ \\
\hline Flexibility & $\begin{array}{l}\text { Additional load- } \\
\text { following reserve for } \\
\text { large un-forecasted } \\
\text { wind/solar ramps } \\
\text { (bidirectional) }\end{array}$ & 5 minutes & 1 hour & 20 minutes & $\begin{array}{l}\text { Continuous } \\
\text { within specified } \\
\text { bid period }\end{array}$ \\
\hline Contingency & $\begin{array}{l}\text { Rapid and immediate } \\
\text { response to a loss in } \\
\text { supply }\end{array}$ & 1 minute & $\leq 30$ minutes & $\leq 10$ minutes & $\leq$ Once per day \\
\hline Energy & $\begin{array}{l}\text { Shed or shift energy } \\
\text { consumption over time }\end{array}$ & 5 minutes & $\geq 1$ hour & 10 minutes & $\begin{array}{l}1-2 \text { times per } \\
\text { day with } 4-8 \\
\text { hour notification }\end{array}$ \\
\hline Capacity & $\begin{array}{l}\text { Ability to serve as an } \\
\text { alternative to } \\
\text { generation }\end{array}$ & $\begin{array}{l}\text { Top } 20 \text { hours } \\
\text { system peak }\end{array}$ & oincident w & alancing aut & ity area \\
\hline
\end{tabular}

Source: Olsen et al. 2013

DR programs have been implemented in a variety of settings and have been well documented (Torriti et al. 2010; Shariatzadeh et al. 2015; Jang et al. 2015; Taniguchi et al. 2016; Alkadi et al. 2013; O’Connell et al. 2015; Nolan et al. 2014). DR programs can take a variety of forms, including sheddable and schedulable load resources (Ma and Cheung 2016). Sheddable load resources are those that can be reduced without substantial impacts on the operations of the demand side; examples include residential and commercial heating and cooling activities and some water pumping activities (Hummon et al. 2013). Schedulable load resources are those that cannot be completely avoided, but which can operate flexibly at different times of the day, and thus can be scheduled to operate during low demand periods (Hummon et al. 2013). DR programs have the effect of reducing overall demands as well as the timing of demands, often 
with a focus on peak demands that also correspond to power plant curtailments and shut downs related to water resources.

Various efforts have examined the impacts of climate- and water-related characteristics on some element of the power sector (Averyt et al. 2013; Elcock 2010; Ibanez et al. 2014; Madden et al. 2013; Miara et al., 2013; Santhosh et al. 2014; Sattler et al. 2012; Srinivasan et al. 2012; Stewart et al. 2013; Stillwell et al. 2013; Stoll et al. 2016; van Vliet et al. 2013a; van Vliet et al. 2013b; van Vliet et al. 2016; Vörösmarty et al. 2010). However, these studies generally do not include a detailed representation of power plant dispatch decisions utilizing production cost models. In addition, despite the importance of water and temperature on power plant operational efficiencies and system reliability, most production cost modeling analyses do not consider these climateand water-related factors. Most production cost modeling efforts use static or seasonal power plant efficiencies and capacities. One effort has looked at the impacts of increasing the price of water and how that might affect power plant dispatch and operations (Sanders et al. 2014), but it did not consider impacts of water availability or temperature on power plant performance. This effort provides a unique contribution by considering the impacts that air and water temperatures can have on power plant performance and reliability, while also considering how DR measures can offset these weather- and climate-driven conditions.

The objectives of this manuscript are to (1) demonstrate the importance of air and water temperatures on the performance, reliability, and cost of electricity generation through linking water and energy system models; (2) quantify and characterize how different cooling technology system configurations can lead to diverse outcomes with respect to system cost, generation mix, and other factors; and (3) identify the role and capacity of DR measures to improve system cost, reliability, and performance in the context of water and air temperature impacts. 


\section{Methods}

The approach undertaken involves the utilization of multiple models and distinct model runs to evaluate the impacts and importance of water and DR measures on the electricity system. Models are not directly coupled, but instead use outputs from other model analyses as their inputs. Figure 2 shows a schematic of the models considered in this analysis.
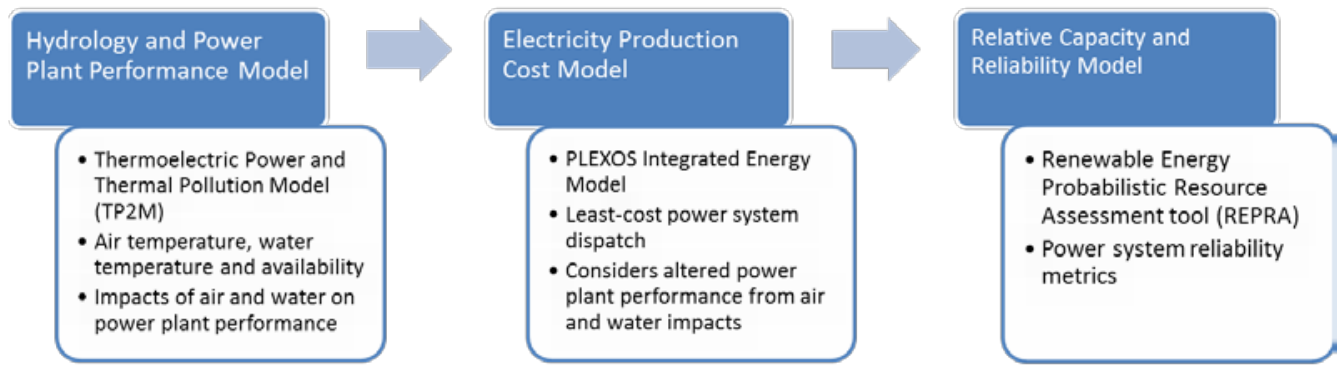

Figure 2. Schematic of models and data flows in analysis

The coupled Water Balance Model (WBM) and Thermoelectric Power and Thermal Pollution Model (TP2M) determine the impacts of climate and water conditions on the performance of electricity generation types. This information on power plant performance changes is used by the production cost model PLEXOS Integrated Energy Model (PLEXOS) to understand how generation dispatch changes under multiple scenarios, including those involving DR measures. The Renewable Energy Probabilistic Resource Assessment (REPRA) model is then employed to analyze PLEXOS model outputs to more closely identify system reliability characteristics associated with the different scenarios. Each component of the project is discussed in detail below.

\subsection{Climate, Hydrology, and Power Plant Performance}

Climate data, hydrology information, and the effects of climatic conditions on power plant performance and capacity are derived from Miara et al. 2013, which uses the Framework for Aquatic Modeling in the Earth System (FrAMES) modeling platform. FrAMES includes calculations from WBM and TP2M that together analyze how power plant efficiencies and capacity are affected by changes in climate and water characteristics. Miara et al. 2013 analyzed power plant performance characteristics for existing power plants in the Northeastern United States in 2010 under the current climate. Results from that work include a daily time series of heat rates and capacities for different power plant configurations (including fuel type, prime mover type, and cooling system type), subject to changing air and water conditions throughout the year. Figure 3 shows an example of TP2M daily relative efficiency (i.e., the inverse of heat rate) outputs for select power plant configuration types, which serve as inputs into the PLEXOS 
model. Note water and climate impacts generally only affect power plant performance from May until September.

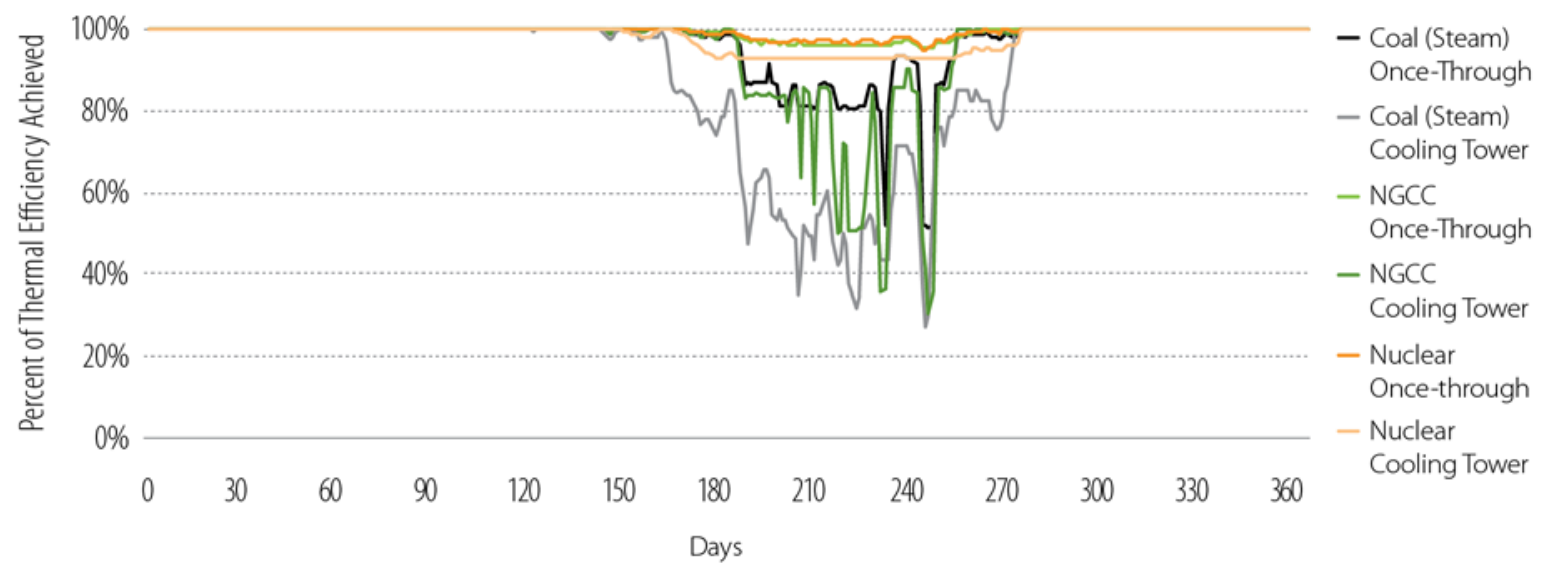

Figure 3. Daily power plant efficiencies for different fuel and cooling system technologies from TP2M

NGCC=natural gas combined cycle

Power plant characteristics are modeled for power plants in the Northeastern United States in 2010 in Miara et al. 2013 and are taken to be representative of power plant configurations and efficiencies of the U.S. fleet for the purposes of this effort. TP2M can also identify instances where thermal effluent from power plants exceeded Clean Water Act (CWA) regulations and thus instances when a power plant would be subject to curtailments or shut downs. More information on modeling results and impacts on power plants are contained in Appendix B. This power plant output data serves as the foundation for power plant heat rate data used in the production cost model PLEXOS.

\subsection{Production Cost Modeling}

This study performs a set of power system simulations where demand response load resources are implemented along with a different mix of cooling technologies using the PLEXOS model. PLEXOS optimizes unit commitment and dispatch of generators in the U.S. electric power system at various timesteps, including sub-hourly, to model the costs of producing electricity and serving all of the demand and ancillary services in the electric sector (Energy Exemplar 2016). The PLEXOS model uses a deterministic, mixed integer, linear program to minimize costs, and the project team has also developed the capability to incorporate hydrologic model outputs (Energy Exemplar 2016). Upfront capital cost and deferred asset investment as a result of demand response are not in the scope of the study. In addition, production cost modeling does not dispatch resources for contingencies or consider long-term planning needs for system adequacy. In this study, PLEXOS power plant capacity and heat rate characteristics were modified from baseline assumptions of input data using the relative changes identified in the TP2M analysis for each power plant configuration type. The results are based on day-ahead simulations, which take into account the variable renewable energy forecast errors between the day-ahead and the real-time dispatches, but the real-time dispatch is not simulated. 
For this analysis, a test case of generators in the PLEXOS models was used, and the generator dataset was modified to include the cooling system cost and performance characteristics of individual generators along with the capability to alter this cooling system type for scenario analyses. New generator characteristics were added to input files, which included daily multipliers on generator thermal efficiencies and variable operating costs, taken from the TP2M model. This approach was taken to provide insight into the importance of water and temperature characteristics as well as cooling systems in the operations of a power system. The features of the test case, in terms of the generator fuel type, generator size, and baseline efficiencies are built upon characteristics of several regions throughout the country to facilitate model design and modifications. Generation mix is shown in Table 2 and roughly corresponds to the generation mix in the Eastern United States in 2010.

Table 2. Generation Mix of Test Case

\begin{tabular}{|ll|}
\multicolumn{2}{|c|}{ Approximate Annual Generation Mix } \\
\hline Nuclear & $13 \%$ \\
\hline Coal & $41 \%$ \\
\hline Gas & $31 \%$ \\
\hline Hydro & $\mathbf{5 \%}$ \\
\hline Wind & $\mathbf{7 \%}$ \\
\hline Solar & $3 \%$ \\
\hline
\end{tabular}

The size of the system and the baseline power plant cost and performance characteristics are drawn from a test system at the National Renewable Energy Laboratory (NREL) of approximately $25 \mathrm{GW}$, generating $78 \mathrm{TWh}$ per year. The model is run for one year on an hourly timestep, with power plant efficiencies, capacities, and cost characteristics changing daily from the TP2M output for each fuel system, prime mover, and cooling system technology combination.

\subsection{Electricity System Reliability}

The NREL-developed REPRA tool evaluates the capacity value of generation, with a particular emphasis on accurately assessing the capacity value of variable generation such as wind and solar technologies (Ibanez and Milligan 2012). The REPRA tool can also be used to provide an assessment of the capacity value of conventional generation subject to water temperature and availability constraints, given the impact that water constraints can have on individual generator operations and availability. The REPRA model was used to analyze water-related vulnerabilities for thermal generators, providing a more comprehensive picture of how thermal capacity values can vary and how these variations affect system-level characteristics. In particular, REPRA analyzes simulations of electricity load with the probability of capacity availability to meet that load at each timestep. Of interest is an estimate of the effective load-carrying capability (ELCC) of generators, which is defined as the additional load that a defined system can support based on the inclusion of that generator without any change in loss of load expectation (LOLE) (Garver 1966). The LOLE is the expected number of hours (or days) where the load will not be met for a specified time period, generally 1 day over the course of 10 years (Keane et al. 2011). To 
calculate ELCC, REPRA takes into consideration the hourly load requirements as well as generator characteristics such as capacity, forced outage rates, and other potential outages.

\subsection{Demand Response Measures and Methods}

DR measures were implemented in PLEXOS in two ways, depending on the type of DR measure. Both sheddable and schedulable load resources were considered in this analysis. The sheddable load resources implemented include: residential cooling, commercial cooling, commercial heating, and municipal pumping. The schedulable load resources implemented include: refrigerated warehouse, waste pump, residential water, data center, and agricultural pumping. In total, the DR included in the study amounts to an annual cumulative availability of $374.17 \mathrm{GWh}$, or $0.4 \%$ of the total electricity use to provide energy and operating reserves.

Many demand response events have a limit on the number of hours they are able to use in a particular day, or are only able to call a certain number of times per day. In many cases, demand response events such as cooling and heating applications are cyclical and must return to a set point after the event occurs. This requires extra generation either before (e.g., pre-cooling) or after (e.g., post-cooling) an event occurs. This constraint is modeled by requiring the generation and excess load from an event to be equal over a particular time period. Sheddable loads are implemented as a storage unit that must return to a pre-defined state, as opposed to requiring the total load and generation to be equivalent over a time period. The balancing time may occur several times each day, once a day, or less frequently if desired. For simplicity, in this study these events are simulated to balance each day. In some cases, a single demand response unit, or a group of units, may provide several different demand response products at varying levels. However, it may not provide both at the same time period. As such, these types of units must be constrained so that only one product associated with the generator may be used at any point in time. DR resources for this test case were derived from recent efforts at Lawrence Berkeley National Laboratory (Olsen et al. 2013) and applied with the same set of operation parameters as previous DR studies such as Hummon et al. 2013. The study does not consider the administrative cost, capital cost, transaction cost, compliance cost of the DR program, or the opportunity cost of lost services - different DR providers may have highly different levels of tolerance for the loss of use of an appliance and piece of equipment due to complexity and data availability issues (Woolf et al. 2013; Ma and Cheung 2016).

\subsection{Scenario Development and Analysis}

The scenarios considered in this analysis arise from three distinct determinants: (1) inclusion of water-related impacts on efficiencies and curtailments, (2) inclusion of demand response measures, and (3) the choice of cooling system. Figure 4 highlights an overview of the scenarios considered. 


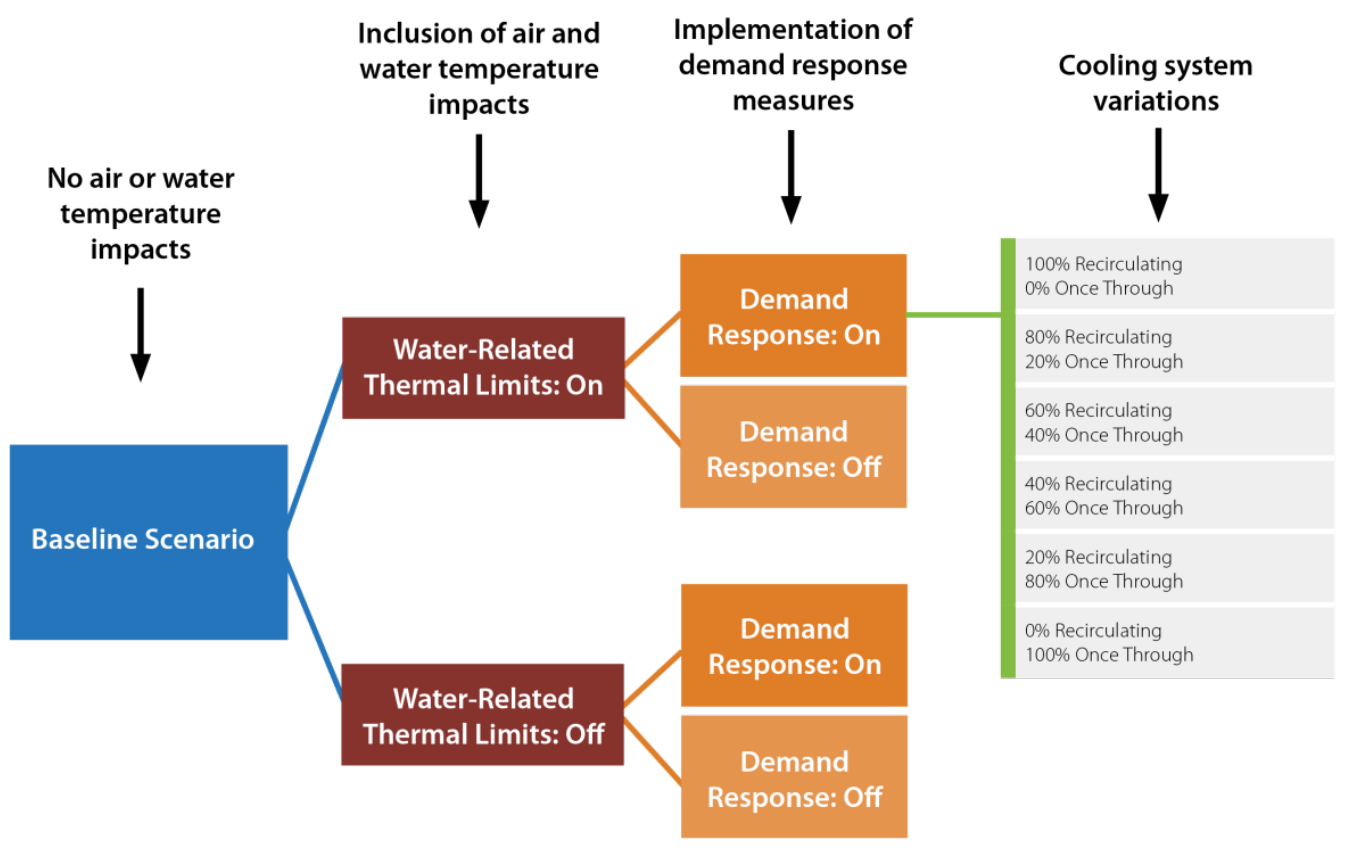

Figure 4. Overview of scenarios considered in this analysis

In the baseline scenario, no water-related impacts on generation are considered, and DR resources are not available. In essence, this reflects how production cost modeling is generally performed. All other scenarios considered include water-related impacts on generators. In the first determinant of scenarios, water-related thermal curtailments are included or not, such that in one set of cases, water-related thermal regulations that lead to curtailments are included (when water discharge temperatures would exceed CWA regulatory limits as modeled by the TP2M analysis), whereas in the other set of cases power plants are allowed to operate even if they violate CWA limits. In both cases, the impacts of temperature on power plant efficiency and capacity are included. For the second determinant of scenarios, demand response measures are turned on or off. For the third determinant of scenarios, multiple cooling system configurations are deployed for all thermal generators to capture the differing cost, performance, and reliability characteristics of the cooling systems for each fuel type. Cooling system compositions for thermal power plants range from $100 \%$ recirculating cooling systems and $0 \%$ once-through cooling systems to $0 \%$ recirculating and $100 \%$ once-through, representing a total of six different cooling system penetration levels. ${ }^{1}$ In total, 25 scenarios (one baseline plus 24 variations of curtailments, DR, and cooling system combinations) were analyzed.

\footnotetext{
${ }^{1}$ Dry cooling is emerging as a viable technology but is not considered here due to its relatively low penetration in any power system. Future efforts could include dry cooling technologies to evaluate tradeoffs in costs, efficiencies, and water use of different cooling systems.
} 


\subsection{Water Withdrawal and Consumption Impacts}

Most water requirements in the energy sector are for thermal power plant cooling, but all lifecycle stages of energy production require water (Meldrum et al. 2013). Although energy supply can also affect water resources through changes in water quality and temperature, water use is typically categorized into two metrics: withdrawal and consumption. Withdrawals are defined as the amount of water removed or diverted from a water source for use, while consumption is the amount of water evaporated, transpired, incorporated into products or crops, or otherwise removed from the immediate water environment (Kenny et al. 2009). Operational water-use requirements are considered in this analysis, as they are orders of magnitude greater than other upstream water requirements (Meldrum et al. 2013). Operational water requirements can vary greatly depending on fuel type, power plant type, and cooling system. Thermal power plants using once-through cooling withdraw far more water for every megawatt-hour of electricity generated than do plants using recirculating cooling systems. For water consumption, however, once-through cooling has slightly lower demands than recirculating systems. Dry cooling can be used to reduce both water withdrawal and consumption for thermal plants, but at a cost and efficiency penalty (EPA 2009). Non-thermal renewable energy technologies (such as PV, wind, and hydropower), in addition to natural gas combustion turbine technologies, do not require water for cooling and, thus, have very low operational water-use intensities. Water use intensities are derived from Macknick et al. 2012 for this analysis. 


\section{Results and Discussion}

Results were analyzed across scenarios for annual and summer (June, July, and August) generation mixes as well as costs. Scenario results are compared with the baseline scenario (which did not evaluate climate or water resource-related impacts) as well as with each other to isolate the impacts of cooling system types, water-related thermal limits, and DR measures on dispatch, cost, and reliability metrics

\subsection{Changes in Generation Mix}

Annual generation mix is shown in Figure 5 for the baseline scenario, with Figure 6 showing a dispatch stack chart for the baseline scenario summer generation.

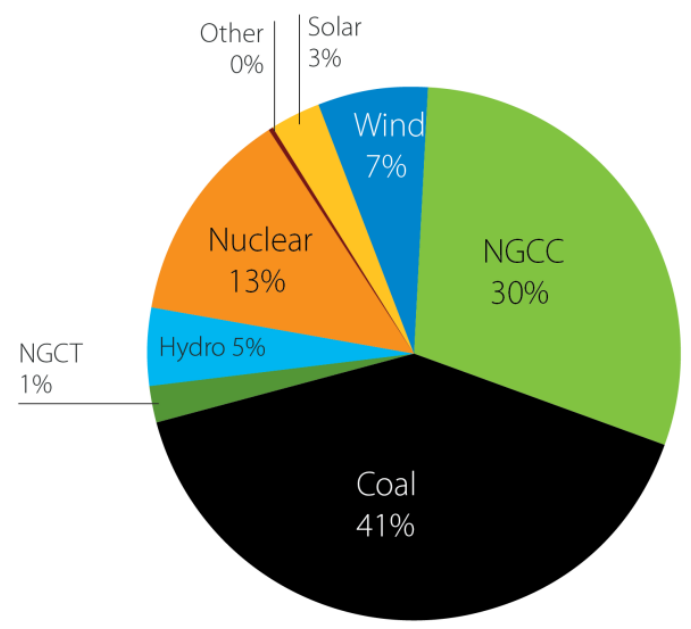

Figure 5. Annual generation mix of the baseline scenario NGCC=natural gas combined cycle; NGCT=natural gas combustion turbine

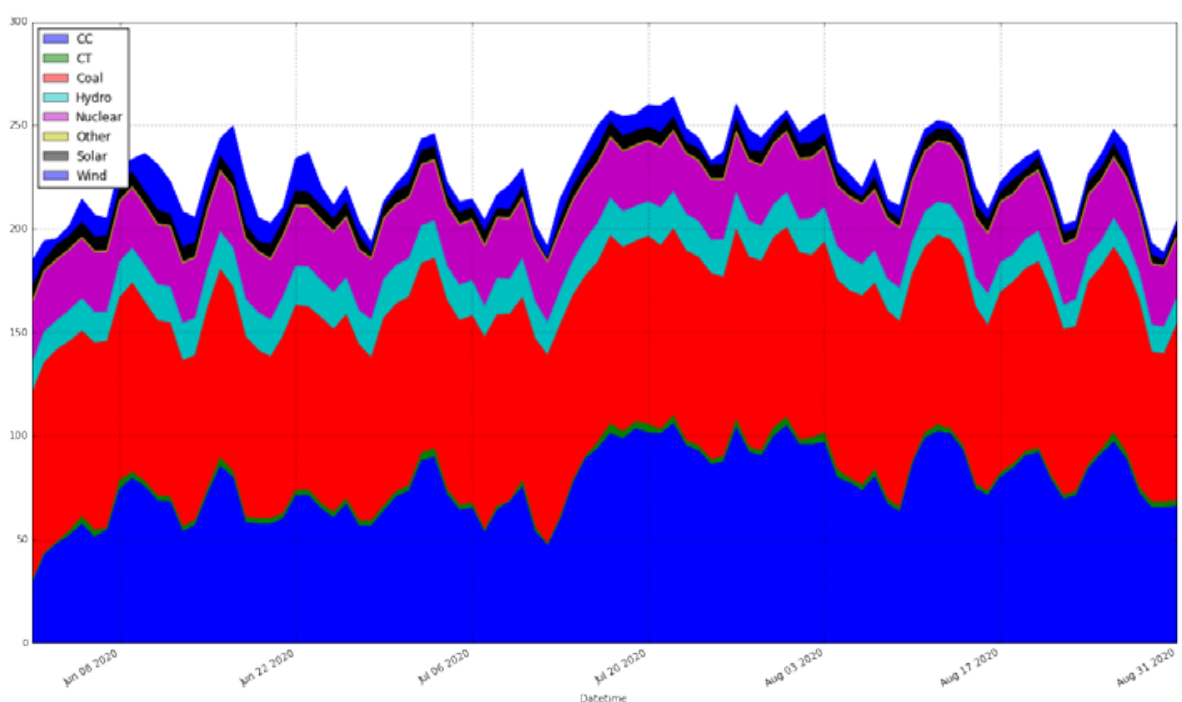

Figure 6. Summer generation dispatch stack of the baseline scenario (GWh) $\mathrm{CC}=$ combined cycle; $\mathrm{CT}=$ combustion turbine 
All scenarios follow the general load and generation trends of the baseline scenario, but there are important differences that can be seen on an annual and a summer-only timeframe, using the baseline scenario, which does not consider any cooling systems or water-related impacts, as the comparison. Full annual scenario generation data are found in Appendix C.

\subsubsection{Comparisons of Generation Results with Baseline Scenario No-Water-Related Thermal Regulations Scenarios}

Considering cases with no water-related thermal regulations, the impact of including air- and water-related efficiency effects on power plants changes depending on the cooling system, as well as whether or not DR measures are employed. Both cooling system characteristics and the inclusion of DR measures can substantially change the cost-optimal technology dispatch, highlighting the importance of including these factors in production cost modeling. Figure 7 highlights the changes in annual generation that result from including water-related impacts on the test case, by different cooling systems, and inclusion of DR measures.
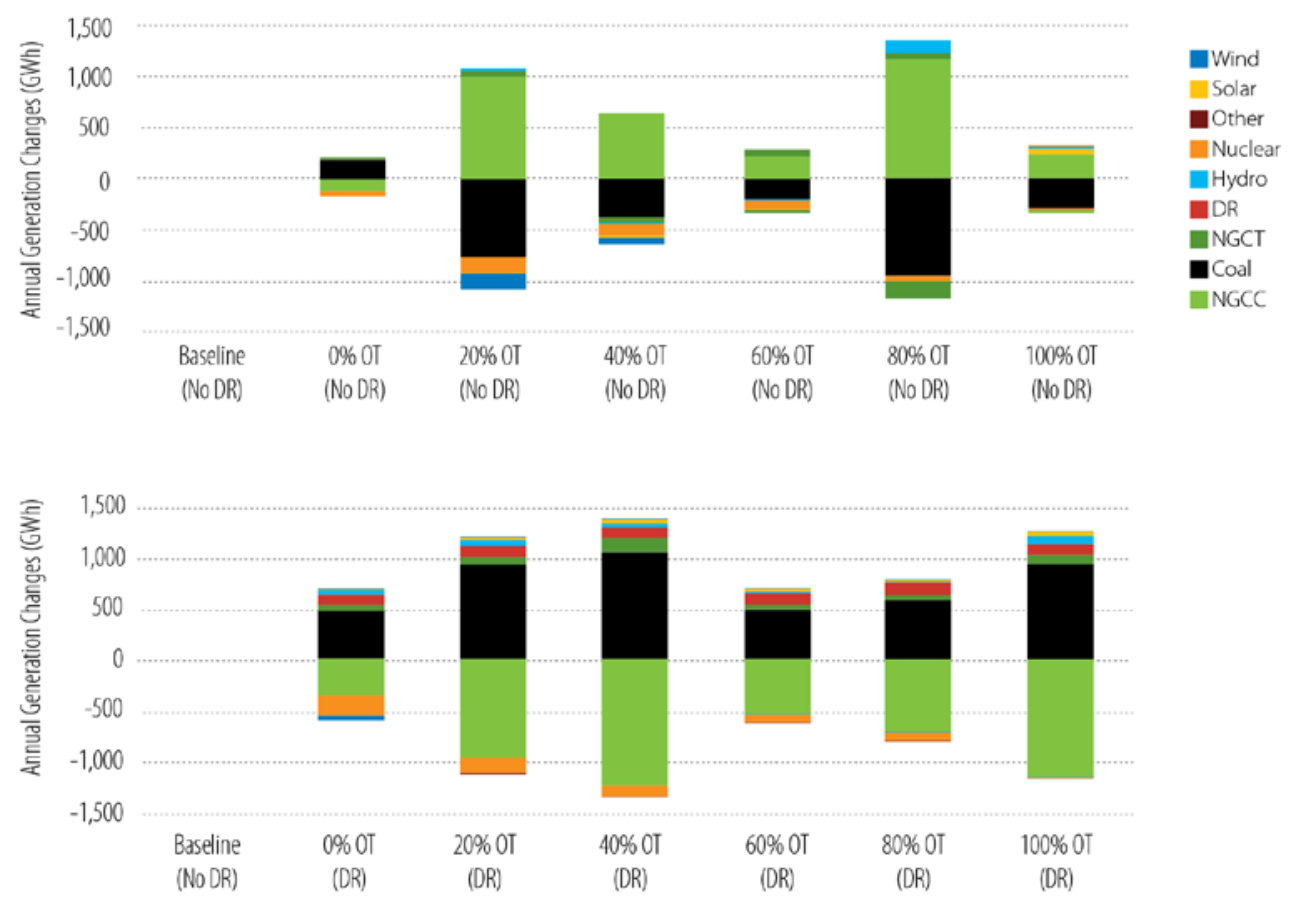

Figure 7. Change in annual generation (GWh) from baseline scenario for scenarios without waterrelated thermal regulations and without demand response (top) and including demand response (bottom)

$\mathrm{OT}=$ once-through cooling; $\mathrm{NGCC}=$ natural gas combined cycle; $\mathrm{NGCT=natural} \mathrm{gas} \mathrm{combustion} \mathrm{turbine;}$ $\mathrm{DR}=$ demand response

In general, the inclusion of air- and water-related impacts leads to changes in generation dispatch, as power plant heat rates and thus operating costs are altered. All six of the scenarios with DR considered here, and two of those without DR, show higher levels of coal power generation and lower levels of natural gas combined cycle generation compared with the baseline scenario, which did not consider cooling systems or DR measures. All scenarios show lower or 
equal levels of nuclear deployment when compared with the baseline, likely a result of lower plant efficiencies resulting from water and temperature impacts. When DR measures are considered, ${ }^{2}$ coal generation tends to increase as compared with generation without DR measures, due to the shifting of load from peak times (which would be served by natural gas combined cycle generation) to other parts of the day when baseload coal can meet demands at lowest cost. It is important to note that there is no consistent increasing or decreasing trend based on cooling system types, despite the evident differences. This can be partially explained by the complexity of power sector dispatch decisions and the impacts of temperature on power plant efficiencies for different cooling systems, but future efforts could specifically address the importance and impact of cooling systems on power system dispatch. Results also indicate that scenarios without DR lead to curtailments of wind generation, relative to the baseline, whereas scenarios that add DR measures eliminate wind curtailment. If the system featured a higher percentage of wind capacity, then the effect of DR could lead to additional wind generation as opposed to increased coal generation; future efforts could evaluate changes in fuel technology capacity (e.g., high penetration of renewables) to better understand the impacts of DR and cooling system choices on technology dispatch. Electricity dispatch results aggregated at the daily level for summer months are shown in Appendix D.

\section{Scenarios with Water-Related Thermal Regulations}

When scenarios that consider water-related thermal regulations are evaluated, a slightly different pattern emerges. Figure 8 highlights the changes in annual generation that result from including water-related impacts on the test case, by different cooling systems and inclusion of DR.

${ }^{2}$ It is important to note that DR is listed as a generation source in the figures, highlighting the effect that DR has in identifying sheddable load in addition to shifting the schedulable load. 


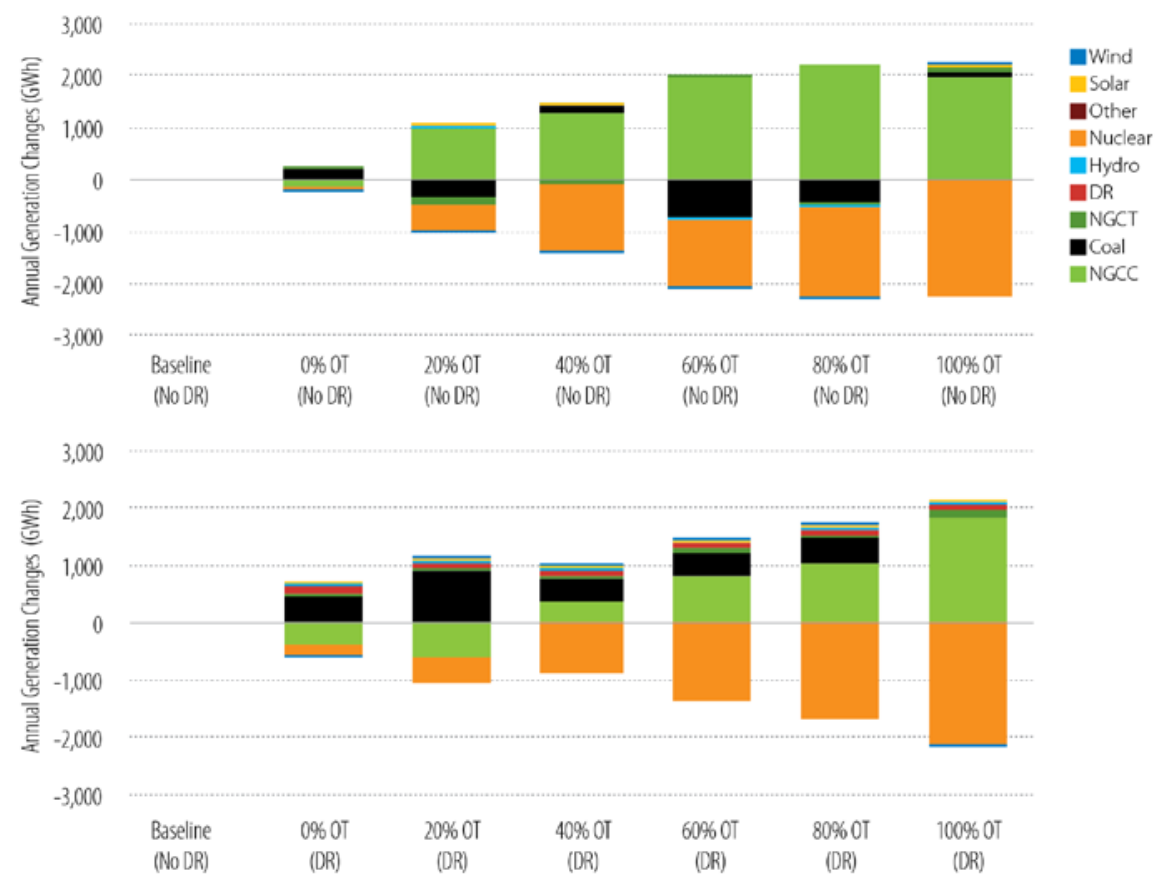

Figure 8. Change in annual generation (GWh) from baseline scenario for scenarios with waterrelated thermal regulations and without demand response (top) and including demand response (bottom)

OT=once-through cooling; NGCC=natural gas combined cycle; NGCT=natural gas combustion turbine; $\mathrm{DR}=$ demand response

When water-related thermal regulations are included, every scenario shows a reduction in nuclear power generation. Water-related impacts increase as once-through cooling system penetrations increase, highlighting the nuclear generating units that are once-through cooled and are subject to CWA limits as well as the impacts on power plant efficiencies. Although coal-fired power plants can also be subject to CWA regulations, annual coal generation declines in only three of the 12 scenarios, likely due to coal making up for loss of generation in other times of the year and its higher overall contribution to annual generation. Natural gas combined cycle generation increases in nine of the 12 scenarios, reflecting its ability to ramp up and down to make up for curtailed generation from other technologies. As the percentage of once-through cooling technologies penetration increases, the total magnitude of water-related curtailment increases. DR measures at higher penetrations of once-through cooled technologies $(40 \%$ and above) have the effect of reducing the total amount of water-related curtailment; future efforts could identify specific thresholds for different systems where DR measures lead to lower levels of water-related curtailment. In addition, with no DR measures, natural gas combined cycle makes up for lost nuclear generation, but when DR is included to shift consumption from peak to off-peak, coal becomes a more significant part of the generation that increases to make up for lost nuclear generation. Note that annual values do not clearly show differences between waterrelated curtailment events and reductions in generation due to efficiency and operating costs; daily data highlighting these changes during summer months are shown in Appendix D. 


\subsubsection{Comparisons of Generation across Scenarios Isolated Effects of Water-Related Thermal Regulations}

Beyond the differences between scenarios of water-related curtailments and the baseline assumptions, there can be important differences across scenarios when isolating the effects of water-related curtailments on the generation mix. Figure 9 compares the annual generation mix differences between scenarios that include water-related curtailments and scenarios that do not, highlighting differences among scenarios with different levels of once-through cooling penetration.

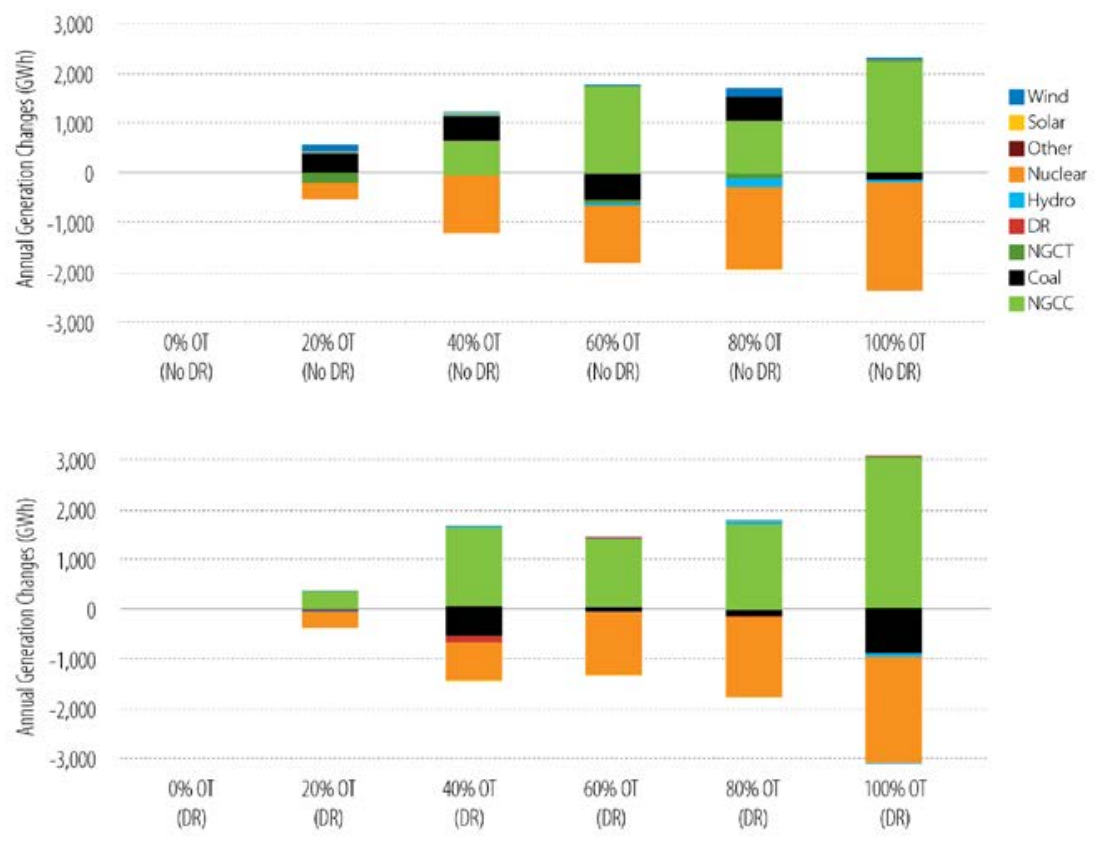

Figure 9. Comparison of annual generation mix for water-related curtailment scenarios minus noncurtailment scenarios (GWh) without demand response (top) and with demand response (bottom)

$\mathrm{OT}=$ once-through cooling; $\mathrm{NGCC}=$ natural gas combined cycle; $\mathrm{NGCT}=$ natural gas combustion turbine; $\mathrm{DR}=$ demand response

Water-related curtailments lead to higher levels of natural gas combined cycle generation, with and without DR measures. As the percentage of once-through cooling penetration increases, there are greater differences and higher levels of natural gas combined cycle generation to make up for other lower generation from other technologies that are affected to a greater degree by water-related curtailment incidents. Nuclear generation on an annual basis is affected more than coal generation, potentially due to the duration and number of water-related curtailment events. Scenarios that include water-related curtailments lead to higher levels of coal generation in three of the scenarios considered, all of which do not include DR measures, potentially due to coal making up for lost nuclear generation when nuclear facilities are being curtailed. When all cooling systems are recirculating cooling, there are no curtailments and thus no differences between the scenarios. 


\section{Isolated Effects of Demand Response}

DR measures can alter the dispatch of a system depending on the dominant cooling system type of generators and whether or not water-related curtailments are included. Figure 10 highlights the isolated impacts of DR measures on scenario results by different cooling system penetrations.
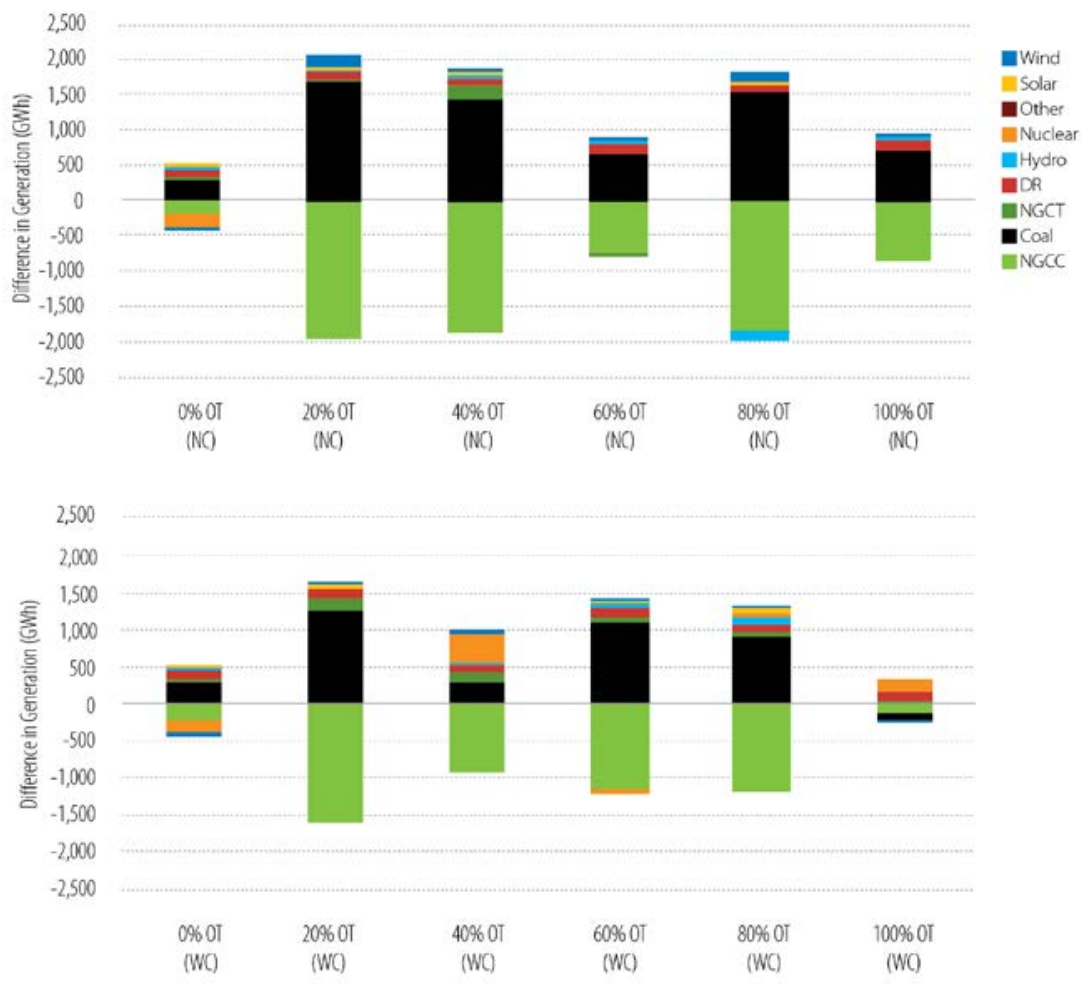

Figure 10. Impacts of demand response measures on electricity generation mixes across scenarios without water-related curtailments (top) and with water-related curtailments (bottom)

Figures show generation for scenarios with DR measures minus scenarios without DR measures, for each cooling system combination.

$\mathrm{OT}=$ once-through cooling; $\mathrm{NC}=$ no curtailment; $\mathrm{WC}=$ with curtailment; $\mathrm{NGCC}=$ natural gas combined cycle; NGCT=natural gas combustion turbine; $\mathrm{DR}=$ demand response

As demand response measures largely target peak electricity demands, they have the effect of reducing generation from technologies that follow load, such as natural gas combined cycle, across all scenarios. As some loads are also shifted to other times of the day when loads can be met by baseload generation, they also lead to greater levels of coal and nuclear generation under the assumptions considered. Note that this work gave no consideration to carbon prices, the U.S. Environmental Protection Agency's Clean Power Plan, state or regional greenhouse gas regulations, or to sensitivities associated with natural gas price assumptions; adding in these elements could further alter the dispatch decisions. The results of the DR measures could be seen as a benefit to the operation of the system, as less ramping up and down is required from generators. In general, the magnitude of generation changes tends to be smaller for scenarios that have water-related curtailments than for scenarios that do not include water-related curtailment, as well as when DR measures are employed, potentially due to offsetting, contrasting trends caused by water-related curtailments (e.g., higher natural gas combined cycle generation) and DR measures (e.g., lower natural gas combined cycle generation) under these system 
characteristics. The effects of DR measures appear to be the smallest under $100 \%$ once-through and $100 \%$ recirculating cooling scenarios. Nuclear generation differences are much more pronounced in scenarios with water-related curtailments than scenarios without water-related curtailments. Fluctuations in the total magnitude of system generation dispatch changes range from less than 1,000 GWh (for $0 \%$ once-through and $100 \%$ once-through with water-related curtailments) to more than $4,000 \mathrm{GWh}$ (for $20 \%$ once-through with no water-related curtailments), representing a range of approximately $1 \%-5 \%$ of total annual generation. Coal generation shows changes as high as $5 \%$, and natural gas combined cycle generation changes can be as high as $9 \%$.

\subsubsection{Summary of Changes in System Generation by Technology Type}

Compared with the baseline scenario (which does not include water-related impacts or cooling system configurations), all scenarios and all cooling system configurations show differences in annual electricity dispatch decisions. Annual generation value differences from the baseline scenario for individual technologies ranged from a $21 \%$ reduction to a $17 \%$ increase. Table 3 summarizes the technology-specific changes in annual generation from the baseline scenario that result from including water-related impacts on the test region and whether DR impacts are included.

Table 3. Changes in Annual Generation from Baseline Scenario due to the Inclusion of WaterRelated Impacts

\begin{tabular}{|lll|}
\hline Technology & $\begin{array}{l}\text { Generation difference } \\
\text { ranges in scenarios } \\
\text { without DR compared with } \\
\text { the baseline }\end{array}$ & $\begin{array}{l}\text { Generation difference } \\
\text { ranges in scenarios with } \\
\text { DR compared with the } \\
\text { baseline }\end{array}$ \\
\hline NGCC & $-1 \%$ to $10 \%$ & $-5 \%$ to $8 \%$ \\
\hline NGCT & $-16 \%$ to $9 \%$ & $1 \%$ to $17 \%$ \\
\hline Coal & $-3 \%$ to $1 \%$ & $0 \%$ to $3 \%$ \\
\hline Nuclear & -21 to $0 \%$ & $-20 \%$ to $0 \%$ \\
\hline NGCC=natural gas combined cycle; NGCT=natural gas combustion turbine; DR=demand response
\end{tabular}

DR measures, despite representing a small percentage of generation and capacity, can substantially alter the dispatch of technologies in an entire system, often leading to reductions in costs. Table 4 summarizes the range of generation impacts that DR measures had on the scenarios considered.

Table 4. Impacts of Demand Response Measures on Annual Electricity Generation by Technology Type

\begin{tabular}{|ll|}
\hline Technology & $\begin{array}{l}\text { Range of annual generation changes } \\
\text { resulting from DR measures }\end{array}$ \\
\hline NGCC & $-8 \%$ to $0 \%$ \\
\hline NGCT & $-3 \%$ to $26 \%$ \\
\hline Coal & $0 \%$ to $5 \%$ \\
\hline Nuclear & $-2 \%$ to $4 \%$ \\
\hline
\end{tabular}

$\mathrm{NGCC}=$ natural gas combined cycle; $\mathrm{NGCT=natural} \mathrm{gas} \mathrm{combustion} \mathrm{turbine;} \mathrm{DR}=$ demand response 
Importantly, DR measures often lead to lower generation levels of natural gas combined cycle technologies and higher generation levels of nuclear and coal technologies, counteracting the annual generation trends caused by air- and water-related impacts.

\subsection{Changes in System Costs}

\subsubsection{Comparison of System Costs with the Baseline Scenario}

A key metric of interest in production cost modeling and in-demand response analyses is the total annual system cost. Differences in the efficiencies and operating characteristics of cooling systems can lead to different technology dispatch patterns and differences in total annual costs. Figure 11 shows the changes in production costs associated with different cooling system characteristics, for scenarios without water-related curtailments.

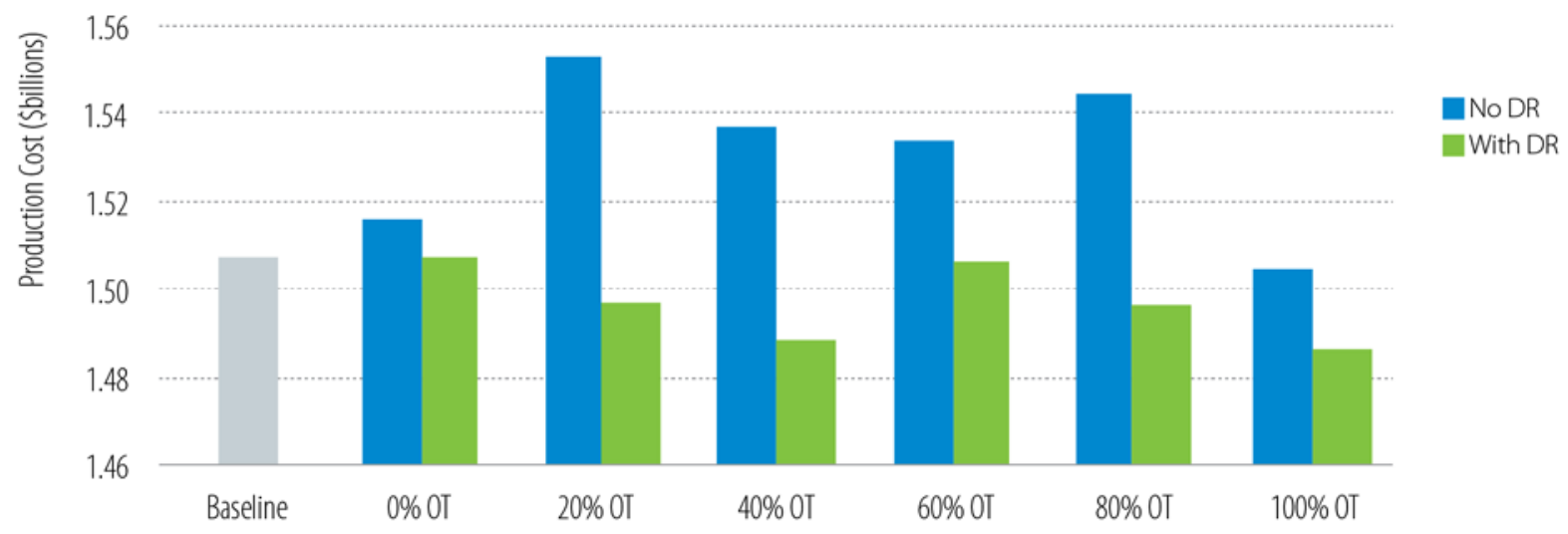

Figure 11. Total annual production costs across no-water-related curtailment scenarios and the baseline

OT=once-through cooling; DR=demand response

Production costs are generally higher for scenarios that include cooling system effects, which take into consideration efficiency losses from different cooling system types. An important exception is for scenarios that include demand response measures, which have lower costs than the baseline scenario. Scenarios that include demand response measures show lower costs than those that do not for all cooling system types. Cost increases from the baseline scenario for nondemand response scenarios range from $0 \%$ to $3 \%$ on an annual basis, though summer monthly costs can be as much as $6 \%$ higher for some scenarios. Similar trends can be seen for scenarios that include water-related curtailments, with a greater increase in production costs from the baseline (Figure 12). 


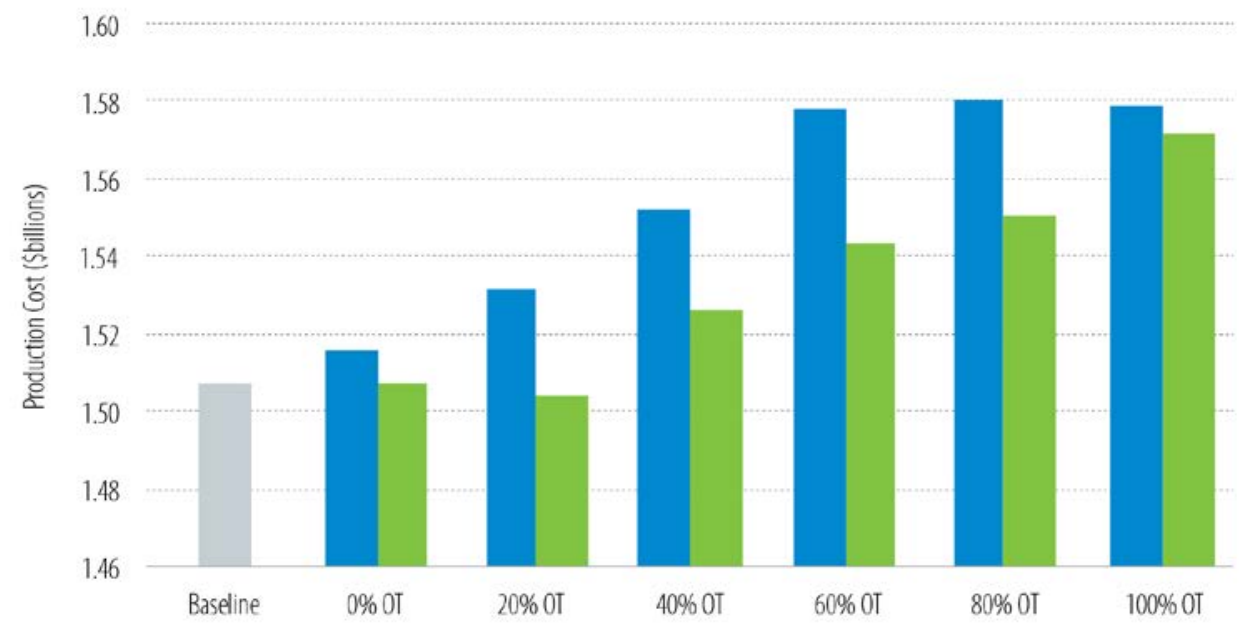

Figure 12. Total annual production costs across water-related curtailment scenarios and the baseline

$\mathrm{OT}=$ once-through cooling; $\mathrm{DR}=$ demand response

When water-related curtailments are taken into consideration, there is a clearer trend in production cost increases. As the share of once-through cooling technologies increases, production costs increase due to the primary generators being curtailed and higher cost generation technologies being dispatched. Annual cost increases from the baseline scenario range from $1 \%$ to $5 \%$, whereas summer monthly increases can be as high as $22 \%$ for the all oncethrough cooling technology scenario.

\subsubsection{Comparisons of System Costs across Scenarios}

DR measures lead to lower production costs across all scenarios. Figure 13 highlights the specific impact of DR measures on production costs for all scenarios by cooling system penetration. 

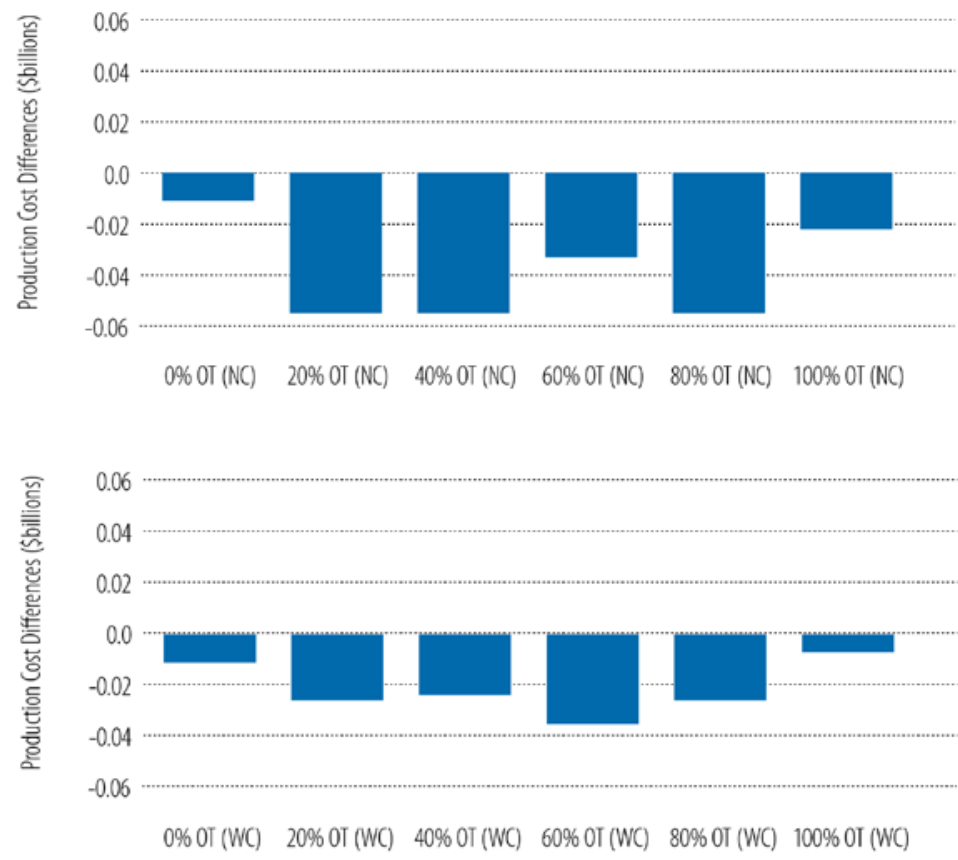

Figure 13. Impacts of including demand response measures on production costs across scenarios without water-related curtailments (top) and those with water-related curtailments (bottom)

$\mathrm{NC}=$ no curtailment; $\mathrm{WC}=$ with curtailment

Demand response measures reduce production costs across all scenarios, regardless of cooling technology configurations or whether water-related curtailments are included. The differences in total production cost represent the operational value of demand response in the system, derived from avoided fuel and operation and maintenance costs across the system. Annual production cost reductions range from $0.6 \%$ to $3.5 \%$ for no-water-related curtailment scenarios, and $0.5 \%$ $2.2 \%$ for scenarios that include water-related curtailments. For summer months, cost impacts range from a $0.7 \%$ increase to a $4.5 \%$ decrease in costs for no-water-related curtailment scenarios, and a $0.7 \%$ increase to a $3.3 \%$ decrease in costs for scenarios with water-related curtailments. DR cost reductions tend to be less pronounced for scenarios that include waterrelated curtailments under similar cooling system configurations.

\subsubsection{Summary Impacts on System Level Costs}

Table 5 highlights the changes in annual and summer month production costs from the baseline scenario that result from including water-related impacts on the test region and whether DR impacts are included. 
Table 5. Changes in Annual Production Costs from Baseline Scenario due to the Inclusion of Water-Related Impacts

\begin{tabular}{|lll|}
\hline Timeframe & $\begin{array}{l}\text { Cost difference ranges in } \\
\text { scenarios without DR } \\
\text { compared with the } \\
\text { baseline }\end{array}$ & $\begin{array}{l}\text { Cost difference ranges in } \\
\text { scenarios with DR } \\
\text { compared with the } \\
\text { baseline }\end{array}$ \\
\hline Annual & $-0.1 \%$ to $4.9 \%$ & $-1.4 \%$ to $4.3 \%$ \\
\hline June & $-1.6 \%$ to $2.7 \%$ & $-2.8 \%$ to $0.2 \%$ \\
\hline July & $1.2 \%$ to $22.3 \%$ & $0.9 \%$ to $20.7 \%$ \\
\hline August & $1.2 \%$ to $21.2 \%$ & $0.6 \%$ to $19.7 \%$ \\
\hline
\end{tabular}

The ranges in both annual costs as well as summer month costs indicate that the inclusion of water-related impacts and cooling system characteristics can have a meaningful impact on production cost analyses.

Water-related impacts are especially important when water-related thermal regulations are enforced, and there are clear trends related to the types of cooling systems used. As the share of once-through cooling technologies increases in the fleet, production costs increase due to the baseload generators being curtailed and higher cost yet more flexible generation technologies being dispatched. Table 6 shows production cost increase trends on the test system based on the types of cooling systems deployed. Table 6. Annual Production Cost Changes Resulting from Water-Related Thermal Regulation
Enforcement

\begin{tabular}{|ll|}
\hline Cooling type & Range of annual production cost changes \\
\hline $\mathbf{0} \%$ Once-through & No change \\
\hline $\mathbf{2 0} \%$ Once-through & $-1.4 \%$ to $0.0 \%$ \\
\hline $\mathbf{4 0} \%$ Once-through & $0.4 \%$ to $1.1 \%$ \\
\hline $\mathbf{6 0} \%$ Once-through & $2.4 \%$ to $3.0 \%$ \\
\hline $\mathbf{8 0} \%$ Once-through & $2.3 \%$ to $2.4 \%$ \\
\hline $\mathbf{1 0 0} \%$ Once-through & $3.5 \%$ to $4.9 \%$ \\
\hline
\end{tabular}

\subsection{Relative Capacity Value and Reliability}

The REPRA model was used to compare the impacts of demand response, cooling system configuration, and water-related curtailments on certain reliability metrics. REPRA results are shown in a variety of different formats to understand various questions. Figure 14 compares maximum daily loads with available daily capacity for a system with no once-through cooling technologies and for all once-through cooling technologies, without considering water-related curtailments or DR measures. 
Once-Through 0\%

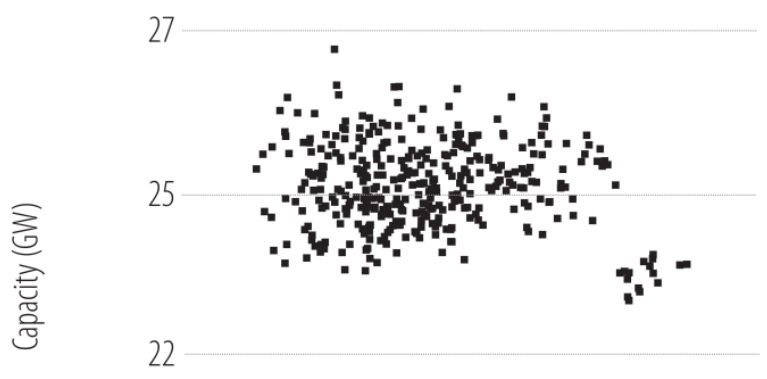

17

Max Daily Load (GW)
Once-Through 100\%

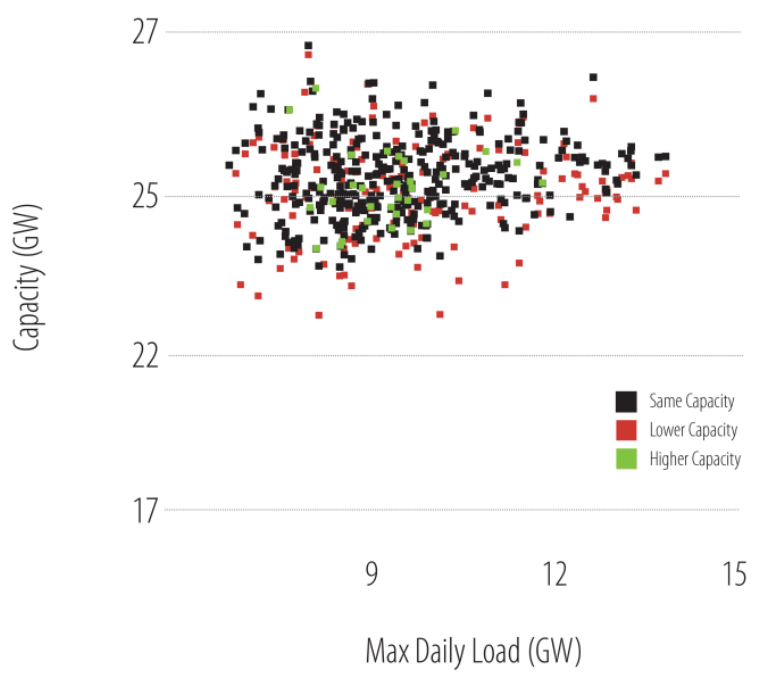

Figure 14. Comparison of daily capacity and maximum daily load for $0 \%$ once-through cooling (left) and $100 \%$ once-through (right) for scenarios with no water-related curtailment

Green dots indicate higher capacity values (and red dots indicate lower capacity values) on equivalent days for the once-through $100 \%$ scenario (right) compared with the once-through $0 \%$ scenario (left).

For some days, the $100 \%$ once-through cooled system shows a lower available daily capacity than the $0 \%$ once-through cooled system, indicating the impact that changes in water temperatures can have on generator performance are relatively minor and occur on just a few days in the summer. During the fall, the $100 \%$ once-through scenario can show capacity improvements over the $0 \%$ once-through scenario, highlighting heat rate benefits from lower water temperatures. Adding water-related curtailments into the analysis, Figure 15 shows how available capacity can be reduced on some days for a $100 \%$ once-through cooled system affected by water-related curtailments. 

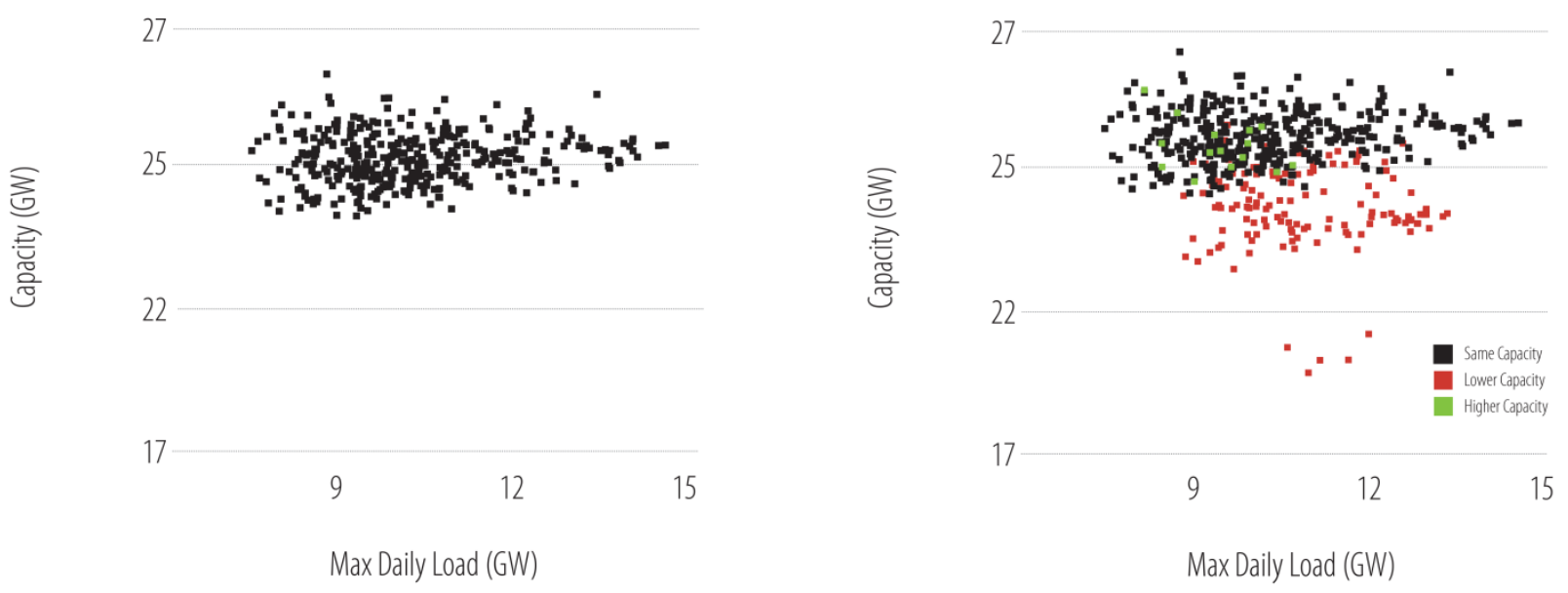

Figure 15. Comparison of daily capacity and maximum daily load for $100 \%$ once-through cooling system scenarios without water-related curtailment (left) and with water-related curtailment (right)

Green dots indicate higher capacity values (and red dots indicate lower capacity values) on equivalent days for the scenario with water-related curtailments (right) compared with the scenario without waterrelated curtailments (left).

More substantial differences are seen once water-related curtailments are considered. Note that for most days, the daily capacity remains the same, but for more than 100 days throughout the summer the daily capacity is noticeably lower under the water-related curtailments case (right) than the no-water-related curtailments case (left), with 5 days having more drastic reductions in available capacity. Note that under this test system overall there are relatively large capacity reserves, so there is no danger of maximum daily load exceeding available capacity, but under actual power systems with less capacity reserves the reductions in available capacity could have a more substantial impact on system reliability. The maximum daily loads for which waterrelated curtailment occurs ranges from around $8 \mathrm{GW}$ to around $14 \mathrm{GW}$, indicating that curtailments can occur on days that are not necessarily the days with the highest loads.

DR measures have a minor impact on REPRA analyses of relative capacity value. Figure 16 highlights how DR measures can affect daily capacity and maximum daily loads for $100 \%$ oncethrough cooled systems in the test region. 
Once-Through 0\%

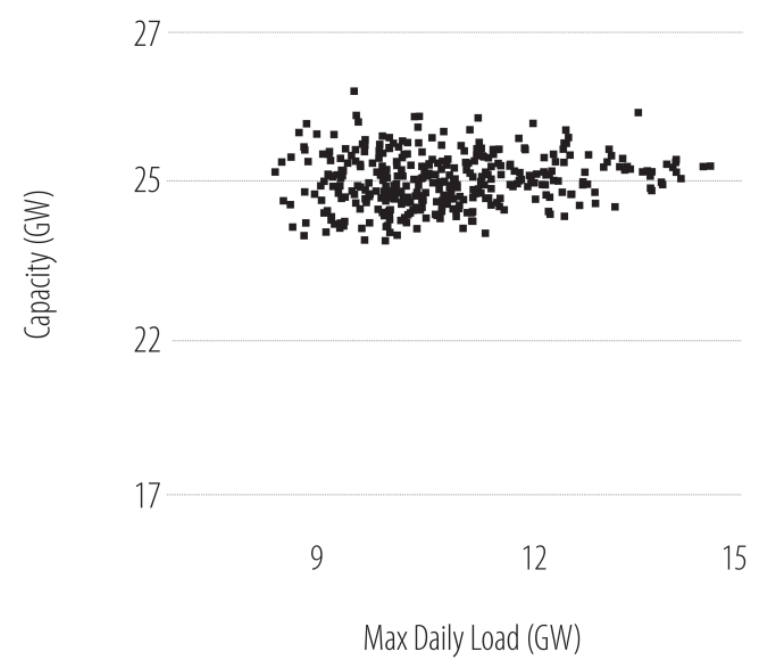

Once-Through 100\% w/Curtailment

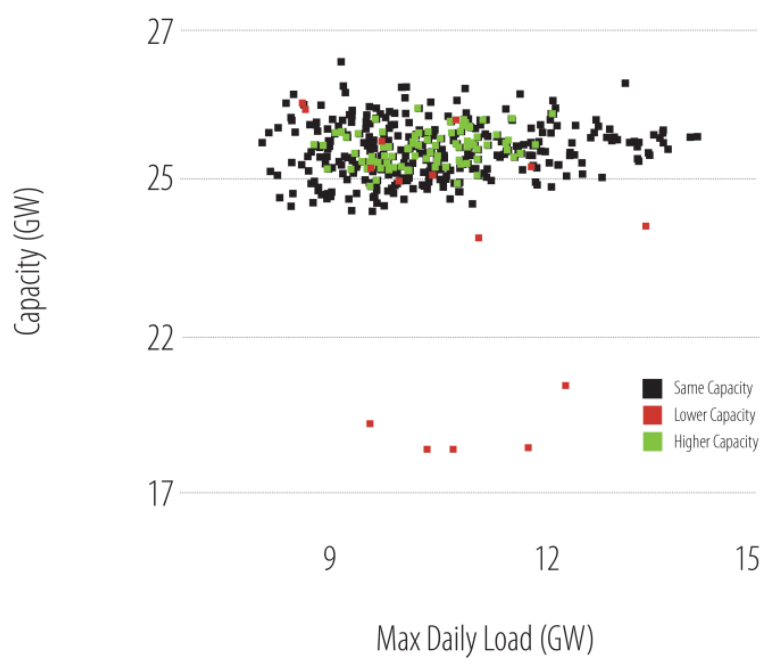

Figure 16. Comparison of daily capacity and maximum daily load for $100 \%$ once-through cooling system scenarios with water-related curtailment that do not include demand response (left) and that do include demand response (right)

Green dots indicate higher capacity values (and red dots indicate lower capacity values) on equivalent days for the case with demand response measures (right) compared with no demand response measures (left).

Adopting demand response measures leads to consistent improvements, although minimal in magnitude, in the relationship between available capacity and maximum daily loads under the test case assumptions. Demand response measures lead to an average of $0.2 \%$ improvement in available capacity, with a maximum daily improvement of $3 \%$.

To capture how loads and daily capacity differences change throughout the year, Figure 17 shows the daily time series over a year of maximum daily load — as well as the available capacity of the baseline-for once-through $100 \%$ scenarios with and without water-related curtailments. 

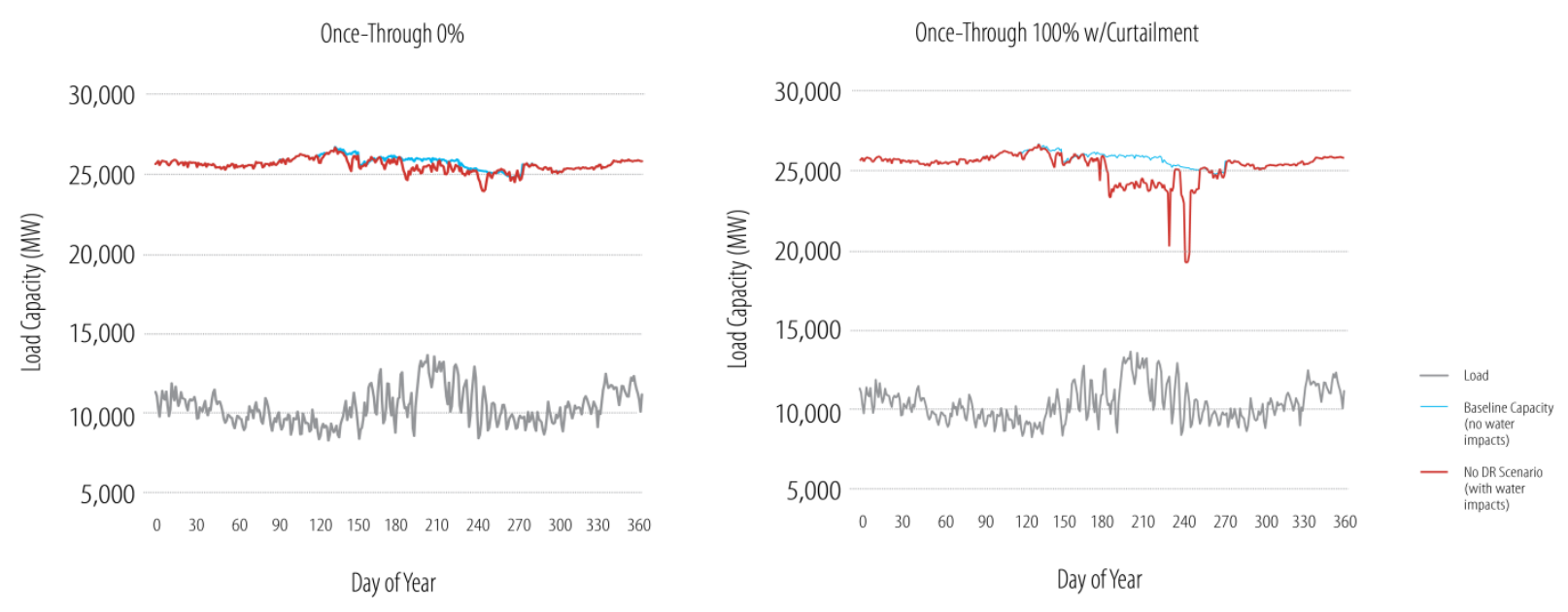

Figure 17. Comparison of daily capacity and maximum daily load for $100 \%$ once-through cooling system scenarios without water-related curtailment (left) and with water-related curtailment (right) for systems without demand response

The baseline scenario, which does not include any water-related impacts on generators, has higher levels of available capacity than the other scenarios during summer months, when temperatures and loads tend to be highest. The scenario without water-related curtailment shows how once-through cooled facilities can be affected during summer months, though this is less extreme than the impact on generators in the scenario with water-related curtailments. In this test case, the available capacity is generally more than twice the maximum daily load, with the exception of short time periods in summer months in the water-related curtailment case. In a real-life system, reserve margins are not nearly as high, and the impacts of water-related curtailments could affect reliability to a greater degree. To better quantify reliability metrics associated with the figures described above, Figure 18 shows the ELCC, or capacity value, of the system.
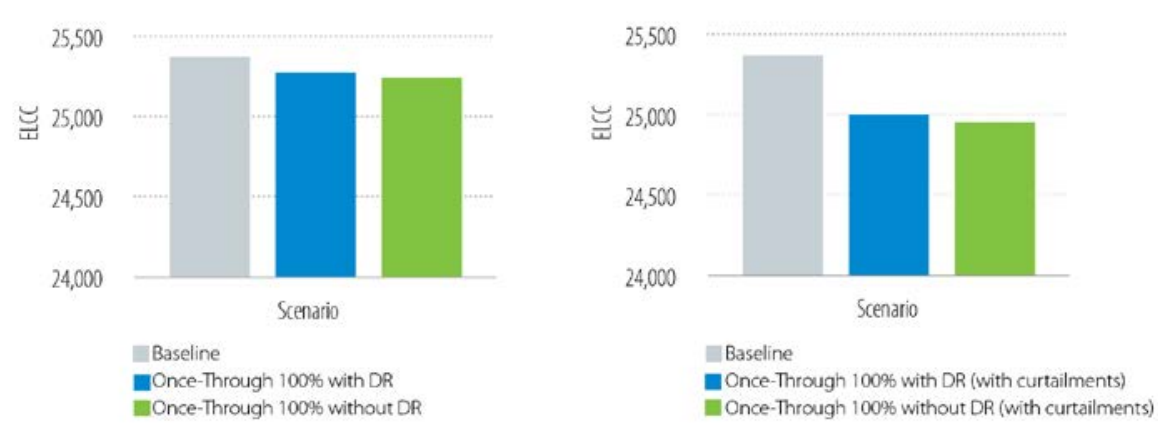

Figure 18. Comparison of effective load-carrying capability for $100 \%$ once-through cooling system scenarios without water-related curtailment (left) and with water-related curtailment (right)

Evaluating the ELCC for these scenarios more clearly shows the impacts of cooling systems, water-related curtailments, and demand response measures on system reliability. The reduction 
in ELCC is most drastic when comparing cases with and without water-related curtailments. Both the with-DR and the no-DR cases show a reduction in ELCC of approximately $1.2 \%$ when comparing with and without water-related curtailments. The effects of including cooling system characteristics on the system leads to a change in ELCC of approximately $0.5 \%$ for the no-waterrelated curtailment case and $1.6 \%$ for the water-related curtailment case. Including DR measures leads to an increase of ELCC of approximately $0.2 \%$ over not including DR measures.

\subsection{Water Withdrawal and Consumption}

Cooling system decisions, water-related curtailments, and DR measures all can affect technology dispatch decisions, which also have water withdrawal and consumption implications. Water withdrawal impacts of scenarios are shown in Figure 19.

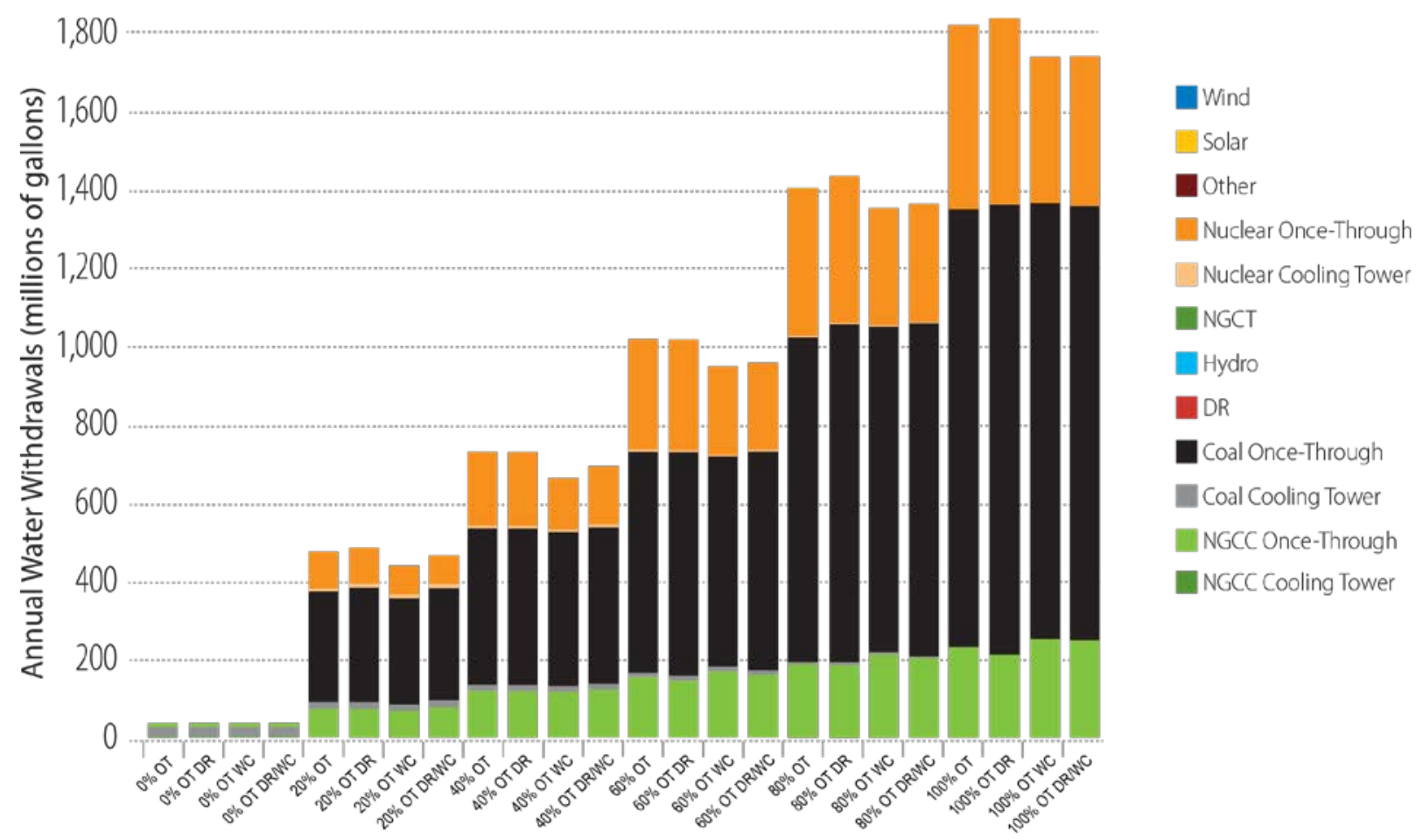

Figure 19. Water withdrawal impacts of scenarios

$\mathrm{OT}=$ once-through cooling; $\mathrm{DR}=$ demand response; $\mathrm{WC}=$ with water-related curtailment scenarios; NGCT=natural gas combustion turbine; NGCC=natural gas combined cycle

As once-through cooling technologies increase in penetration, water withdrawals increase; this is due to water withdrawal characteristics of once-through cooling technologies in comparison with recirculating cooling tower systems. As water-related curtailments are considered, water withdrawals decrease as water-related curtailments primarily affect once-through cooled systems, and generation is made up mainly by recirculating cooling tower systems. Demand response measures lead to slight increases in water withdrawals, as under these scenarios coal tends to increase generation and natural gas tends to decrease generation, and the water withdrawal rate of coal is higher than that of natural gas combined cycle, given identical cooling system characteristics. The impact of demand response on water withdrawals is smaller than that related to the cooling system and water-related curtailments. 
Whereas higher penetrations of once-through cooling technologies led to increases in water withdrawals, water consumption decreases under higher penetrations of once-through cooling technologies. Figure 20 highlights water consumption impacts.

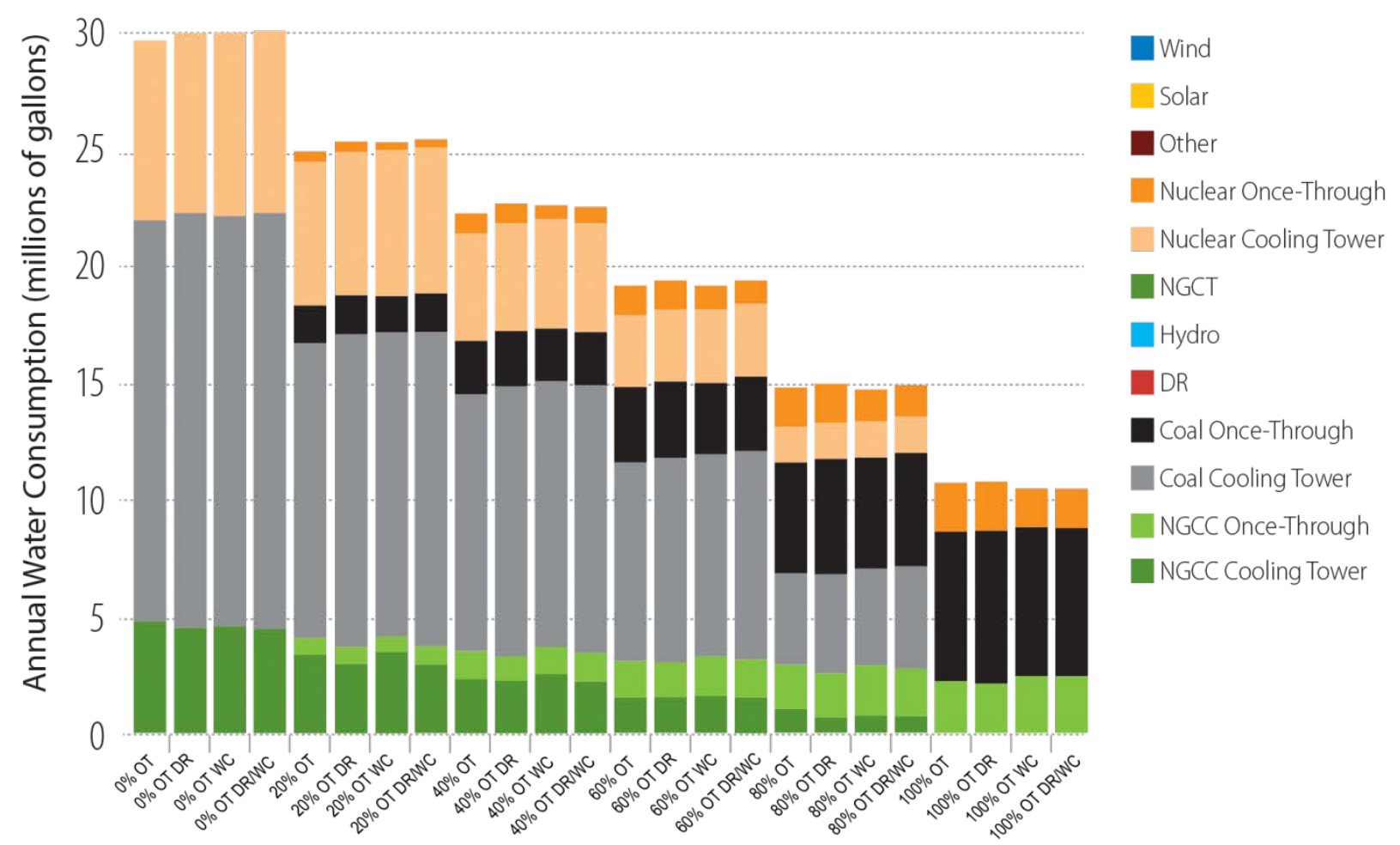

Figure 20. Water consumption impacts of scenarios

$\mathrm{OT}=$ once-through cooling; $\mathrm{DR}=$ demand response; $\mathrm{WC}=$ with curtailment scenarios; $\mathrm{NGCT= \text {naturalgas }}$ combustion turbine; NGCC=natural gas combined cycle

Although the magnitude of water consumption trends are opposite of withdrawals, the impacts of curtailments and DR are similar to withdrawals. Water-related curtailment scenarios tend to have lower water consumption impacts than scenarios that do not consider curtailments, and DR measure scenarios tend to have higher water consumption values than those that do not include DR measures. 


\section{Implications}

Results from this work suggest that air and water resource characteristics can substantially affect the performance of individual electricity generators, technology dispatch decisions, total energy system costs, and system reliability. DR measures can play a role in reducing system costs, changing the magnitude and type of generators dispatched, and can also have a subtle role in improving system reliability in the context of water-related vulnerabilities. The novel modeling framework used here, which links inputs and outputs from a climate-hydrology model, an electricity production cost model, and a relative capacity value model, enables a comprehensive assessment of multiple energy sector characteristics that are affected by water resource considerations. Specifically, this effort highlights the importance of water resource considerations in energy system modeling related to cooling system characteristics, water policies and regulations, and demand-side energy management, and provides a foundation upon which future production cost modeling efforts can expand and improve.

This effort addresses the importance of cooling system characteristics on energy system performance in two ways. First, to highlight the fundamental importance of water and temperatures on energy system performance, we compare a baseline scenario that does not consider any cooling system impacts from air or water resources with scenarios that do. Second, we look at a range of cooling technology compositions to better understand the water-related sensitivities of the energy sector to the different types of cooling technologies that could be deployed. Comparisons of baseline scenario results with results that consider cooling technologies indicate that the inclusion of cooling technology and water resource characteristics in production cost modeling can lead to changes in the types of generators that are optimally dispatched. Changes in dispatch generally led to reductions in baseload generating technologies that are more susceptible to water-related impacts (e.g., coal and nuclear) and increases in the flexible technologies that can make up for lost generation from those facilities (e.g., natural gas combined cycle). Examining trends across cooling technology compositions, generally there is greater deviation from baseline scenario results with higher penetrations of once-through cooling technologies (which are more prone to water-related vulnerabilities). Changes in the types of generators dispatched also lead to changes in system costs, and all scenarios that include waterrelated characteristics (except some that included DR measures) had higher annual system costs than the baseline scenario. In addition, the reliability analyses performed with the REPRA model showed that production cost models that do not take into account water resource characteristics could be missing some losses of capacity, and thus might overestimate system reliability. These changes in dispatch decisions, associated costs, and reliability estimates are important from a planning and operations perspective, and highlight the importance of including water resource and cooling technology characteristics in production cost modeling, while also suggesting that traditional production cost modeling analyses are omitting a crucial component that affects the operations of the electricity sector.

Results from this work indicate that the impacts of water-related curtailments are greatest, and thus the change in the dispatch of generating units is greatest, at higher levels of once-through cooling technology penetration during the summer. This is relevant in the context of water policy and regulations and their impacts on energy system costs and reliability concerns. Water policies and regulations can affect the scheduling of certain generators and often water-induced curtailments occur during times of high energy demand. This overall trend is expected, as once- 
through cooling technologies are more susceptible to vulnerabilities related to changes in water temperature, and this work provides some estimates of the magnitude of change for system differences. In this test case considered here, the inclusion of water-related curtailment regulations in the most extreme case led to a $13 \%$ increase in natural gas combined cycle generation, with a corresponding $25 \%$ reduction in nuclear generation.

Water-related curtailments can also lead to substantial increases in system costs, as more expensive generators are put on line to make up for lost generation from baseload generators. In the most extreme test case, annual production costs increased by $6 \%$ when compared with the same technology configuration with and without water-related curtailments. Water-related curtailments also greatly affected reliability analysis differences in this test case. The greatest differences in ELCC analyses to measure the capacity value of generators on the system were a result of the inclusion of water-related curtailments on the system. Although many production cost analyses take into consideration some types of generator outages, water-related outages are generally not considered.

Lastly, this effort considers how DR measures could affect the generation, costs, and reliability of systems that consider water-related impacts. Including DR measures on the test case generally leads to greater annual generation of baseload units (e.g., nuclear and coal) and less generation from natural gas combined cycle technologies. Although generation from coal and nuclear technologies is greater on an annual basis, there is no indication that these water-vulnerable units perform better during peak load and high water-related vulnerability periods as a result of DR measures. There is a slight improvement in ELCC for DR scenarios over scenarios that do not consider DR measures. DR measures reduce system costs across all scenarios considered. Individual cost reductions resulting from DR scenarios tend to be lower for scenarios with waterrelated curtailments than without water-related curtailments, perhaps due to the greater dependency on vulnerable baseload units in DR cases and the greater costs associated with ramping up other generators during water-related curtailment incidents. Still, DR measures do lead to small improvements in costs and reliability for systems with water-related vulnerabilities, although the impact is more indirect. 


\section{Limitations and Next Steps}

This effort has undertaken initial energy-water-climate modeling to demonstrate the feasibility of linking electricity production cost models with energy and climate models, while also underlining the importance of water resources in power system modeling. This work provides fundamental innovations and insights on these topics, and future research could address gaps and limitations of this study. Future efforts could improve upon the current work in a variety of ways. First, this effort used a test case that is loosely modeled after the Eastern Interconnection in 2010. Future studies could evaluate an actual region that has the required water and energy data readily available. Evaluating a specific region could lead to insights that could inform decision-makers, and could also provide more realistic bounds on cooling technologies and water regulations.

Improving the coupling and automation of the electricity, water, and climate models could also improve the results and lead to greater insights on the water-related vulnerabilities of the energy sector. This effort used water temperature data based on a certain electricity generation scenario, whereas greater coupling of PLEXOS and TP2M (or other similar models) could lead to a more iterative approach, where PLEXOS dispatch is optimized based on iterations with TP2M to maximize system output and minimize water-related vulnerabilities.

Another way in which future work could build on this effort is to look at changing compositions of generator technology types, such as a high renewable, high fossil, or high nuclear systems. Evaluating system dispatch, costs, and reliability under these variations could lead to insights on the relative merits of different types of electricity generating technologies under scenarios of water stress. Certain technologies, such as variable renewable energy sources like wind and photovoltaics, can have challenges associated with integration, yet also can provide "droughtproof" electricity due to their not needing water for operations. The system composition, such as generation mix, load profiles, resource capability, and transmission capacity, can also cause significant variations in DR's operational value (Ma and Cheung 2016).

Energy policy impacts could also be a promising area of future work. Energy policies could affect the composition of generator technology types as well as demand response opportunities, energy efficiency implementation, reserve margin requirements, or other factors, which in turn could affect not only dispatch decisions but also larger questions of system reliability and costs.

The performance of the system could also change greatly depending on hydrological and weather conditions under different climate scenarios. Future work could evaluate how an existing energy system would perform under stressed water scenarios, or how that system would perform in a future climate. Related efforts could also look at capacity expansion of the electricity sector under different climate scenarios, and then model system performance under these conditions to understand what the most reliable and cost-effective system would be.

Lastly, future work could also more effectively address questions of uncertainty and sensitivity of model outputs to variations in inputs, both in isolation and in combination. Evaluating these sensitivities would allow for an improved understanding of what characteristics related to water are driving the biggest changes in dispatch, costs, and reliability, and could improve energy system planning and operations, in addition to guiding future research priorities in this space. 


\section{Summary and Conclusion}

This paper describes a unique modeling framework linking climate and water resource characteristics with an electricity production cost model and a relative capacity value model to better understand how water resource characteristics can affect power system operations and vulnerabilities and the additional impacts of including DR measures on a system. This effort analyzes 25 scenarios, studying variations in cooling system compositions of generators, water policy and regulations, and DR measures, to compare system dispatch, costs, and reliability metrics. Incorporation of cooling technology characteristics led to changes in electricity dispatch, costs, and ELCC during certain times of the year. Different cooling technology compositions had different system generation, costs, and ELCC results. Incorporating water policies and regulations amplified changes in system dispatch, costs, and ELCC. DR measures altered the generation dispatch to rely more on baseload technologies, and also led to consistent reductions in system costs. The beneficial effects of DR were slightly lower in systems that included water regulations, but were still an improvement over systems that did not include DR. This effort provides unique data on water-related impacts on production cost modeling output for a test system, and there are many opportunities for future work to build upon these fundamental results. 


\section{References}

Aghaei, Jamshid, and Mohammad-Iman Alizadeh. 2013. "Demand response in smart electricity grids equipped with renewable energy sources: A review." Renewable and Sustainable Energy Reviews 18:64-72. http://dx.doi.org/10.1016/j.rser.2012.09.019.

Albadi, M.H., and E.F. El-Saadany. 2008. "A summary of demand response in electricity markets.” Electric Power Systems Research 78(11):1989-1996. http://dx.doi.org/10.1016/j.epsr.2008.04.002.

Alkadi, N., P. Cappers, P. Denholm, J. Dudley, S. Goli, M. Hummon, S. Kiliccote, B. Kirby, O. Ma, J. MacDonald, N. Matson, D. Olsen, M. O’Malley, C. Rose, M.D. Sohn, and M. Starke. 2013. "Demand Response for Ancillary Services." IEEE Transactions on Smart Grid 4(4):19881995.

Averyt, K., J. Macknick, J. Rogers, N. Madden, J. Fisher, J. Meldrum, and R. Newmark. 2013. "Water use for electricity in the United States: an analysis of reported and calculated water use information for 2008." Environmental Research Letters 8(1):1-9.

http://dx.doi.org/10.1088/1748-9326/8/1/015001.

Cappers, Peter, Charles Goldman, and David Kathan. 2010. "Demand response in U.S. electricity markets: Empirical evidence.” Energy 35(4):1526-1535.

http://dx.doi.org/10.1016/j.energy.2009.06.029.

Elcock, Deborah. 2010. "Future U.S. Water Consumption: The Role of Energy Production." JAWRA Journal of the American Water Resources Association 46(3):447-460.

Energy Exemplar. 2016. "PLEXOS® Integrated Energy Model.” Accessed May 16. http://energyexemplar.com/software/plexos-desktop-edition/.

EPA (U.S. Environmental Protection Agency). 2009. “Cooling Water Intake Structures-CWA 316(b), Phase II-Large Existing Electric Generating Plants.” Washington, DC: U.S.

Environmental Protection Agency.

Garver, L.L. 1966. "Effective load carrying capability of generating units." IEEE Transactions on Power Apparatus and Systems 85(8):910- 919.

Hummon, Marissa, David Palchak, Paul Denholm, Jennie Jorgenson, Daniel J. Olsen, Sila Kiliccote, Nance Matson, Michael Sohn, Cody Rose, Junqiao Dudley, Sasank Goli, and Ookie Ma. 2013. Grid Integration of Aggregated Demand Response, Part 2: Modeling Demand Response in a Production Cost Model. NREL/TP-6A20-58492. Golden, CO: National Renewable Energy Laboratory. http://www.nrel.gov/docs/fy14osti/58492.pdf.

Ibanez, E., and M. Milligan. 2012. "A Probabilistic Approach to Quantifying the Contribution of Variable Generation and Transmission to System Reliability." NREL/CP-5500-56219. Paper presented at the 11th Annual International Workshop on Large-Scale Integration of Wind Power into Power Systems as Well as on Transmission Networks for Offshore Wind Power Plants Conference, Lisbon, Portugal, November 13-15. http://www.nrel.gov/docs/fy12osti/56219.pdf. 
Ibanez, Eduardo, Timothy Magee, Mitch Clement, Gregory Brinkman, Michael Milligan, and Edith Zagona. 2014. "Enhancing Hydropower Modeling in Variable Generation Integration Studies.” Energy 74:518-528. http://dx.doi.org/10.1016/j.energy.2014.07.017.

Jang, Dongsik, Jiyong Eom, Moon Gyu Kim, and Jae Jeung Rho. 2015. "Demand responses of Korean commercial and industrial businesses to critical peak pricing of electricity." Journal of Cleaner Production 90:275-290. http://dx.doi.org/10.1016/j.jclepro.2014.11.052.

Keane, Andrew, Michael Milligan, Chris J. Dent, Bernhard Hasche, Claudine D’Annunzio, Ken Dragoon, Hannele Holttinen, Nader Samaan, Lennart Soder, and Mark O’Malley. 2011.

"Capacity Value of Wind Power." IEEE Transactions on Power Systems 26(2):564-572. http://dx.doi.org/10.1109/TPWRS.2010.2062543.

Kenny, Joan F., Nancy L. Barber, Susan S. Hutson, Kristin S. Linsey, John K. Lovelace, and Molly A. Maupin. 2009. Estimated Use of Water in the United States in 2005. Circular 1344. Reston, VA: U.S. Geological Survey. http://pubs.usgs.gov/circ/1344/pdf/c1344.pdf.

Kundzewicz, Z.W., L.J. Mata, N.W. Arnell, P. Döll, B. Jimenez, K. Miller, T. Oki, Z. Şen, and I. Shiklomanov. 2008. "The implications of projected climate change for freshwater resources and their management." Hydrological Sciences Journal 53(1):3-10.

http://dx.doi.org/10.1623/hysj.53.1.3.

Ma, Ookie, and Kerry Cheung. 2016. Demand Response and Energy Storage Integration Study. Washington, D.C.: U.S. Department of Energy. http://www.energy.gov/sites/prod/files/2016/03/f30/DOE-EE-1282.pdf.

Macknick, J., R. Newmark, G. Heath and K.C. Hallett. 2012. "Operational water consumption and withdrawal factors for electricity generating technologies: a review of existing literature." Environmental Research Letters 7(4). http://dx.doi.org/10.1088/1748-9326/7/4/045802.

Madden, N., A. Lewis, and M. Davis. 2013. "Thermal effluent from the power sector: an analysis of once-through cooling system impacts on surface water temperature." Environmental Research Letters 8. http://dx.doi.org/10.1088/1748-9326/8/3/035006.

Maupin, Molly A., Joan F. Kenny, Susan S. Hutson, John K. Lovelace, Nancy L. Barber, and Kristin S. Linsey. 2014. Estimated Use of Water in the United States in 2010. Circular 1405. Reston, VA: U.S. Geological Survey. http://pubs.usgs.gov/circ/1405/.

McCall, J., J. Macknick, and D. Hillman. 2016. Water-Related Power Plant Curtailments: An Overview of Incidents and Contributing Factors. NREL/TP-6A20-67084. Golden, CO: National Renewable Energy Laboratory. http://www.nrel.gov/docs/fy16osti/67084.pdf.

Meldrum, J., S. Nettles-Anderson, G. Heath, and J. Macknick. 2013. "Life Cycle Water Use for Electricity Generation: A Review and Harmonization of Literature Estimates." Environmental Research Letters 8. http://dx.doi.org/10.1088/1748-9326/8/1/015031.

Miara, Ariel, Charles J. Vörösmarty, Robert J. Stewart, Wilfred M. Wollheim, and Bernice Rosenzweig. 2013. "Riverine ecosystem services and the thermoelectric sector: strategic issues 
facing the Northeastern United States." Environmental Research Letters 8. http://dx.doi.org/10.1088/1748-9326/8/2/025017.

NETL (National Energy Technology Laboratory). 2008. Electricity Reliability Impacts of a Mandatory Cooling Tower Rule for Existing Steam Generation Units. Washington, D.C.: U.S. Department of Energy Office of Electricity Delivery and Energy Reliability.

Nolan, Sheila, Mark O’Malley, Marissa Hummon, Sila Kiliccote, and Ookie Ma. 2014. “A Methodology for Estimating the Capacity Value of Demand Response." Paper presented at the IEEE Power \& Energy Society General Meeting, National Harbor, Maryland, July 27-31.

O'Connell, Niamh, Elaine Hale, Ian Doebber, and Jennie Jorgenson. 2015. On the Inclusion of Energy-Shifting Demand Response in Production Cost Models: Methodology and a Case Study. NREL/TP-6A20-64465. Golden, CO: National Renewable Energy Laboratory. http://www.nrel.gov/docs/fy15osti/64465.pdf.

Olsen, Daniel J., Nance Matson, Michael D. Sohn, Cody Rose, Junqiao Dudley, Sasank Goli, Sila Kiliccote, Marissa Hummon, David Palchak, Paul Denholm, Jennie Jorgenson, and Ookie Ma. 2013. Grid Integration of Aggregated Demand Response, Part 1: Load Availability Profiles and Constraints for the Western Interconnection. LBNL-6417E. Berkeley, CA: Lawrence Berkeley National Laboratory. http://eetd.lbl.gov/sites/all/files/lbnl-6417e.pdf.

Palensky, Peter, and Dietmar Dietrich. 2011. "Demand Side Management: Demand Response, Intelligent Energy Systems, and Smart Loads." IEEE Transactions on Industrial Informatics 7(3):381-388.

Paulus, Moritz, and Frieder Borggrefe. 2011. "The potential of demand-side management in energy-intensive industries for electricity markets in Germany." Applied Energy 88(2):432-441. http://dx.doi.org/10.1016/j.apenergy.2010.03.017.

Rogers, John, Kristen Averyt, Steve Clemmer, Michelle Davis, Francisco Flores-Lopez, Doug Kenney, Jordan Macknick, Nadia Madden, James Meldrum, Sandra Sattler, Erika SpangerSiegfried, and David Yates. 2013. Water-Smart Power: Strengthening the U.S. Electricity System in a Warming World. Cambridge, MA: Union of Concerned Scientists. http://www.ucsusa.org/sites/default/files/legacy/assets/documents/clean energy/Water-SmartPower-Full-Report.pdf.

Sæle, Hanne, and Ove S. Grande. 2011. "Demand Response From Household Customers: Experiences From a Pilot Study in Norway." IEEE Transactions on Smart Grid 2(1):102-109. http://dx.doi.org/10.1109/TSG.2010.2104165.

Sanders, Kelly T., Michael F. Blackhurst, Carey W. King, and Michael E. Webber. 2014. "The Impact of Water Use Fees on Dispatching and Water Requirements for Water-Cooled Power Plants in Texas." Environmental Science \& Technology 48(12):7128-7134. http://dx.doi.org/10.1021/es500469q. 
Santhosh, Apoorva, Amro M. Farid, and Kamal Youcef-Toumi. 2014. "Real-time economic dispatch for the supply side of the energy-water nexus." Applied Energy 122:42-52. http://dx.doi.org/10.1016/j.apenergy.2014.01.062.

Sattler, S., J. Macknick, D. Yates, F. Flores-Lopez, A. Lopez, and J. Rogers. 2012. "Linking electricity and water models to assess electricity choices at water-relevant scales."

Environmental Research Letters 7. http://dx.doi.org/10.1088/1748-9326/7/4/045804.

Shariatzadeh, Farshid, Paras Mandal, and Anurag K. Srivastava. 2015. "Demand response for sustainable energy systems: A review, application and implementation strategy." Renewable and Sustainable Energy Reviews 45:343-350. http://dx.doi.org/10.1016/j.rser.2015.01.062.

Srinivasan, V., E. F. Lambin, S. M. Gorelick, B. H. Thompson, and S. Rozelle. 2012. "The nature and causes of the global water crisis: Syndromes from a meta-analysis of coupled human water studies." Water Resources Research 48(10):1-16. http://dx.doi.org/10.1029/2011WR011087.

Stewart, Robert J., Wilfred M., Wollheim, Ariel Miara, Charles J. Vörösmarty, Balazs Fekete, Richard B. Lammers, and Bernice Rosenzweig. 2013. "Horizontal cooling towers: riverine ecosystem services and the fate of thermoelectric heat in the contemporary Northeast US." Environmental Research Letters 8. http://dx.doi.org/10.1088/1748-9326/8/2/025010.

Stillwell, Ashlynn S., and Michael E. Webber. 2013. "Evaluation of power generation operations in response to changes in surface water reservoir storage." Environmental Research Letters 8. http://dx.doi.org/10.1088/1748-9326/8/2/025014.

Stoll, Brady, Gregory Brinkman, Aaron Townsend, and Aaron Bloom. 2016. Analysis of Modeling Assumptions used in Production Cost Models for Renewable Integration Studies. NREL/TP-6A20-65383. Golden, CO: National Renewable Energy Laboratory. http://www.nrel.gov/docs/fy16osti/65383.pdf.

Sullivan, Patrick, Jesse Colman, and Eric Kalendra. 2015. Predicting the Response of Electricity Load to Climate Change. NREL/TP-6A20-64297. Golden, CO: National Renewable Energy Laboratory. http://www.nrel.gov/docs/fy15osti/64297.pdf.

Taniguchi, Ayako, Takuya Inoue, Masaya Otsuki, Yohei Yamaguchi, Yoshiyuki Shimoda, Akinobu Takami, and Kanako Hanaoka. 2016. "Estimation of the contribution of the residential sector to summer peak demand reduction in Japan using an energy end-use simulation model." Energy and Buildings 112:80-92. http://dx.doi.org/10.1016/j.enbuild.2015.11.064.

Torriti, Jacopo, Mohamed G. Hassan, and Matthew Leach. 2010. "Demand response experience in Europe: Policies, programmes and implementation." Energy 35(4):1575-1583. http://dx.doi.org/10.1016/j.energy.2009.05.021.

van Vliet, Michelle T. H., D. Wiberg, S. Leduc, and K. Riahi. 2016. "Power-generation system vulnerability and adaptation to changes in climate and water resources." Nature Climate Change 6(4): 375-380. 
van Vliet, Michelle T.H., Stefan Vögele, and Dirk Rübbelke. 2013. "Water constraints on European power supply under climate change: impacts on electricity prices." Environmental Research Letters 8. http://dx.doi.org/10.1088/1748-9326/8/3/035010. (a)

van Vliet, Michelle T.H., Wietse H.P. Franssen, John R. Yearsley, Fulco Ludwig, Ingjerd Haddeland, Dennis P. Lettenmaier, and Pavel Kabat. 2013. "Global river discharge and water temperature under climate change." Global Environmental Change 23(2):450-464. http://dx.doi.org/10.1016/j.gloenvcha.2012.11.002. (b)

Vörösmarty, C.J., P.B. McIntyre, M.O. Gessner, D. Dudgeon, A. Prusevich, P. Green, S. Glidden, S.E. Bunn, C.A. Sullivan, C. Reidy Liermann, and P.M. Davies. 2010. "Global threats to human water security and river biodiversity." Nature 467:555-561.

http://dx.doi.org/10.1038/nature09440.

Woolf, Tim, Erin Malone, Lisa Schwartz, and John Shenot. 2013. A Framework for Evaluating the Cost-Effectiveness of Demand Response. Berkeley, CA: Lawrence Berkeley National Laboratory. https://emp.lbl.gov/sites/all/files/napdr-cost-effectiveness_0.pdf. 


\section{Appendix A. Detail on Water-Related Power Plant Curtailments}

Table A - 1. Detail on Water-Related Power Plant Curtailments

\begin{tabular}{|c|c|c|c|c|c|c|c|}
\hline $\begin{array}{l}\text { Map } \\
\text { ID }\end{array}$ & Plant Name & Fuel & Reason & Date & State & $\begin{array}{l}\text { Cooling } \\
\text { System }\end{array}$ & Source \\
\hline 1 & Coal Creek & Coal & $\begin{array}{l}\text { Intake water volume } \\
\text { insufficient }\end{array}$ & $3 / 26 / 2009$ & ND & Recirculating & Gehring 2009 \\
\hline 2 & Leland Olds & Coal & $\begin{array}{l}\text { Intake water volume } \\
\text { insufficient }\end{array}$ & $3 / 26 / 2009$ & ND & Once-through & Gehring 2009 \\
\hline 3 & $\begin{array}{l}\text { Duane Arnold } \\
\text { Energy Center }\end{array}$ & Nuclear & $\begin{array}{l}\text { Inadequate Water Intake } \\
\text { Volume }\end{array}$ & 8/9/2012 & IA & Recirculating & DeWitte 2012 \\
\hline 4 & Prairie Island & Nuclear & $\begin{array}{l}\text { Intake Water } \\
\text { Temperature }\end{array}$ & $7 / 29 / 2006$ & $\mathrm{MN}$ & Once-Through & Krier 2012 \\
\hline $5 a$ & $\begin{array}{l}\text { LaSalle Generating } \\
\text { Station }\end{array}$ & Nuclear & I/D Water Temperature & 2001 & IL & Cooling Pond & $\begin{array}{l}\text { U.S. NRC } 2016 \\
\text { ADAMS } \\
\text { ML012330070 }\end{array}$ \\
\hline $5 b$ & $\begin{array}{l}\text { LaSalle Generating } \\
\text { Station }\end{array}$ & Nuclear & I/D Water Temperature & 2002 & $\mathrm{IL}$ & Cooling Pond & $\begin{array}{l}\text { U.S. NRC } 2016 \\
\text { ADAMS } \\
\text { ML15023A459 }\end{array}$ \\
\hline $5 c$ & $\begin{array}{l}\text { LaSalle Generating } \\
\text { Station }\end{array}$ & Nuclear & I/D Water Temperature & 2005 & $\mathrm{IL}$ & Cooling Pond & $\begin{array}{l}\text { U.S. NRC } 2016 \\
\text { ADAMS } \\
\text { ML052200481 }\end{array}$ \\
\hline $5 d$ & $\begin{array}{l}\text { LaSalle Generating } \\
\text { Station }\end{array}$ & Nuclear & I/D Water Temperature & 2009 & $\mathrm{IL}$ & Cooling Pond & $\begin{array}{l}\text { U.S. NRC } 2016 \\
\text { ADAMS } \\
\text { ML092040381 }\end{array}$ \\
\hline $5 e$ & $\begin{array}{l}\text { LaSalle Generating } \\
\text { Station }\end{array}$ & Nuclear & I/D Water Temperature & $8 / 12 / 2010$ & $\mathrm{IL}$ & Cooling Pond & $\begin{array}{l}\text { U.S. NRC } 2016 \\
\text { ADAMS } \\
\text { ML102371289 }\end{array}$ \\
\hline 6 & $\begin{array}{l}\text { Dresden Generating } \\
\text { Station }\end{array}$ & Nuclear & I/D Water Temperature & $7 / 29 / 2006$ & $\mathrm{IL}$ & Cooling Pond & Krier 2012 \\
\hline
\end{tabular}




\begin{tabular}{|c|c|c|c|c|c|c|c|}
\hline $\begin{array}{l}\text { Map } \\
\text { ID }\end{array}$ & Plant Name & Fuel & Reason & Date & State & $\begin{array}{l}\text { Cooling } \\
\text { System }\end{array}$ & Source \\
\hline 7 & Will County & Coal & $\begin{array}{l}\text { Discharge Water } \\
\text { Temperature }\end{array}$ & $7 / 5 / 2012$ & IL & Once-Through & IL EPA 2012 \\
\hline 8 & Joliet 9 & Coal & $\begin{array}{l}\text { Discharge Water } \\
\text { Temperature }\end{array}$ & $7 / 1 / 2012$ & $\mathrm{IL}$ & Once-Through & IL EPA 2012 \\
\hline 9 & Joliet 29 & Coal & $\begin{array}{l}\text { Discharge Water } \\
\text { Temperature }\end{array}$ & $7 / 1 / 2012$ & $\mathrm{IL}$ & Once-Through & IL EPA 2012 \\
\hline 10 & Perry & Nuclear & $\begin{array}{l}\text { Intake Water } \\
\text { Temperature }\end{array}$ & $7 / 26 / 2012$ & $\mathrm{OH}$ & Recirculating & Krier 2012 \\
\hline 11 & Donald C. Cook & Nuclear & $\begin{array}{l}\text { Intake water temperature } \\
\text { too high }\end{array}$ & $7 / 30 / 2006$ & MI & Once-through & Krier 2012 \\
\hline 12 & $\begin{array}{l}\text { Quad Cities } \\
\text { Generating Station }\end{array}$ & Nuclear & $\begin{array}{l}\text { Discharge Water } \\
\text { Temperature }\end{array}$ & $7 / 29 / 2006$ & $\mathrm{IL}$ & Once-Through & Krier 2012 \\
\hline 13 & Powerton & Coal & $\begin{array}{l}\text { Intake Water } \\
\text { Temperature }\end{array}$ & $7 / 10 / 2012$ & $\mathrm{IL}$ & Cooling Pond & Bruch 2012 \\
\hline $14 a$ & Cumberland & Coal & $\begin{array}{l}\text { Discharge Water } \\
\text { Temperature }\end{array}$ & 2008 & $\mathrm{TN}$ & Once-Through & $\begin{array}{l}\text { U.S. Army } \\
\text { Corps of } \\
\text { Engineers } 2009\end{array}$ \\
\hline $14 b$ & Cumberland & Coal & $\begin{array}{l}\text { Discharge Water } \\
\text { Temperature }\end{array}$ & 2012 & $\mathrm{TN}$ & Once-Through & $\begin{array}{l}\text { Union of } \\
\text { Concerned } \\
\text { Scientists } 2013\end{array}$ \\
\hline 15 & $\begin{array}{l}\text { Braidwood } \\
\text { Generation Station }\end{array}$ & Nuclear & $\begin{array}{l}\text { Discharge Water } \\
\text { Temperature }\end{array}$ & $7 / 1 / 2012$ & $\mathrm{IL}$ & Cooling Pond & Wald 2012 \\
\hline
\end{tabular}




\begin{tabular}{|c|c|c|c|c|c|c|c|}
\hline $\begin{array}{l}\text { Map } \\
\text { ID }\end{array}$ & Plant Name & Fuel & Reason & Date & State & $\begin{array}{l}\text { Cooling } \\
\text { System }\end{array}$ & Source \\
\hline 16 & Limerick & Nuclear & $\begin{array}{l}\text { Intake Water } \\
\text { Temperature }\end{array}$ & 2010 & PA & Recirculating & $\begin{array}{l}\text { Wise } \\
\text { International } \\
2013\end{array}$ \\
\hline 17 & Vermont Yankee & Nuclear & $\begin{array}{l}\text { Inadequate Water Intake } \\
\text { Volume }\end{array}$ & $7 / 12 / 2012$ & VT & Once-Through & Krier 2012 \\
\hline 18 & Pilgrim & Nuclear & $\begin{array}{l}\text { Intake Water } \\
\text { Temperature }\end{array}$ & $7 / 20 / 2013$ & MA & Once-through & Clemmer 2013 \\
\hline 19 & Millstone & Nuclear & $\begin{array}{l}\text { Intake Water } \\
\text { Temperature }\end{array}$ & $8 / 14 / 2012$ & CT & Once-Through & $\begin{array}{l}\text { Wise } \\
\text { International } \\
2013\end{array}$ \\
\hline 20 & Oyster Creek & Nuclear & $\begin{array}{l}\text { Discharge Water } \\
\text { Temperature }\end{array}$ & $12 / 9 / 2010$ & NJ & Once-through & $\begin{array}{l}\text { New Jersey } \\
\text { Department of } \\
\text { Environmental } \\
\text { Protection } 2016\end{array}$ \\
\hline 21 & $\begin{array}{l}\text { PSEG Hope Creek } \\
\text { Generating Station }\end{array}$ & Nuclear & $\begin{array}{l}\text { Intake Water } \\
\text { Temperature }\end{array}$ & 2010 & NJ & Recirculating & $\begin{array}{l}\text { Wise } \\
\text { International } \\
2013\end{array}$ \\
\hline 22 & Riverbend & Coal & $\begin{array}{l}\text { Discharge Water } \\
\text { Temperature }\end{array}$ & $8 / 12 / 2007$ & NC & Once-Through & DOE 2013 \\
\hline 23 & G G Allen & Coal & $\begin{array}{l}\text { Discharge Water } \\
\text { Temperature }\end{array}$ & $8 / 12 / 2007$ & $\mathrm{NC}$ & Once-Through & $\begin{array}{l}\text { Union of } \\
\text { Concerned } \\
\text { Scientists } 2013\end{array}$ \\
\hline $24 a$ & Gallatin & Coal & $\begin{array}{l}\text { Discharge Water } \\
\text { Temperature }\end{array}$ & 2008 & MO & Once-Through & $\begin{array}{l}\text { Union of } \\
\text { Concerned } \\
\text { Scientists } 2013\end{array}$ \\
\hline $24 b$ & Gallatin & Coal & $\begin{array}{l}\text { Discharge Water } \\
\text { Temperature }\end{array}$ & 2012 & MO & Once-Through & $\begin{array}{l}\text { Union of } \\
\text { Concerned } \\
\text { Scientists } 2013\end{array}$ \\
\hline
\end{tabular}




\begin{tabular}{|c|c|c|c|c|c|c|c|}
\hline $\begin{array}{l}\text { Map } \\
\text { ID }\end{array}$ & Plant Name & Fuel & Reason & Date & State & $\begin{array}{l}\text { Cooling } \\
\text { System }\end{array}$ & Source \\
\hline $25 a$ & Browns Ferry & Nuclear & $\begin{array}{l}\text { Discharge Water } \\
\text { Temperature }\end{array}$ & $8 / 5 / 2008$ & $A L$ & Once-Through & Krier 2012 \\
\hline $25 b$ & Browns Ferry & Nuclear & $\begin{array}{l}\text { Discharge Water } \\
\text { Temperature }\end{array}$ & $8 / 1 / 2010$ & $\mathrm{AL}$ & Once-Through & $\begin{array}{l}\text { Times Free } \\
\text { Press } 2010\end{array}$ \\
\hline $25 c$ & Browns Ferry & Nuclear & $\begin{array}{l}\text { Discharge Water } \\
\text { Temperature }\end{array}$ & $8 / 1 / 2011$ & $\mathrm{AL}$ & Once-Through & Krier 2012 \\
\hline 26 & Hammond & Coal & $\begin{array}{l}\text { Discharge Water } \\
\text { Temperature }\end{array}$ & $\begin{array}{l}2007- \\
2008\end{array}$ & GA & Once-Through & $\begin{array}{l}\text { Union of } \\
\text { Concerned } \\
\text { Scientists } 2013\end{array}$ \\
\hline 27 & Yates & Coal & $\begin{array}{l}\text { Inadequate Water Intake } \\
\text { Volume }\end{array}$ & $8 / 1 / 2000$ & GA & Recirculating & McGee 2000 \\
\hline 28 & Turkey Point & Nuclear & $\begin{array}{l}\text { Discharge Water } \\
\text { Temperature }\end{array}$ & $7 / 20 / 2014$ & $\mathrm{FL}$ & Cooling Pond & $\begin{array}{l}\text { U.S. NRC } 2016 \\
\text { ADAMS } \\
\text { ML15314A515 }\end{array}$ \\
\hline 29 & Monticello & Nuclear & $\begin{array}{l}\text { Discharge Water } \\
\text { Temperature }\end{array}$ & $7 / 29 / 2006$ & $\mathrm{MN}$ & Recirculating & Krier 2012 \\
\hline 30 & Calvert Cliffs & Nuclear & $\begin{array}{l}\text { Inadequate water intake } \\
\text { volume }\end{array}$ & $1 / 21 / 2014$ & MD & Once-through & $\begin{array}{l}\text { Smith Hopkins } \\
2014\end{array}$ \\
\hline
\end{tabular}




\section{References}

Bruch, Thomas. 2012. "Dead Fish Did Not Cause Powerton Shutdown." Prairie State Outdoors. August 8.

http://www.prairiestateoutdoors.com/pso/article/dead_fish_did_not_cause_powerton_shutdown.

Clemmer, Steve. 2013. "Energy-Water Collisions: A Shared Concern for State Utility Regulators." Union of Concerned Scientists (UCS). July 30. http://blog.ucsusa.org/steveclemmer/state-utility-regulators-share-concern-for-energy-water-collisions193?.ga=1.239891395.1750629502.1463505880.

DeWitte, Dave. 2012. "Palo Nuclear Plant Operator Eyeing Cedar River Levels Cautiously.” The Gazette. http://www.thegazette.com/2012/08/09/palo-nuclear-plant-operator-eyeing-cedar-riverlevels-cautiously.

DOE. 2013. "U.S. Energy Sector Vulnerabilities to Climate Change and Extreme Weather." http://energy.gov/downloads/us-energy-sector-vulnerabilities-climate-change-and-extremeweather.

Gehring, Brian. 2009. "Plants along the River Shut down." Bismarck Tribune. March 26. http://bismarcktribune.com/news/local/plants-along-the-river-shut-down/article 5e4b5540-28625aaa-9cf9-546866395419.html.

IL EPA (Illinois Environmental Protection Agency). 2012. "Illinois EPA Grants Midwest Generation Joliet Station 9, Joliet Station 29, and Will County Station Provisional Variance from Discharge Requirements." July 5.

http://www3.illinois.gov/PressReleases/ShowPressRelease.cfm?SubjectID=29\&RecNum=10364

Krier, Robert. 2012. "Extreme Heat, Drought Show Vulnerability of Nuclear Power Plants." InsideClimate News. August 15. http://insideclimatenews.org/news/20120815/nuclear-powerplants-energy-nrc-drought-weather-heat-water.

McGee, Joshua. 2000. "Drought in US Southeast Provokes Power Plant Cutbacks - Oil \& Gas Journal." Oil and Gas Journal. August 2. http://www.ogj.com/articles/2000/08/drought-in-ussoutheast-provokes-power-plant-cutbacks.html.

New Jersey Department of Environmental Protection. 2016. "Comprehensive Plan of Action Item \#1: Close Oyster Creek Nuclear Power Plant.” June 16. http://www.nj.gov/dep/barnegatbay/plan-oystercreek.htm.

Smith Hopkins, Jamies. 2014. "Nuclear Regulators Send Inspectors to Calvert Cliffs." The Baltimore Sun. January 27. http://articles.baltimoresun.com/2014-01-27/business/bs-bz-calvertcliffs-reactors-running-20140127_ 1_calvert-cliffs-kory-raftery-constellation-energy-nucleargroup.

Times Free Press. 2010. "Hot River Forces Costly Cutback for TVA | Times Free Press." August 23. http://www.timesfreepress.com/news/news/story/2010/aug/23/hot-river-forces-costlycutback-tva/27261/. 
U.S. Army Core of Engineers. 2009. "Managing Our Water Retention Systems.” Nashville, TN. http://www.ussdams.com/proceedings/2009Proc/1517-1532.pdf.

U.S. NRC (United States Nuclear Regulatory Commission). 2016. “ADAMS Public Documents." http://www.nrc.gov/reading-rm/adams.html.

Union of Concerned Scientists. 2013. "Water Dependence Risks for America's Aging Coal Fleet." April. http://www.ucsusa.org/clean_energy/our-energy-choices/energy-and-wateruse/coal-plants-water-use-risks.html\#.V1dBAnovZR8.

Wald, Matthew. 2012a. "So, How Hot Was It?” The New York Times. July 17.

http://green.blogs.nytimes.com/2012/07/17/so-how-hot-was-it/? r=0.

Wise International. 2013. "Climate Change, Water and Energy." October 24.

https://www.wiseinternational.org/node/4149. 


\section{Appendix B. TP2M Results on Technology Efficiencies}

Table B - 1. Daily Power Plant Efficiency Multipliers by Technology Type for Scenarios with No Curtailments

\begin{tabular}{|c|c|c|c|c|c|c|}
\hline Category & Coal & Coal & NGCC & NGCC & Nuclear & Nuclear \\
\hline Cooling & $\begin{array}{c}\text { Once- } \\
\text { through }\end{array}$ & $\begin{array}{c}\text { Cooling } \\
\text { tower }\end{array}$ & $\begin{array}{c}\text { Once- } \\
\text { through }\end{array}$ & $\begin{array}{c}\text { Cooling } \\
\text { tower }\end{array}$ & $\begin{array}{c}\text { Once- } \\
\text { through }\end{array}$ & $\begin{array}{c}\text { Cooling } \\
\text { tower }\end{array}$ \\
\hline \multicolumn{7}{|l|}{ Dates } \\
\hline $1 / 1 / 2010$ & 1 & 1 & 1 & 1 & 1 & 1 \\
\hline $1 / 2 / 2010$ & 1 & 1 & 1 & 1 & 1 & 1 \\
\hline $1 / 3 / 2010$ & 1 & 1 & 1 & 1 & 1 & 1 \\
\hline $1 / 4 / 2010$ & 1 & 1 & 1 & 1 & 1 & 1 \\
\hline $1 / 5 / 2010$ & 1 & 1 & 1 & 1 & 1 & 1 \\
\hline $1 / 6 / 2010$ & 1 & 1 & 1 & 1 & 1 & 1 \\
\hline $1 / 7 / 2010$ & 1 & 1 & 1 & 1 & 1 & 1 \\
\hline $1 / 8 / 2010$ & 1 & 1 & 1 & 1 & 1 & 1 \\
\hline 1/9/2010 & 1 & 1 & 1 & 1 & 1 & 1 \\
\hline $1 / 10 / 2010$ & 1 & 1 & 1 & 1 & 1 & 1 \\
\hline $1 / 11 / 2010$ & 1 & 1 & 1 & 1 & 1 & 1 \\
\hline $1 / 12 / 2010$ & 1 & 1 & 1 & 1 & 1 & 1 \\
\hline $1 / 13 / 2010$ & 1 & 1 & 1 & 1 & 1 & 1 \\
\hline $1 / 14 / 2010$ & 1 & 1 & 1 & 1 & 1 & 1 \\
\hline $1 / 15 / 2010$ & 1 & 1 & 1 & 1 & 1 & 1 \\
\hline $1 / 16 / 2010$ & 1 & 1 & 1 & 1 & 1 & 1 \\
\hline $1 / 17 / 2010$ & 1 & 1 & 1 & 1 & 1 & 1 \\
\hline $1 / 18 / 2010$ & 1 & 1 & 1 & 1 & 1 & 1 \\
\hline $1 / 19 / 2010$ & 1 & 1 & 1 & 1 & 1 & 1 \\
\hline $1 / 20 / 2010$ & 1 & 1 & 1 & 1 & 1 & 1 \\
\hline $1 / 21 / 2010$ & 1 & 1 & 1 & 1 & 1 & 1 \\
\hline $1 / 22 / 2010$ & 1 & 1 & 1 & 1 & 1 & 1 \\
\hline $1 / 23 / 2010$ & 1 & 1 & 1 & 1 & 1 & 1 \\
\hline $1 / 24 / 2010$ & 1 & 1 & 1 & 1 & 1 & 1 \\
\hline $1 / 25 / 2010$ & 1 & 1 & 1 & 1 & 1 & 1 \\
\hline $1 / 26 / 2010$ & 1 & 1 & 1 & 1 & 1 & 1 \\
\hline $1 / 27 / 2010$ & 1 & 1 & 1 & 1 & 1 & 1 \\
\hline $1 / 28 / 2010$ & 1 & 1 & 1 & 1 & 1 & 1 \\
\hline $1 / 29 / 2010$ & 1 & 1 & 1 & 1 & 1 & 1 \\
\hline $1 / 30 / 2010$ & 1 & 1 & 1 & 1 & 1 & 1 \\
\hline $1 / 31 / 2010$ & 1 & 1 & 1 & 1 & 1 & 1 \\
\hline $2 / 1 / 2010$ & 1 & 1 & 1 & 1 & 1 & 1 \\
\hline $2 / 2 / 2010$ & 1 & 1 & 1 & 1 & 1 & 1 \\
\hline $2 / 3 / 2010$ & 1 & 1 & 1 & 1 & 1 & 1 \\
\hline $2 / 4 / 2010$ & 1 & 1 & 1 & 1 & 1 & 1 \\
\hline $2 / 5 / 2010$ & 1 & 1 & 1 & 1 & 1 & 1 \\
\hline
\end{tabular}




\begin{tabular}{|c|c|c|c|c|c|c|}
\hline Category & Coal & Coal & NGCC & NGCC & Nuclear & Nuclear \\
\hline Cooling & $\begin{array}{c}\text { Once- } \\
\text { through }\end{array}$ & $\begin{array}{c}\text { Cooling } \\
\text { tower }\end{array}$ & $\begin{array}{l}\text { Once- } \\
\text { through }\end{array}$ & $\begin{array}{c}\text { Cooling } \\
\text { tower }\end{array}$ & $\begin{array}{l}\text { Once- } \\
\text { through }\end{array}$ & $\begin{array}{c}\text { Cooling } \\
\text { tower }\end{array}$ \\
\hline \multicolumn{7}{|l|}{ Dates } \\
\hline $2 / 6 / 2010$ & 1 & 1 & 1 & 1 & 1 & 1 \\
\hline $2 / 7 / 2010$ & 1 & 1 & 1 & 1 & 1 & 1 \\
\hline $2 / 8 / 2010$ & 1 & 1 & 1 & 1 & 1 & 1 \\
\hline $2 / 9 / 2010$ & 1 & 1 & 1 & 1 & 1 & 1 \\
\hline $2 / 10 / 2010$ & 1 & 1 & 1 & 1 & 1 & 1 \\
\hline $2 / 11 / 2010$ & 1 & 1 & 1 & 1 & 1 & 1 \\
\hline $2 / 12 / 2010$ & 1 & 1 & 1 & 1 & 1 & 1 \\
\hline $2 / 13 / 2010$ & 1 & 1 & 1 & 1 & 1 & 1 \\
\hline $2 / 14 / 2010$ & 1 & 1 & 1 & 1 & 1 & 1 \\
\hline $2 / 15 / 2010$ & 1 & 1 & 1 & 1 & 1 & 1 \\
\hline $2 / 16 / 2010$ & 1 & 1 & 1 & 1 & 1 & 1 \\
\hline $2 / 17 / 2010$ & 1 & 1 & 1 & 1 & 1 & 1 \\
\hline $2 / 18 / 2010$ & 1 & 1 & 1 & 1 & 1 & 1 \\
\hline $2 / 19 / 2010$ & 1 & 1 & 1 & 1 & 1 & 1 \\
\hline $2 / 20 / 2010$ & 1 & 1 & 1 & 1 & 1 & 1 \\
\hline $2 / 21 / 2010$ & 1 & 1 & 1 & 1 & 1 & 1 \\
\hline $2 / 22 / 2010$ & 1 & 1 & 1 & 1 & 1 & 1 \\
\hline $2 / 23 / 2010$ & 1 & 1 & 1 & 1 & 1 & 1 \\
\hline $2 / 24 / 2010$ & 1 & 1 & 1 & 1 & 1 & 1 \\
\hline $2 / 25 / 2010$ & 1 & 1 & 1 & 1 & 1 & 1 \\
\hline $2 / 26 / 2010$ & 1 & 1 & 1 & 1 & 1 & 1 \\
\hline $2 / 27 / 2010$ & 1 & 1 & 1 & 1 & 1 & 1 \\
\hline $2 / 28 / 2010$ & 1 & 1 & 1 & 1 & 1 & 1 \\
\hline $3 / 1 / 2010$ & 1 & 1 & 1 & 1 & 1 & 1 \\
\hline $3 / 2 / 2010$ & 1 & 1 & 1 & 1 & 1 & 1 \\
\hline $3 / 3 / 2010$ & 1 & 1 & 1 & 1 & 1 & 1 \\
\hline $3 / 4 / 2010$ & 1 & 1 & 1 & 1 & 1 & 1 \\
\hline $3 / 5 / 2010$ & 1 & 1 & 1 & 1 & 1 & 1 \\
\hline $3 / 6 / 2010$ & 1 & 1 & 1 & 1 & 1 & 1 \\
\hline $3 / 7 / 2010$ & 1 & 1 & 1 & 1 & 1 & 1 \\
\hline $3 / 8 / 2010$ & 1 & 1 & 1 & 1 & 1 & 1 \\
\hline $3 / 9 / 2010$ & 1 & 1 & 1 & 1 & 1 & 1 \\
\hline $3 / 10 / 2010$ & 1 & 1 & 1 & 1 & 1 & 1 \\
\hline $3 / 11 / 2010$ & 1 & 1 & 1 & 1 & 1 & 1 \\
\hline $3 / 12 / 2010$ & 1 & 1 & 1 & 1 & 1 & 1 \\
\hline $3 / 13 / 2010$ & 1 & 1 & 1 & 1 & 1 & 1 \\
\hline $3 / 14 / 2010$ & 1 & 1 & 1 & 1 & 1 & 1 \\
\hline $3 / 15 / 2010$ & 1 & 1 & 1 & 1 & 1 & 1 \\
\hline $3 / 16 / 2010$ & 1 & 1 & 1 & 1 & 1 & 1 \\
\hline $3 / 17 / 2010$ & 1 & 1 & 1 & 1 & 1 & 1 \\
\hline
\end{tabular}




\begin{tabular}{|c|c|c|c|c|c|c|}
\hline Category & Coal & Coal & NGCC & NGCC & Nuclear & Nuclear \\
\hline Cooling & $\begin{array}{c}\text { Once- } \\
\text { through }\end{array}$ & $\begin{array}{c}\text { Cooling } \\
\text { tower }\end{array}$ & $\begin{array}{l}\text { Once- } \\
\text { through }\end{array}$ & $\begin{array}{c}\text { Cooling } \\
\text { tower }\end{array}$ & $\begin{array}{l}\text { Once- } \\
\text { through }\end{array}$ & $\begin{array}{c}\text { Cooling } \\
\text { tower }\end{array}$ \\
\hline \multicolumn{7}{|l|}{ Dates } \\
\hline $3 / 18 / 2010$ & 1 & 1 & 1 & 1 & 1 & 1 \\
\hline $3 / 19 / 2010$ & 1 & 1 & 1 & 1 & 1 & 1 \\
\hline $3 / 20 / 2010$ & 1 & 1 & 1 & 1 & 1 & 1 \\
\hline $3 / 21 / 2010$ & 1 & 1 & 1 & 1 & 1 & 1 \\
\hline $3 / 22 / 2010$ & 1 & 1 & 1 & 1 & 1 & 1 \\
\hline $3 / 23 / 2010$ & 1 & 1 & 1 & 1 & 1 & 1 \\
\hline $3 / 24 / 2010$ & 1 & 1 & 1 & 1 & 1 & 1 \\
\hline $3 / 25 / 2010$ & 1 & 1 & 1 & 1 & 1 & 1 \\
\hline $3 / 26 / 2010$ & 1 & 1 & 1 & 1 & 1 & 1 \\
\hline $3 / 27 / 2010$ & 1 & 1 & 1 & 1 & 1 & 1 \\
\hline $3 / 28 / 2010$ & 1 & 1 & 1 & 1 & 1 & 1 \\
\hline $3 / 29 / 2010$ & 1 & 1 & 1 & 1 & 1 & 1 \\
\hline $3 / 30 / 2010$ & 1 & 1 & 1 & 1 & 1 & 1 \\
\hline $3 / 31 / 2010$ & 1 & 1 & 1 & 1 & 1 & 1 \\
\hline $4 / 1 / 2010$ & 1 & 1 & 1 & 1 & 1 & 1 \\
\hline $4 / 2 / 2010$ & 1 & 1 & 1 & 1 & 1 & 1 \\
\hline $4 / 3 / 2010$ & 1 & 1 & 1 & 1 & 1 & 1 \\
\hline $4 / 4 / 2010$ & 1 & 1 & 1 & 1 & 1 & 1 \\
\hline $4 / 5 / 2010$ & 1 & 1 & 1 & 1 & 1 & 1 \\
\hline $4 / 6 / 2010$ & 1 & 1 & 1 & 1 & 1 & 1 \\
\hline $4 / 7 / 2010$ & 1 & 0.999594783 & 1 & 1 & 1 & 1 \\
\hline $4 / 8 / 2010$ & 1 & 1 & 1 & 1 & 1 & 1 \\
\hline $4 / 9 / 2010$ & 1 & 1 & 1 & 1 & 1 & 1 \\
\hline $4 / 10 / 2010$ & 1 & 1 & 1 & 1 & 1 & 1 \\
\hline $4 / 11 / 2010$ & 1 & 1 & 1 & 1 & 1 & 1 \\
\hline $4 / 12 / 2010$ & 1 & 1 & 1 & 1 & 1 & 1 \\
\hline $4 / 13 / 2010$ & 1 & 1 & 1 & 1 & 1 & 1 \\
\hline $4 / 14 / 2010$ & 1 & 1 & 1 & 1 & 1 & 1 \\
\hline $4 / 15 / 2010$ & 1 & 1 & 1 & 1 & 1 & 1 \\
\hline $4 / 16 / 2010$ & 1 & 1 & 1 & 1 & 1 & 1 \\
\hline $4 / 17 / 2010$ & 1 & 1 & 1 & 1 & 1 & 1 \\
\hline $4 / 18 / 2010$ & 1 & 1 & 1 & 1 & 1 & 1 \\
\hline $4 / 19 / 2010$ & 1 & 1 & 1 & 1 & 1 & 1 \\
\hline $4 / 20 / 2010$ & 1 & 1 & 1 & 1 & 1 & 1 \\
\hline $4 / 21 / 2010$ & 1 & 1 & 1 & 1 & 1 & 1 \\
\hline $4 / 22 / 2010$ & 1 & 1 & 1 & 1 & 1 & 1 \\
\hline $4 / 23 / 2010$ & 1 & 1 & 1 & 1 & 1 & 1 \\
\hline $4 / 24 / 2010$ & 1 & 1 & 1 & 1 & 1 & 1 \\
\hline $4 / 25 / 2010$ & 1 & 1 & 1 & 1 & 1 & 1 \\
\hline $4 / 26 / 2010$ & 1 & 1 & 1 & 1 & 1 & 1 \\
\hline
\end{tabular}




\begin{tabular}{|c|c|c|c|c|c|c|}
\hline Category & Coal & Coal & NGCC & NGCC & Nuclear & Nuclear \\
\hline Cooling & $\begin{array}{c}\text { Once- } \\
\text { through }\end{array}$ & $\begin{array}{c}\text { Cooling } \\
\text { tower }\end{array}$ & $\begin{array}{c}\text { Once- } \\
\text { through }\end{array}$ & $\begin{array}{c}\text { Cooling } \\
\text { tower }\end{array}$ & $\begin{array}{c}\text { Once- } \\
\text { through }\end{array}$ & $\begin{array}{c}\text { Cooling } \\
\text { tower }\end{array}$ \\
\hline \multicolumn{7}{|l|}{ Dates } \\
\hline $4 / 27 / 2010$ & 1 & 1 & 1 & 1 & 1 & 1 \\
\hline $4 / 28 / 2010$ & 1 & 1 & 1 & 1 & 1 & 1 \\
\hline $4 / 29 / 2010$ & 1 & 1 & 1 & 1 & 1 & 1 \\
\hline $4 / 30 / 2010$ & 1 & 1 & 1 & 1 & 1 & 1 \\
\hline $5 / 1 / 2010$ & 1 & 0.998850652 & 1 & 1 & 1 & 1 \\
\hline $5 / 2 / 2010$ & 1 & 0.9903475 & 1 & 0.999209091 & 1 & 1 \\
\hline $5 / 3 / 2010$ & 1 & 0.998998652 & 1 & 0.998784091 & 1 & 1 \\
\hline $5 / 4 / 2010$ & 1 & 1 & 1 & 1 & 1 & 1 \\
\hline $5 / 5 / 2010$ & 1 & 1 & 1 & 1 & 1 & 1 \\
\hline $5 / 6 / 2010$ & 1 & 1 & 1 & 1 & 1 & 1 \\
\hline $5 / 7 / 2010$ & 1 & 1 & 1 & 1 & 1 & 1 \\
\hline $5 / 8 / 2010$ & 1 & 1 & 1 & 1 & 1 & 1 \\
\hline $5 / 9 / 2010$ & 1 & 1 & 1 & 1 & 1 & 1 \\
\hline $5 / 10 / 2010$ & 1 & 1 & 1 & 1 & 1 & 1 \\
\hline $5 / 11 / 2010$ & 1 & 1 & 1 & 1 & 1 & 1 \\
\hline $5 / 12 / 2010$ & 1 & 1 & 1 & 1 & 1 & 1 \\
\hline $5 / 13 / 2010$ & 1 & 1 & 1 & 1 & 1 & 1 \\
\hline $5 / 14 / 2010$ & 1 & 0.999691804 & 1 & 1 & 1 & 1 \\
\hline $5 / 15 / 2010$ & 1 & 1 & 1 & 1 & 1 & 1 \\
\hline $5 / 16 / 2010$ & 1 & 1 & 1 & 1 & 1 & 1 \\
\hline $5 / 17 / 2010$ & 1 & 1 & 1 & 1 & 1 & 1 \\
\hline $5 / 18 / 2010$ & 1 & 1 & 1 & 1 & 1 & 1 \\
\hline $5 / 19 / 2010$ & 1 & 1 & 1 & 1 & 1 & 1 \\
\hline $5 / 20 / 2010$ & 1 & 1 & 1 & 1 & 1 & 1 \\
\hline $5 / 21 / 2010$ & 1 & 1 & 1 & 1 & 1 & 1 \\
\hline $5 / 22 / 2010$ & 1 & 0.99846737 & 1 & 1 & 1 & 1 \\
\hline $5 / 23 / 2010$ & 1 & 0.997916674 & 1 & 1 & 1 & 1 \\
\hline $5 / 24 / 2010$ & 1 & 0.987282891 & 1 & 0.999990909 & 1 & 1 \\
\hline $5 / 25 / 2010$ & 1 & 0.977772739 & 1 & 0.995672727 & 1 & 1 \\
\hline $5 / 26 / 2010$ & 1 & 0.97278263 & 1 & 0.984672727 & 1 & 1 \\
\hline $5 / 27 / 2010$ & 1 & 0.981459326 & 1 & 0.998325 & 1 & 0.9993 \\
\hline $5 / 28 / 2010$ & 1 & 0.993233804 & 1 & 0.999979545 & 1 & 0.9978 \\
\hline $5 / 29 / 2010$ & 1 & 0.998868478 & 1 & 0.999972727 & 1 & 0.9972 \\
\hline $5 / 30 / 2010$ & 1 & 0.999599804 & 1 & 0.999954545 & 1 & 0.9953 \\
\hline $5 / 31 / 2010$ & 0.99998 & 0.993901804 & 1 & 0.999931818 & 1 & 0.9932 \\
\hline $6 / 1 / 2010$ & 0.999875 & 0.992112609 & 1 & 0.997613636 & 1 & 0.9925 \\
\hline $6 / 2 / 2010$ & 0.999625 & 0.996536652 & 1 & 0.998827273 & 1 & 0.9897 \\
\hline $6 / 3 / 2010$ & 0.999505 & 0.995811913 & 1 & 0.997236364 & 1 & 0.9883 \\
\hline $6 / 4 / 2010$ & 0.99925 & 0.97666137 & 1 & 0.995465909 & 0.9998 & 0.9843 \\
\hline $6 / 5 / 2010$ & 0.999055 & 0.973421065 & 1 & 0.993231818 & 0.999366667 & 0.9812 \\
\hline
\end{tabular}




\begin{tabular}{|c|c|c|c|c|c|c|}
\hline Category & Coal & Coal & NGCC & NGCC & Nuclear & Nuclear \\
\hline Cooling & $\begin{array}{c}\text { Once- } \\
\text { through }\end{array}$ & $\begin{array}{c}\text { Cooling } \\
\text { tower }\end{array}$ & $\begin{array}{c}\text { Once- } \\
\text { through }\end{array}$ & $\begin{array}{c}\text { Cooling } \\
\text { tower }\end{array}$ & $\begin{array}{c}\text { Once- } \\
\text { through }\end{array}$ & $\begin{array}{c}\text { Cooling } \\
\text { tower }\end{array}$ \\
\hline \multicolumn{7}{|l|}{ Dates } \\
\hline $6 / 6 / 2010$ & 0.998915 & 0.977277826 & 1 & 0.995843182 & 0.999533333 & 0.9785 \\
\hline $6 / 7 / 2010$ & 0.999455 & 0.97826087 & 1 & 0.999795455 & 1 & 0.9825 \\
\hline $6 / 8 / 2010$ & 0.999915 & 0.97826087 & 1 & 0.999897727 & 1 & 0.9886 \\
\hline $6 / 9 / 2010$ & 1 & 0.97826087 & 1 & 0.999961364 & 1 & 0.9931 \\
\hline $6 / 10 / 2010$ & 1 & 0.978201543 & 1 & 0.999993182 & 1 & 0.9963 \\
\hline $6 / 11 / 2010$ & 1 & 1 & 1 & 1 & 1 & 0.9978 \\
\hline $6 / 12 / 2010$ & 1 & 0.971913696 & 1 & 0.999954545 & 1 & 0.9993 \\
\hline $6 / 13 / 2010$ & 0.99997 & 0.926882043 & 1 & 0.999722727 & 1 & 0.9993 \\
\hline $6 / 14 / 2010$ & 0.999855 & 0.867245304 & 1 & 0.999997727 & 1 & 0.9978 \\
\hline $6 / 15 / 2010$ & 0.999715 & 0.847591087 & 1 & 0.999961364 & 1 & 0.9954 \\
\hline $6 / 16 / 2010$ & 0.999535 & 0.845659391 & 1 & 0.999920455 & 1 & 0.9932 \\
\hline $6 / 17 / 2010$ & 0.99902 & 0.847694022 & 1 & 0.999279545 & 1 & 0.9895 \\
\hline $6 / 18 / 2010$ & 0.997415 & 0.8465985 & 1 & 0.995813636 & 0.999433333 & 0.985 \\
\hline $6 / 19 / 2010$ & 0.995995 & 0.834827739 & 0.9998 & 0.994015909 & 0.998066667 & 0.9809 \\
\hline $6 / 20 / 2010$ & 0.99346 & 0.838907391 & 0.9985 & 0.985575 & 0.9963 & 0.9752 \\
\hline $6 / 21 / 2010$ & 0.989895 & 0.824316152 & 0.9936 & 0.987913636 & 0.9948 & 0.9685 \\
\hline $6 / 22 / 2010$ & 0.98913 & 0.800200652 & 0.9952 & 0.993022727 & 0.993433333 & 0.9621 \\
\hline $6 / 23 / 2010$ & 0.98722 & 0.763556587 & 0.9953 & 0.981863636 & 0.991933333 & 0.9556 \\
\hline $6 / 24 / 2010$ & 0.98374 & 0.770395457 & 0.9948 & 0.977479545 & 0.9905 & 0.9489 \\
\hline $6 / 25 / 2010$ & 0.98322 & 0.781596087 & 0.9942 & 0.993075 & 0.9897 & 0.9433 \\
\hline $6 / 26 / 2010$ & 0.9838 & 0.778100739 & 0.9933 & 0.988588636 & 0.989266667 & 0.9396 \\
\hline $6 / 27 / 2010$ & 0.98225 & 0.750287674 & 0.9926 & 0.982990909 & 0.9885 & 0.9348 \\
\hline $6 / 28 / 2010$ & 0.98013 & 0.741888543 & 0.9932 & 0.9719 & 0.987433333 & 0.9306 \\
\hline $6 / 29 / 2010$ & 0.976985 & 0.759257109 & 0.9945 & 0.978559091 & 0.9874 & 0.9306 \\
\hline $6 / 30 / 2010$ & 0.98203 & 0.782482739 & 0.9962 & 0.995997727 & 0.9894 & 0.9305 \\
\hline $7 / 1 / 2010$ & 0.98774 & 0.782608696 & 0.9975 & 0.997838636 & 0.991233333 & 0.9362 \\
\hline $7 / 2 / 2010$ & 0.988655 & 0.847826087 & 0.9978 & 0.997818182 & 0.992033333 & 0.9394 \\
\hline $7 / 3 / 2010$ & 0.9856 & 0.847583435 & 0.9971 & 0.996518182 & 0.992066667 & 0.9396 \\
\hline $7 / 4 / 2010$ & 0.97893 & 0.822976739 & 0.9887 & 0.981161364 & 0.991133333 & 0.9367 \\
\hline $7 / 5 / 2010$ & 0.971435 & 0.737610739 & 0.9797 & 0.9724 & 0.9895 & 0.9315 \\
\hline $7 / 6 / 2010$ & 0.961135 & 0.648103478 & 0.9785 & 0.910597727 & 0.986066667 & 0.9315 \\
\hline 7/7/2010 & 0.86479 & 0.566113652 & 0.9755 & 0.828488636 & 0.983466667 & 0.9315 \\
\hline $7 / 8 / 2010$ & 0.86698 & 0.477111935 & 0.9754 & 0.835931818 & 0.980333333 & 0.9315 \\
\hline $7 / 9 / 2010$ & 0.86626 & 0.519075304 & 0.9701 & 0.835006818 & 0.977233333 & 0.9315 \\
\hline $7 / 10 / 2010$ & 0.86757 & 0.556269413 & 0.9711 & 0.839202273 & 0.9756 & 0.9315 \\
\hline $7 / 11 / 2010$ & 0.86844 & 0.622271109 & 0.9719 & 0.842725 & 0.9741 & 0.9315 \\
\hline $7 / 12 / 2010$ & 0.86733 & 0.637199978 & 0.9638 & 0.839263636 & 0.9723 & 0.9315 \\
\hline $7 / 13 / 2010$ & 0.867005 & 0.654337348 & 0.9675 & 0.838859091 & 0.971433333 & 0.9315 \\
\hline $7 / 14 / 2010$ & 0.86894 & 0.657381957 & 0.9735 & 0.839781818 & 0.970966667 & 0.9315 \\
\hline $7 / 15 / 2010$ & 0.918665 & 0.635777674 & 0.97 & 0.844340909 & 0.970566667 & 0.9315 \\
\hline
\end{tabular}




\begin{tabular}{|c|c|c|c|c|c|c|}
\hline Category & Coal & Coal & NGCC & NGCC & Nuclear & Nuclear \\
\hline Cooling & $\begin{array}{c}\text { Once- } \\
\text { through }\end{array}$ & $\begin{array}{c}\text { Cooling } \\
\text { tower }\end{array}$ & $\begin{array}{c}\text { Once- } \\
\text { through }\end{array}$ & $\begin{array}{c}\text { Cooling } \\
\text { tower }\end{array}$ & $\begin{array}{c}\text { Once- } \\
\text { through }\end{array}$ & $\begin{array}{c}\text { Cooling } \\
\text { tower }\end{array}$ \\
\hline \multicolumn{7}{|l|}{ Dates } \\
\hline $7 / 16 / 2010$ & 0.8691 & 0.546230674 & 0.9735 & 0.8386 & 0.9702 & 0.9315 \\
\hline $7 / 17 / 2010$ & 0.86237 & 0.531857565 & 0.9657 & 0.83225 & 0.9672 & 0.9315 \\
\hline $7 / 18 / 2010$ & 0.81139 & 0.558928261 & 0.9622 & 0.833045455 & 0.965766667 & 0.9315 \\
\hline $7 / 19 / 2010$ & 0.81175 & 0.533677152 & 0.9654 & 0.837904545 & 0.968066667 & 0.9315 \\
\hline $7 / 20 / 2010$ & 0.81144 & 0.534410217 & 0.9657 & 0.837206818 & 0.969366667 & 0.9315 \\
\hline $7 / 21 / 2010$ & 0.813275 & 0.512102652 & 0.964 & 0.773018182 & 0.9704 & 0.9315 \\
\hline $7 / 22 / 2010$ & 0.86175 & 0.493161413 & 0.9642 & 0.843847727 & 0.971233333 & 0.9315 \\
\hline $7 / 23 / 2010$ & 0.862865 & 0.486472478 & 0.9623 & 0.848159091 & 0.9725 & 0.9315 \\
\hline $7 / 24 / 2010$ & 0.81463 & 0.352569043 & 0.9651 & 0.830329545 & 0.972366667 & 0.9315 \\
\hline $7 / 25 / 2010$ & 0.809335 & 0.406612043 & 0.9651 & 0.634688636 & 0.9683 & 0.9315 \\
\hline $7 / 26 / 2010$ & 0.81435 & 0.520442717 & 0.9632 & 0.854488636 & 0.971333333 & 0.9315 \\
\hline $7 / 27 / 2010$ & 0.81233 & 0.4955525 & 0.9632 & 0.845129545 & 0.9699 & 0.9315 \\
\hline $7 / 28 / 2010$ & 0.81106 & 0.490793891 & 0.9632 & 0.773359091 & 0.968833333 & 0.9315 \\
\hline $7 / 29 / 2010$ & 0.808365 & 0.432181217 & 0.9632 & 0.572518182 & 0.9669 & 0.9315 \\
\hline $7 / 30 / 2010$ & 0.813805 & 0.542980043 & 0.9632 & 0.787752273 & 0.972533333 & 0.9315 \\
\hline $7 / 31 / 2010$ & 0.864825 & 0.543325022 & 0.9632 & 0.857781818 & 0.976066667 & 0.9315 \\
\hline $8 / 1 / 2010$ & 0.86746 & 0.586232978 & 0.9632 & 0.858304545 & 0.976633333 & 0.9315 \\
\hline $8 / 2 / 2010$ & 0.866345 & 0.600675174 & 0.9632 & 0.854043182 & 0.975966667 & 0.9315 \\
\hline $8 / 3 / 2010$ & 0.863205 & 0.547673348 & 0.9632 & 0.843993182 & 0.9728 & 0.9315 \\
\hline $8 / 4 / 2010$ & 0.85741 & 0.477721457 & 0.9632 & 0.6796 & 0.967566667 & 0.9315 \\
\hline $8 / 5 / 2010$ & 0.80699 & 0.422232696 & 0.9632 & 0.501859091 & 0.9663 & 0.9315 \\
\hline $8 / 6 / 2010$ & 0.804495 & 0.433258022 & 0.9632 & 0.507379545 & 0.964966667 & 0.9315 \\
\hline $8 / 7 / 2010$ & 0.810245 & 0.499671717 & 0.9632 & 0.720609091 & 0.971333333 & 0.9315 \\
\hline $8 / 8 / 2010$ & 0.81109 & 0.475184391 & 0.9632 & 0.716809091 & 0.9712 & 0.9315 \\
\hline $8 / 9 / 2010$ & 0.80728 & 0.379477413 & 0.9632 & 0.504947727 & 0.967233333 & 0.9315 \\
\hline $8 / 10 / 2010$ & 0.802535 & 0.336766413 & 0.9632 & 0.504006818 & 0.964233333 & 0.9315 \\
\hline $8 / 11 / 2010$ & 0.80234 & 0.318635065 & 0.9632 & 0.507120455 & 0.965866667 & 0.9315 \\
\hline $8 / 12 / 2010$ & 0.80893 & 0.342076522 & 0.9632 & 0.512672727 & 0.970733333 & 0.9315 \\
\hline $8 / 13 / 2010$ & 0.812595 & 0.516119065 & 0.9632 & 0.515284091 & 0.9719 & 0.9315 \\
\hline $8 / 14 / 2010$ & 0.812665 & 0.513762043 & 0.9632 & 0.562436364 & 0.971033333 & 0.9315 \\
\hline $8 / 15 / 2010$ & 0.863345 & 0.547941891 & 0.9632 & 0.7213 & 0.9727 & 0.9315 \\
\hline $8 / 16 / 2010$ & 0.864625 & 0.535135739 & 0.9632 & 0.845886364 & 0.973166667 & 0.9315 \\
\hline $8 / 17 / 2010$ & 0.855635 & 0.475698217 & 0.9632 & 0.772268182 & 0.966266667 & 0.9315 \\
\hline $8 / 18 / 2010$ & 0.80408 & 0.520049652 & 0.9632 & 0.577038636 & 0.9647 & 0.9315 \\
\hline $8 / 19 / 2010$ & 0.79946 & 0.4330495 & 0.9632 & 0.357695455 & 0.963533333 & 0.9315 \\
\hline $8 / 20 / 2010$ & 0.51894 & 0.433905848 & 0.9632 & 0.361838636 & 0.964533333 & 0.9315 \\
\hline $8 / 21 / 2010$ & 0.805765 & 0.433451587 & 0.9632 & 0.543909091 & 0.970633333 & 0.9315 \\
\hline $8 / 22 / 2010$ & 0.860825 & 0.55594637 & 0.9632 & 0.783972727 & 0.975933333 & 0.9315 \\
\hline $8 / 23 / 2010$ & 0.92366 & 0.604733652 & 0.9657 & 0.857147727 & 0.980666667 & 0.9315 \\
\hline $8 / 24 / 2010$ & 0.93243 & 0.716587674 & 0.9667 & 0.859484091 & 0.982 & 0.9328 \\
\hline
\end{tabular}




\begin{tabular}{|c|c|c|c|c|c|c|}
\hline Category & Coal & Coal & NGCC & NGCC & Nuclear & Nuclear \\
\hline Cooling & $\begin{array}{c}\text { Once- } \\
\text { through }\end{array}$ & $\begin{array}{c}\text { Cooling } \\
\text { tower }\end{array}$ & $\begin{array}{c}\text { Once- } \\
\text { through }\end{array}$ & $\begin{array}{c}\text { Cooling } \\
\text { tower }\end{array}$ & $\begin{array}{c}\text { Once- } \\
\text { through }\end{array}$ & $\begin{array}{c}\text { Cooling } \\
\text { tower }\end{array}$ \\
\hline \multicolumn{7}{|l|}{ Dates } \\
\hline $8 / 25 / 2010$ & 0.934925 & 0.715594413 & 0.9699 & 0.857127273 & 0.982966667 & 0.9346 \\
\hline $8 / 26 / 2010$ & 0.932155 & 0.716347261 & 0.9709 & 0.857195455 & 0.9817 & 0.9321 \\
\hline $8 / 27 / 2010$ & 0.930855 & 0.717134978 & 0.971 & 0.905286364 & 0.980933333 & 0.9308 \\
\hline $8 / 28 / 2010$ & 0.92885 & 0.69536837 & 0.9716 & 0.905511364 & 0.979933333 & 0.9302 \\
\hline $8 / 29 / 2010$ & 0.921175 & 0.694116109 & 0.965 & 0.848656818 & 0.972066667 & 0.9302 \\
\hline $8 / 30 / 2010$ & 0.912825 & 0.601561652 & 0.9586 & 0.844056818 & 0.9662 & 0.9302 \\
\hline $8 / 31 / 2010$ & 0.808955 & 0.489412565 & 0.9548 & 0.594977273 & 0.957933333 & 0.9302 \\
\hline $9 / 1 / 2010$ & 0.52131 & 0.360528826 & 0.9548 & 0.481493182 & 0.950766667 & 0.9302 \\
\hline 9/2/2010 & 0.51638 & 0.275233109 & 0.9548 & 0.414545455 & 0.9475 & 0.9302 \\
\hline $9 / 3 / 2010$ & 0.516005 & 0.298873717 & 0.9548 & 0.307579545 & 0.9521 & 0.9302 \\
\hline $9 / 4 / 2010$ & 0.518805 & 0.608669957 & 0.9548 & 0.358868182 & 0.959533333 & 0.9302 \\
\hline $9 / 5 / 2010$ & 0.860665 & 0.73908037 & 0.9676 & 0.653572727 & 0.974366667 & 0.9302 \\
\hline $9 / 6 / 2010$ & 0.866495 & 0.760793522 & 0.9675 & 0.858702273 & 0.9762 & 0.9302 \\
\hline $9 / 7 / 2010$ & 0.866975 & 0.75996663 & 0.9677 & 0.85415 & 0.973566667 & 0.9302 \\
\hline $9 / 8 / 2010$ & 0.863925 & 0.716337696 & 0.9683 & 0.848318182 & 0.969866667 & 0.9302 \\
\hline 9/9/2010 & 0.919205 & 0.782478674 & 0.9702 & 0.859393182 & 0.978166667 & 0.9302 \\
\hline $9 / 10 / 2010$ & 0.92659 & 0.782552283 & 0.9733 & 0.906018182 & 0.983233333 & 0.9302 \\
\hline $9 / 11 / 2010$ & 0.9294 & 0.804334739 & 0.976 & 0.929281818 & 0.984533333 & 0.9302 \\
\hline $9 / 12 / 2010$ & 0.98263 & 0.847826087 & 0.9788 & 0.997227273 & 0.9882 & 0.9324 \\
\hline $9 / 13 / 2010$ & 0.985235 & 0.847826087 & 0.9814 & 0.997613636 & 0.9893 & 0.9378 \\
\hline $9 / 14 / 2010$ & 0.983645 & 0.847603565 & 0.984 & 0.997086364 & 0.988733333 & 0.9389 \\
\hline $9 / 15 / 2010$ & 0.988385 & 0.847826087 & 0.9867 & 0.997929545 & 0.992466667 & 0.9432 \\
\hline $9 / 16 / 2010$ & 0.989175 & 0.826086957 & 0.9888 & 0.998111364 & 0.993166667 & 0.9442 \\
\hline $9 / 17 / 2010$ & 0.986825 & 0.825675043 & 0.9936 & 0.996663636 & 0.992 & 0.9536 \\
\hline $9 / 18 / 2010$ & 0.987705 & 0.847778022 & 0.9959 & 0.997445455 & 0.9938 & 0.9542 \\
\hline 9/19/2010 & 0.98549 & 0.826086957 & 0.9953 & 0.997343182 & 0.994166667 & 0.9492 \\
\hline $9 / 20 / 2010$ & 0.98887 & 0.826085283 & 0.9967 & 0.997611364 & 0.997866667 & 0.9504 \\
\hline $9 / 21 / 2010$ & 0.99184 & 0.826086957 & 0.9976 & 0.998172727 & 0.9991 & 0.952 \\
\hline $9 / 22 / 2010$ & 0.98701 & 0.824756587 & 0.9977 & 0.995895455 & 0.995133333 & 0.9537 \\
\hline $9 / 23 / 2010$ & 0.980495 & 0.781657935 & 0.998 & 0.995370455 & 0.993233333 & 0.95 \\
\hline $9 / 24 / 2010$ & 0.980595 & 0.752664 & 0.9994 & 0.990661364 & 0.9945 & 0.9508 \\
\hline $9 / 25 / 2010$ & 0.97167 & 0.760049565 & 0.9996 & 0.984759091 & 0.987233333 & 0.9487 \\
\hline 9/26/2010 & 0.979745 & 0.78225387 & 1 & 0.995586364 & 0.9978 & 0.9491 \\
\hline $9 / 27 / 2010$ & 0.988185 & 0.847144978 & 1 & 0.996422727 & 1 & 0.9563 \\
\hline $9 / 28 / 2010$ & 0.98731 & 0.865192761 & 1 & 0.989954545 & 0.999733333 & 0.9593 \\
\hline 9/29/2010 & 0.981605 & 0.955934239 & 1 & 0.991693182 & 0.994266667 & 0.9579 \\
\hline 9/30/2010 & 0.98172 & 0.998258391 & 1 & 0.989836364 & 0.995433333 & 0.9588 \\
\hline $10 / 1 / 2010$ & 0.985195 & 0.999093261 & 1 & 0.990406818 & 0.995266667 & 0.9669 \\
\hline $10 / 2 / 2010$ & 0.99566 & 1 & 1 & 0.998929545 & 1 & 0.9919 \\
\hline $10 / 3 / 2010$ & 0.999395 & 1 & 1 & 0.999713636 & 1 & 1 \\
\hline
\end{tabular}




\begin{tabular}{|c|c|c|c|c|c|c|}
\hline Category & Coal & Coal & NGCC & NGCC & Nuclear & Nuclear \\
\hline Cooling & $\begin{array}{c}\text { Once- } \\
\text { through }\end{array}$ & $\begin{array}{c}\text { Cooling } \\
\text { tower }\end{array}$ & $\begin{array}{c}\text { Once- } \\
\text { through }\end{array}$ & $\begin{array}{c}\text { Cooling } \\
\text { tower }\end{array}$ & $\begin{array}{c}\text { Once- } \\
\text { through }\end{array}$ & $\begin{array}{c}\text { Cooling } \\
\text { tower }\end{array}$ \\
\hline \multicolumn{7}{|l|}{ Dates } \\
\hline $10 / 4 / 2010$ & 0.999865 & 0.999819087 & 1 & 0.999236364 & 1 & 1 \\
\hline $10 / 5 / 2010$ & 1 & 0.999811804 & 1 & 0.999229545 & 1 & 1 \\
\hline $10 / 6 / 2010$ & 1 & 1 & 1 & 0.999556818 & 1 & 1 \\
\hline $10 / 7 / 2010$ & 1 & 1 & 1 & 1 & 1 & 1 \\
\hline $10 / 8 / 2010$ & 1 & 1 & 1 & 1 & 1 & 1 \\
\hline $10 / 9 / 2010$ & 1 & 1 & 1 & 1 & 1 & 1 \\
\hline $10 / 10 / 2010$ & 1 & 1 & 1 & 1 & 1 & 1 \\
\hline $10 / 11 / 2010$ & 1 & 1 & 1 & 0.999972727 & 1 & 1 \\
\hline $10 / 12 / 2010$ & 1 & 0.999959565 & 1 & 0.999754545 & 1 & 1 \\
\hline $10 / 13 / 2010$ & 1 & 1 & 1 & 1 & 1 & 1 \\
\hline $10 / 14 / 2010$ & 1 & 1 & 1 & 1 & 1 & 1 \\
\hline $10 / 15 / 2010$ & 1 & 1 & 1 & 1 & 1 & 1 \\
\hline $10 / 16 / 2010$ & 1 & 1 & 1 & 1 & 1 & 1 \\
\hline $10 / 17 / 2010$ & 1 & 1 & 1 & 1 & 1 & 1 \\
\hline $10 / 18 / 2010$ & 1 & 1 & 1 & 1 & 1 & 1 \\
\hline $10 / 19 / 2010$ & 1 & 1 & 1 & 1 & 1 & 1 \\
\hline $10 / 20 / 2010$ & 1 & 1 & 1 & 1 & 1 & 1 \\
\hline $10 / 21 / 2010$ & 1 & 1 & 1 & 1 & 1 & 1 \\
\hline $10 / 22 / 2010$ & 1 & 1 & 1 & 1 & 1 & 1 \\
\hline $10 / 23 / 2010$ & 1 & 1 & 1 & 1 & 1 & 1 \\
\hline $10 / 24 / 2010$ & 1 & 1 & 1 & 1 & 1 & 1 \\
\hline $10 / 25 / 2010$ & 1 & 1 & 1 & 0.999911364 & 1 & 1 \\
\hline $10 / 26 / 2010$ & 1 & 0.999961261 & 1 & 0.999768182 & 1 & 1 \\
\hline $10 / 27 / 2010$ & 1 & 0.999546283 & 1 & 0.999645455 & 1 & 1 \\
\hline $10 / 28 / 2010$ & 1 & 0.999948587 & 1 & 0.999652273 & 1 & 1 \\
\hline $10 / 29 / 2010$ & 1 & 1 & 1 & 1 & 1 & 1 \\
\hline $10 / 30 / 2010$ & 1 & 1 & 1 & 1 & 1 & 1 \\
\hline $10 / 31 / 2010$ & 1 & 1 & 1 & 1 & 1 & 1 \\
\hline $11 / 1 / 2010$ & 1 & 1 & 1 & 1 & 1 & 1 \\
\hline $11 / 2 / 2010$ & 1 & 1 & 1 & 1 & 1 & 1 \\
\hline $11 / 3 / 2010$ & 1 & 1 & 1 & 1 & 1 & 1 \\
\hline $11 / 4 / 2010$ & 1 & 1 & 1 & 1 & 1 & 1 \\
\hline $11 / 5 / 2010$ & 1 & 1 & 1 & 0.999795455 & 1 & 1 \\
\hline $11 / 6 / 2010$ & 1 & 1 & 1 & 1 & 1 & 1 \\
\hline $11 / 7 / 2010$ & 1 & 1 & 1 & 1 & 1 & 1 \\
\hline $11 / 8 / 2010$ & 1 & 1 & 1 & 1 & 1 & 1 \\
\hline $11 / 9 / 2010$ & 1 & 1 & 1 & 1 & 1 & 1 \\
\hline $11 / 10 / 2010$ & 1 & 1 & 1 & 1 & 1 & 1 \\
\hline $11 / 11 / 2010$ & 1 & 1 & 1 & 1 & 1 & 1 \\
\hline $11 / 12 / 2010$ & 1 & 1 & 1 & 1 & 1 & 1 \\
\hline
\end{tabular}




\begin{tabular}{|c|c|c|c|c|c|c|}
\hline Category & Coal & Coal & NGCC & NGCC & Nuclear & Nuclear \\
\hline Cooling & $\begin{array}{c}\text { Once- } \\
\text { through }\end{array}$ & $\begin{array}{c}\text { Cooling } \\
\text { tower }\end{array}$ & $\begin{array}{l}\text { Once- } \\
\text { through }\end{array}$ & $\begin{array}{c}\text { Cooling } \\
\text { tower }\end{array}$ & $\begin{array}{c}\text { Once- } \\
\text { through }\end{array}$ & $\begin{array}{c}\text { Cooling } \\
\text { tower }\end{array}$ \\
\hline \multicolumn{7}{|l|}{ Dates } \\
\hline $11 / 13 / 2010$ & 1 & 1 & 1 & 1 & 1 & 1 \\
\hline $11 / 14 / 2010$ & 1 & 1 & 1 & 1 & 1 & 1 \\
\hline $11 / 15 / 2010$ & 1 & 1 & 1 & 1 & 1 & 1 \\
\hline $11 / 16 / 2010$ & 1 & 1 & 1 & 1 & 1 & 1 \\
\hline $11 / 17 / 2010$ & 1 & 1 & 1 & 1 & 1 & 1 \\
\hline $11 / 18 / 2010$ & 1 & 1 & 1 & 1 & 1 & 1 \\
\hline $11 / 19 / 2010$ & 1 & 1 & 1 & 1 & 1 & 1 \\
\hline $11 / 20 / 2010$ & 1 & 1 & 1 & 1 & 1 & 1 \\
\hline $11 / 21 / 2010$ & 1 & 1 & 1 & 1 & 1 & 1 \\
\hline $11 / 22 / 2010$ & 1 & 1 & 1 & 1 & 1 & 1 \\
\hline $11 / 23 / 2010$ & 1 & 1 & 1 & 1 & 1 & 1 \\
\hline $11 / 24 / 2010$ & 1 & 1 & 1 & 1 & 1 & 1 \\
\hline $11 / 25 / 2010$ & 1 & 1 & 1 & 1 & 1 & 1 \\
\hline $11 / 26 / 2010$ & 1 & 1 & 1 & 1 & 1 & 1 \\
\hline $11 / 27 / 2010$ & 1 & 1 & 1 & 1 & 1 & 1 \\
\hline $11 / 28 / 2010$ & 1 & 1 & 1 & 1 & 1 & 1 \\
\hline $11 / 29 / 2010$ & 1 & 1 & 1 & 1 & 1 & 1 \\
\hline $11 / 30 / 2010$ & 1 & 1 & 1 & 1 & 1 & 1 \\
\hline $12 / 1 / 2010$ & 1 & 1 & 1 & 1 & 1 & 1 \\
\hline $12 / 2 / 2010$ & 1 & 1 & 1 & 1 & 1 & 1 \\
\hline $12 / 3 / 2010$ & 1 & 1 & 1 & 1 & 1 & 1 \\
\hline $12 / 4 / 2010$ & 1 & 1 & 1 & 1 & 1 & 1 \\
\hline $12 / 5 / 2010$ & 1 & 1 & 1 & 1 & 1 & 1 \\
\hline $12 / 6 / 2010$ & 1 & 1 & 1 & 1 & 1 & 1 \\
\hline $12 / 7 / 2010$ & 1 & 1 & 1 & 1 & 1 & 1 \\
\hline $12 / 8 / 2010$ & 1 & 1 & 1 & 1 & 1 & 1 \\
\hline $12 / 9 / 2010$ & 1 & 1 & 1 & 1 & 1 & 1 \\
\hline $12 / 10 / 2010$ & 1 & 1 & 1 & 1 & 1 & 1 \\
\hline $12 / 11 / 2010$ & 1 & 1 & 1 & 1 & 1 & 1 \\
\hline $12 / 12 / 2010$ & 1 & 1 & 1 & 1 & 1 & 1 \\
\hline $12 / 13 / 2010$ & 1 & 1 & 1 & 1 & 1 & 1 \\
\hline $12 / 14 / 2010$ & 1 & 1 & 1 & 1 & 1 & 1 \\
\hline $12 / 15 / 2010$ & 1 & 1 & 1 & 1 & 1 & 1 \\
\hline $12 / 16 / 2010$ & 1 & 1 & 1 & 1 & 1 & 1 \\
\hline $12 / 17 / 2010$ & 1 & 1 & 1 & 1 & 1 & 1 \\
\hline $12 / 18 / 2010$ & 1 & 1 & 1 & 1 & 1 & 1 \\
\hline $12 / 19 / 2010$ & 1 & 1 & 1 & 1 & 1 & 1 \\
\hline $12 / 20 / 2010$ & 1 & 1 & 1 & 1 & 1 & 1 \\
\hline $12 / 21 / 2010$ & 1 & 1 & 1 & 1 & 1 & 1 \\
\hline $12 / 22 / 2010$ & 1 & 1 & 1 & 1 & 1 & 1 \\
\hline
\end{tabular}




\begin{tabular}{|c|c|c|c|c|c|c|}
\hline Category & Coal & Coal & NGCC & NGCC & Nuclear & Nuclear \\
\hline Cooling & $\begin{array}{c}\text { Once- } \\
\text { through }\end{array}$ & $\begin{array}{c}\text { Cooling } \\
\text { tower }\end{array}$ & $\begin{array}{c}\text { Once- } \\
\text { through }\end{array}$ & $\begin{array}{l}\text { Cooling } \\
\text { tower }\end{array}$ & $\begin{array}{l}\text { Once- } \\
\text { through }\end{array}$ & $\begin{array}{c}\text { Cooling } \\
\text { tower }\end{array}$ \\
\hline \multicolumn{7}{|l|}{ Dates } \\
\hline $12 / 23 / 2010$ & 1 & 1 & 1 & 1 & 1 & 1 \\
\hline $12 / 24 / 2010$ & 1 & 1 & 1 & 1 & 1 & 1 \\
\hline $12 / 25 / 2010$ & 1 & 1 & 1 & 1 & 1 & 1 \\
\hline $12 / 26 / 2010$ & 1 & 1 & 1 & 1 & 1 & 1 \\
\hline $12 / 27 / 2010$ & 1 & 1 & 1 & 1 & 1 & 1 \\
\hline $12 / 28 / 2010$ & 1 & 1 & 1 & 1 & 1 & 1 \\
\hline $12 / 29 / 2010$ & 1 & 1 & 1 & 1 & 1 & 1 \\
\hline $12 / 30 / 2010$ & 1 & 1 & 1 & 1 & 1 & 1 \\
\hline $12 / 31 / 2010$ & 1 & 1 & 1 & 1 & 1 & 1 \\
\hline
\end{tabular}

NGCC=natural gas combined cycle 
Table B - 2. Daily Power Plant Efficiency Multipliers by Technology Type for Scenarios with Curtailments

\begin{tabular}{|c|c|c|c|c|c|c|}
\hline Category & Coal & Coal & NGCC & NGCC & Nuclear & Nuclear \\
\hline Cooling & $\begin{array}{c}\text { Once- } \\
\text { through }\end{array}$ & $\begin{array}{c}\text { Cooling } \\
\text { tower }\end{array}$ & $\begin{array}{c}\text { Once- } \\
\text { through }\end{array}$ & $\begin{array}{c}\text { Cooling } \\
\text { tower }\end{array}$ & $\begin{array}{c}\text { Once- } \\
\text { through }\end{array}$ & $\begin{array}{c}\text { Cooling } \\
\text { tower }\end{array}$ \\
\hline \multicolumn{7}{|l|}{ Dates } \\
\hline $1 / 1 / 2010$ & 1 & 1 & 1 & 1 & 1 & 1 \\
\hline $1 / 2 / 2010$ & 1 & 1 & 1 & 1 & 1 & 1 \\
\hline $1 / 3 / 2010$ & 1 & 1 & 1 & 1 & 1 & 1 \\
\hline $1 / 4 / 2010$ & 1 & 1 & 1 & 1 & 1 & 1 \\
\hline $1 / 5 / 2010$ & 1 & 1 & 1 & 1 & 1 & 1 \\
\hline $1 / 6 / 2010$ & 1 & 1 & 1 & 1 & 1 & 1 \\
\hline $1 / 7 / 2010$ & 1 & 1 & 1 & 1 & 1 & 1 \\
\hline $1 / 8 / 2010$ & 1 & 1 & 1 & 1 & 1 & 1 \\
\hline $1 / 9 / 2010$ & 1 & 1 & 1 & 1 & 1 & 1 \\
\hline $1 / 10 / 2010$ & 1 & 1 & 1 & 1 & 1 & 1 \\
\hline $1 / 11 / 2010$ & 1 & 1 & 1 & 1 & 1 & 1 \\
\hline $1 / 12 / 2010$ & 1 & 1 & 1 & 1 & 1 & 1 \\
\hline $1 / 13 / 2010$ & 1 & 1 & 1 & 1 & 1 & 1 \\
\hline $1 / 14 / 2010$ & 1 & 1 & 1 & 1 & 1 & 1 \\
\hline $1 / 15 / 2010$ & 1 & 1 & 1 & 1 & 1 & 1 \\
\hline $1 / 16 / 2010$ & 1 & 1 & 1 & 1 & 1 & 1 \\
\hline $1 / 17 / 2010$ & 1 & 1 & 1 & 1 & 1 & 1 \\
\hline $1 / 18 / 2010$ & 1 & 1 & 1 & 1 & 1 & 1 \\
\hline $1 / 19 / 2010$ & 1 & 1 & 1 & 1 & 1 & 1 \\
\hline $1 / 20 / 2010$ & 1 & 1 & 1 & 1 & 1 & 1 \\
\hline $1 / 21 / 2010$ & 1 & 1 & 1 & 1 & 1 & 1 \\
\hline $1 / 22 / 2010$ & 1 & 1 & 1 & 1 & 1 & 1 \\
\hline $1 / 23 / 2010$ & 1 & 1 & 1 & 1 & 1 & 1 \\
\hline $1 / 24 / 2010$ & 1 & 1 & 1 & 1 & 1 & 1 \\
\hline $1 / 25 / 2010$ & 1 & 1 & 1 & 1 & 1 & 1 \\
\hline $1 / 26 / 2010$ & 1 & 1 & 1 & 1 & 1 & 1 \\
\hline $1 / 27 / 2010$ & 1 & 1 & 1 & 1 & 1 & 1 \\
\hline $1 / 28 / 2010$ & 1 & 1 & 1 & 1 & 1 & 1 \\
\hline $1 / 29 / 2010$ & 1 & 1 & 1 & 1 & 1 & 1 \\
\hline $1 / 30 / 2010$ & 1 & 1 & 1 & 1 & 1 & 1 \\
\hline $1 / 31 / 2010$ & 1 & 1 & 1 & 1 & 1 & 1 \\
\hline $2 / 1 / 2010$ & 1 & 1 & 1 & 1 & 1 & 1 \\
\hline $2 / 2 / 2010$ & 1 & 1 & 1 & 1 & 1 & 1 \\
\hline $2 / 3 / 2010$ & 1 & 1 & 1 & 1 & 1 & 1 \\
\hline $2 / 4 / 2010$ & 1 & 1 & 1 & 1 & 1 & 1 \\
\hline $2 / 5 / 2010$ & 1 & 1 & 1 & 1 & 1 & 1 \\
\hline $2 / 6 / 2010$ & 1 & 1 & 1 & 1 & 1 & 1 \\
\hline $2 / 7 / 2010$ & 1 & 1 & 1 & 1 & 1 & 1 \\
\hline
\end{tabular}




\begin{tabular}{|c|c|c|c|c|c|c|}
\hline Category & Coal & Coal & NGCC & NGCC & Nuclear & Nuclear \\
\hline Cooling & $\begin{array}{c}\text { Once- } \\
\text { through }\end{array}$ & $\begin{array}{c}\text { Cooling } \\
\text { tower }\end{array}$ & $\begin{array}{c}\text { Once- } \\
\text { through }\end{array}$ & $\begin{array}{c}\text { Cooling } \\
\text { tower }\end{array}$ & $\begin{array}{c}\text { Once- } \\
\text { through }\end{array}$ & $\begin{array}{c}\text { Cooling } \\
\text { tower }\end{array}$ \\
\hline \multicolumn{7}{|l|}{ Dates } \\
\hline $2 / 8 / 2010$ & 1 & 1 & 1 & 1 & 1 & 1 \\
\hline $2 / 9 / 2010$ & 1 & 1 & 1 & 1 & 1 & 1 \\
\hline $2 / 10 / 2010$ & 1 & 1 & 1 & 1 & 1 & 1 \\
\hline $2 / 11 / 2010$ & 1 & 1 & 1 & 1 & 1 & 1 \\
\hline $2 / 12 / 2010$ & 1 & 1 & 1 & 1 & 1 & 1 \\
\hline $2 / 13 / 2010$ & 1 & 1 & 1 & 1 & 1 & 1 \\
\hline $2 / 14 / 2010$ & 1 & 1 & 1 & 1 & 1 & 1 \\
\hline $2 / 15 / 2010$ & 1 & 1 & 1 & 1 & 1 & 1 \\
\hline $2 / 16 / 2010$ & 1 & 1 & 1 & 1 & 1 & 1 \\
\hline $2 / 17 / 2010$ & 1 & 1 & 1 & 1 & 1 & 1 \\
\hline $2 / 18 / 2010$ & 1 & 1 & 1 & 1 & 1 & 1 \\
\hline $2 / 19 / 2010$ & 1 & 1 & 1 & 1 & 1 & 1 \\
\hline $2 / 20 / 2010$ & 1 & 1 & 1 & 1 & 1 & 1 \\
\hline $2 / 21 / 2010$ & 1 & 1 & 1 & 1 & 1 & 1 \\
\hline $2 / 22 / 2010$ & 1 & 1 & 1 & 1 & 1 & 1 \\
\hline $2 / 23 / 2010$ & 1 & 1 & 1 & 1 & 1 & 1 \\
\hline $2 / 24 / 2010$ & 1 & 1 & 1 & 1 & 1 & 1 \\
\hline $2 / 25 / 2010$ & 1 & 1 & 1 & 1 & 1 & 1 \\
\hline $2 / 26 / 2010$ & 1 & 1 & 1 & 1 & 1 & 1 \\
\hline $2 / 27 / 2010$ & 1 & 1 & 1 & 1 & 1 & 1 \\
\hline $2 / 28 / 2010$ & 1 & 1 & 1 & 1 & 1 & 1 \\
\hline $3 / 1 / 2010$ & 1 & 1 & 1 & 1 & 1 & 1 \\
\hline $3 / 2 / 2010$ & 1 & 1 & 1 & 1 & 1 & 1 \\
\hline $3 / 3 / 2010$ & 1 & 1 & 1 & 1 & 1 & 1 \\
\hline $3 / 4 / 2010$ & 1 & 1 & 1 & 1 & 1 & 1 \\
\hline $3 / 5 / 2010$ & 1 & 1 & 1 & 1 & 1 & 1 \\
\hline $3 / 6 / 2010$ & 1 & 1 & 1 & 1 & 1 & 1 \\
\hline $3 / 7 / 2010$ & 1 & 1 & 1 & 1 & 1 & 1 \\
\hline $3 / 8 / 2010$ & 1 & 1 & 1 & 1 & 1 & 1 \\
\hline $3 / 9 / 2010$ & 1 & 1 & 1 & 1 & 1 & 1 \\
\hline $3 / 10 / 2010$ & 1 & 1 & 1 & 1 & 1 & 1 \\
\hline $3 / 11 / 2010$ & 1 & 1 & 1 & 1 & 1 & 1 \\
\hline $3 / 12 / 2010$ & 1 & 1 & 1 & 1 & 1 & 1 \\
\hline $3 / 13 / 2010$ & 1 & 1 & 1 & 1 & 1 & 1 \\
\hline $3 / 14 / 2010$ & 1 & 1 & 1 & 1 & 1 & 1 \\
\hline $3 / 15 / 2010$ & 1 & 1 & 1 & 1 & 1 & 1 \\
\hline $3 / 16 / 2010$ & 1 & 1 & 1 & 1 & 1 & 1 \\
\hline $3 / 17 / 2010$ & 1 & 1 & 1 & 1 & 1 & 1 \\
\hline $3 / 18 / 2010$ & 1 & 1 & 1 & 1 & 1 & 1 \\
\hline $3 / 19 / 2010$ & 1 & 1 & 1 & 1 & 1 & 1 \\
\hline
\end{tabular}




\begin{tabular}{|c|c|c|c|c|c|c|}
\hline Category & Coal & Coal & NGCC & NGCC & Nuclear & Nuclear \\
\hline Cooling & $\begin{array}{c}\text { Once- } \\
\text { through }\end{array}$ & $\begin{array}{c}\text { Cooling } \\
\text { tower }\end{array}$ & $\begin{array}{c}\text { Once- } \\
\text { through }\end{array}$ & $\begin{array}{c}\text { Cooling } \\
\text { tower }\end{array}$ & $\begin{array}{l}\text { Once- } \\
\text { through }\end{array}$ & $\begin{array}{c}\text { Cooling } \\
\text { tower }\end{array}$ \\
\hline \multicolumn{7}{|l|}{ Dates } \\
\hline $3 / 20 / 2010$ & 1 & 1 & 1 & 1 & 1 & 1 \\
\hline $3 / 21 / 2010$ & 1 & 1 & 1 & 1 & 1 & 1 \\
\hline $3 / 22 / 2010$ & 1 & 1 & 1 & 1 & 1 & 1 \\
\hline $3 / 23 / 2010$ & 1 & 1 & 1 & 1 & 1 & 1 \\
\hline $3 / 24 / 2010$ & 1 & 1 & 1 & 1 & 1 & 1 \\
\hline $3 / 25 / 2010$ & 1 & 1 & 1 & 1 & 1 & 1 \\
\hline $3 / 26 / 2010$ & 1 & 1 & 1 & 1 & 1 & 1 \\
\hline $3 / 27 / 2010$ & 1 & 1 & 1 & 1 & 1 & 1 \\
\hline $3 / 28 / 2010$ & 1 & 1 & 1 & 1 & 1 & 1 \\
\hline $3 / 29 / 2010$ & 1 & 1 & 1 & 1 & 1 & 1 \\
\hline $3 / 30 / 2010$ & 1 & 1 & 1 & 1 & 1 & 1 \\
\hline $3 / 31 / 2010$ & 1 & 1 & 1 & 1 & 1 & 1 \\
\hline $4 / 1 / 2010$ & 1 & 1 & 1 & 1 & 1 & 1 \\
\hline $4 / 2 / 2010$ & 1 & 1 & 1 & 1 & 1 & 1 \\
\hline $4 / 3 / 2010$ & 1 & 1 & 1 & 1 & 1 & 1 \\
\hline $4 / 4 / 2010$ & 1 & 1 & 1 & 1 & 1 & 1 \\
\hline $4 / 5 / 2010$ & 1 & 1 & 1 & 1 & 1 & 1 \\
\hline $4 / 6 / 2010$ & 1 & 1 & 1 & 1 & 1 & 1 \\
\hline 4/7/2010 & 1 & 0.99959478 & 1 & 1 & 1 & 1 \\
\hline $4 / 8 / 2010$ & 1 & 1 & 1 & 1 & 1 & 1 \\
\hline 4/9/2010 & 1 & 1 & 1 & 1 & 1 & 1 \\
\hline $4 / 10 / 2010$ & 1 & 1 & 1 & 1 & 1 & 1 \\
\hline $4 / 11 / 2010$ & 1 & 1 & 1 & 1 & 1 & 1 \\
\hline $4 / 12 / 2010$ & 1 & 1 & 1 & 1 & 1 & 1 \\
\hline $4 / 13 / 2010$ & 1 & 1 & 1 & 1 & 1 & 1 \\
\hline 4/14/2010 & 1 & 1 & 1 & 1 & 1 & 1 \\
\hline $4 / 15 / 2010$ & 1 & 1 & 1 & 1 & 1 & 1 \\
\hline 4/16/2010 & 1 & 1 & 1 & 1 & 1 & 1 \\
\hline $4 / 17 / 2010$ & 1 & 1 & 1 & 1 & 1 & 1 \\
\hline $4 / 18 / 2010$ & 1 & 1 & 1 & 1 & 1 & 1 \\
\hline $4 / 19 / 2010$ & 1 & 1 & 1 & 1 & 1 & 1 \\
\hline $4 / 20 / 2010$ & 1 & 1 & 1 & 1 & 1 & 1 \\
\hline $4 / 21 / 2010$ & 1 & 1 & 1 & 1 & 1 & 1 \\
\hline $4 / 22 / 2010$ & 1 & 1 & 1 & 1 & 1 & 1 \\
\hline $4 / 23 / 2010$ & 1 & 1 & 1 & 1 & 1 & 1 \\
\hline $4 / 24 / 2010$ & 1 & 1 & 1 & 1 & 1 & 1 \\
\hline $4 / 25 / 2010$ & 1 & 1 & 1 & 1 & 1 & 1 \\
\hline $4 / 26 / 2010$ & 1 & 1 & 1 & 1 & 1 & 1 \\
\hline $4 / 27 / 2010$ & 1 & 1 & 1 & 1 & 1 & 1 \\
\hline $4 / 28 / 2010$ & 1 & 1 & 1 & 1 & 1 & 1 \\
\hline
\end{tabular}




\begin{tabular}{|c|c|c|c|c|c|c|}
\hline Category & Coal & Coal & NGCC & NGCC & Nuclear & Nuclear \\
\hline Cooling & $\begin{array}{c}\text { Once- } \\
\text { through }\end{array}$ & $\begin{array}{c}\text { Cooling } \\
\text { tower }\end{array}$ & $\begin{array}{c}\text { Once- } \\
\text { through }\end{array}$ & $\begin{array}{c}\text { Cooling } \\
\text { tower }\end{array}$ & $\begin{array}{c}\text { Once- } \\
\text { through }\end{array}$ & $\begin{array}{c}\text { Cooling } \\
\text { tower }\end{array}$ \\
\hline \multicolumn{7}{|l|}{ Dates } \\
\hline 4/29/2010 & 1 & 1 & 1 & 1 & 1 & 1 \\
\hline $4 / 30 / 2010$ & 1 & 1 & 1 & 1 & 1 & 1 \\
\hline $5 / 1 / 2010$ & 1 & 0.99885065 & 1 & 1 & 1 & 1 \\
\hline $5 / 2 / 2010$ & 1 & 0.9903475 & 1 & 0.99920909 & 1 & 1 \\
\hline $5 / 3 / 2010$ & 1 & 0.99899865 & 1 & 0.99878409 & 1 & 1 \\
\hline $5 / 4 / 2010$ & 1 & 1 & 1 & 1 & 1 & 1 \\
\hline $5 / 5 / 2010$ & 1 & 1 & 1 & 1 & 1 & 1 \\
\hline $5 / 6 / 2010$ & 1 & 1 & 1 & 1 & 1 & 1 \\
\hline $5 / 7 / 2010$ & 1 & 1 & 1 & 1 & 1 & 1 \\
\hline $5 / 8 / 2010$ & 1 & 1 & 1 & 1 & 1 & 1 \\
\hline $5 / 9 / 2010$ & 1 & 1 & 1 & 1 & 1 & 1 \\
\hline $5 / 10 / 2010$ & 1 & 1 & 1 & 1 & 1 & 1 \\
\hline $5 / 11 / 2010$ & 1 & 1 & 1 & 1 & 1 & 1 \\
\hline $5 / 12 / 2010$ & 1 & 1 & 1 & 1 & 1 & 1 \\
\hline $5 / 13 / 2010$ & 1 & 1 & 1 & 1 & 1 & 1 \\
\hline $5 / 14 / 2010$ & 1 & 0.9996918 & 1 & 1 & 1 & 1 \\
\hline $5 / 15 / 2010$ & 1 & 1 & 1 & 1 & 1 & 1 \\
\hline $5 / 16 / 2010$ & 1 & 1 & 1 & 1 & 1 & 1 \\
\hline $5 / 17 / 2010$ & 1 & 1 & 1 & 1 & 1 & 1 \\
\hline $5 / 18 / 2010$ & 1 & 1 & 1 & 1 & 1 & 1 \\
\hline $5 / 19 / 2010$ & 1 & 1 & 1 & 1 & 1 & 1 \\
\hline $5 / 20 / 2010$ & 1 & 1 & 1 & 1 & 1 & 1 \\
\hline $5 / 21 / 2010$ & 1 & 1 & 1 & 1 & 1 & 1 \\
\hline $5 / 22 / 2010$ & 1 & 0.99846737 & 1 & 1 & 1 & 1 \\
\hline $5 / 23 / 2010$ & 1 & 0.99791667 & 1 & 1 & 1 & 1 \\
\hline $5 / 24 / 2010$ & 1 & 0.98728289 & 1 & 0.99999091 & 1 & 1 \\
\hline $5 / 25 / 2010$ & 1 & 0.97777274 & 1 & 0.99567273 & 1 & 1 \\
\hline $5 / 26 / 2010$ & 1 & 0.97278263 & 1 & 0.98467273 & 1 & 1 \\
\hline $5 / 27 / 2010$ & 1 & 0.98145933 & 1 & 0.998325 & 1 & 0.9993 \\
\hline $5 / 28 / 2010$ & 1 & 0.9932338 & 1 & 0.99997955 & 1 & 0.9978 \\
\hline $5 / 29 / 2010$ & 1 & 0.99886848 & 1 & 0.99997273 & 1 & 0.9972 \\
\hline $5 / 30 / 2010$ & 1 & 0.9995998 & 1 & 0.99995455 & 1 & 0.9953 \\
\hline $5 / 31 / 2010$ & 0.99998 & 0.9939018 & 1 & 0.99993182 & 1 & 0.9932 \\
\hline $6 / 1 / 2010$ & 0.999875 & 0.99211261 & 1 & 0.99761364 & 1 & 0.9925 \\
\hline $6 / 2 / 2010$ & 0.999625 & 0.99653665 & 1 & 0.99882727 & 1 & 0.9897 \\
\hline $6 / 3 / 2010$ & 0.999505 & 0.99581191 & 1 & 0.99723636 & 1 & 0.9883 \\
\hline $6 / 4 / 2010$ & 0.99925 & 0.97666137 & 1 & 0.99546591 & 0.9998 & 0.9843 \\
\hline $6 / 5 / 2010$ & 0.999055 & 0.97342107 & 1 & 0.99323182 & 0.99936667 & 0.9812 \\
\hline $6 / 6 / 2010$ & 0.998915 & 0.97727783 & 1 & 0.99584318 & 0.99953333 & 0.9785 \\
\hline 6/7/2010 & 0.999455 & 0.97826087 & 1 & 0.99979546 & 1 & 0.9825 \\
\hline
\end{tabular}




\begin{tabular}{|c|c|c|c|c|c|c|}
\hline Category & Coal & Coal & NGCC & NGCC & Nuclear & Nuclear \\
\hline Cooling & $\begin{array}{c}\text { Once- } \\
\text { through }\end{array}$ & $\begin{array}{c}\text { Cooling } \\
\text { tower }\end{array}$ & $\begin{array}{c}\text { Once- } \\
\text { through }\end{array}$ & $\begin{array}{c}\text { Cooling } \\
\text { tower }\end{array}$ & $\begin{array}{c}\text { Once- } \\
\text { through }\end{array}$ & $\begin{array}{c}\text { Cooling } \\
\text { tower }\end{array}$ \\
\hline \multicolumn{7}{|l|}{ Dates } \\
\hline $6 / 8 / 2010$ & 0.999915 & 0.97826087 & 1 & 0.99989773 & 1 & 0.9886 \\
\hline 6/9/2010 & 1 & 0.97826087 & 1 & 0.99996136 & 1 & 0.9931 \\
\hline $6 / 10 / 2010$ & 1 & 0.97820154 & 1 & 0.99999318 & 1 & 0.9963 \\
\hline $6 / 11 / 2010$ & 1 & 1 & 1 & 1 & 1 & 0.9978 \\
\hline $6 / 12 / 2010$ & 1 & 0.9719137 & 1 & 0.99995455 & 1 & 0.9993 \\
\hline $6 / 13 / 2010$ & 0.99997 & 0.92688204 & 1 & 0.99972273 & 1 & 0.9993 \\
\hline $6 / 14 / 2010$ & 0.999855 & 0.8672453 & 1 & 0.99999773 & 1 & 0.9978 \\
\hline $6 / 15 / 2010$ & 0.999715 & 0.84759109 & 1 & 0.99996136 & 1 & 0.9954 \\
\hline $6 / 16 / 2010$ & 0.999535 & 0.84565939 & 1 & 0.99992046 & 1 & 0.9932 \\
\hline $6 / 17 / 2010$ & 0.99902 & 0.84769402 & 1 & 0.99927955 & 1 & 0.9895 \\
\hline $6 / 18 / 2010$ & 0.997415 & 0.8465985 & 1 & 0.99581364 & 0.99943333 & 0.985 \\
\hline $6 / 19 / 2010$ & 0.995995 & 0.83482774 & 0.9998 & 0.99401591 & 0.99806667 & 0.9809 \\
\hline $6 / 20 / 2010$ & 0.99346 & 0.83890739 & 0.9985 & 0.985575 & 0.9963 & 0.9752 \\
\hline $6 / 21 / 2010$ & 0.989895 & 0.82431615 & 0.9936 & 0.98791364 & 0.9948 & 0.9685 \\
\hline $6 / 22 / 2010$ & 0.98913 & 0.80020065 & 0.9952 & 0.99302273 & 0.99343333 & 0.9621 \\
\hline $6 / 23 / 2010$ & 0.98722 & 0.76355659 & 0.9953 & 0.98186364 & 0.99193333 & 0.9556 \\
\hline $6 / 24 / 2010$ & 0.98374 & 0.77039546 & 0.9948 & 0.97747955 & 0.9905 & 0.9489 \\
\hline $6 / 25 / 2010$ & 0.98322 & 0.78159609 & 0.9942 & 0.993075 & 0.9897 & 0.9433 \\
\hline $6 / 26 / 2010$ & 0.9838 & 0.77810074 & 0.9933 & 0.98858864 & 0.98926667 & 0.9396 \\
\hline $6 / 27 / 2010$ & 0.98225 & 0.75028767 & 0.9926 & 0.98299091 & 0.9885 & 0.9348 \\
\hline $6 / 28 / 2010$ & 0.98013 & 0.74188854 & 0.9932 & 0.9719 & 0.98743333 & 0.9306 \\
\hline $6 / 29 / 2010$ & 0.976985 & 0.75925711 & 0.9945 & 0.97855909 & 0.9874 & 0 \\
\hline $6 / 30 / 2010$ & 0.98203 & 0.78248274 & 0.9962 & 0.99599773 & 0.9894 & 0.9305 \\
\hline $7 / 1 / 2010$ & 0.98774 & 0.7826087 & 0.9975 & 0.99783864 & 0.99123333 & 0.9362 \\
\hline $7 / 2 / 2010$ & 0.988655 & 0.84782609 & 0.9978 & 0.99781818 & 0.99203333 & 0.9394 \\
\hline $7 / 3 / 2010$ & 0.9856 & 0.84758344 & 0.9971 & 0.99651818 & 0.99206667 & 0.9396 \\
\hline $7 / 4 / 2010$ & 0.97893 & 0.82297674 & 0.9887 & 0.98116136 & 0.99113333 & 0.9367 \\
\hline $7 / 5 / 2010$ & 0.971435 & 0.73761074 & 0.9797 & 0.9724 & 0.9895 & 0.9315 \\
\hline $7 / 6 / 2010$ & 0.961135 & 0.64810348 & 0.9785 & 0.91059773 & 0.98606667 & 0 \\
\hline $7 / 7 / 2010$ & 0.86479 & 0.56611365 & 0.9755 & 0.82848864 & 0.98346667 & 0 \\
\hline $7 / 8 / 2010$ & 0.86698 & 0.47711194 & 0.9754 & 0.83593182 & 0.98033333 & 0 \\
\hline $7 / 9 / 2010$ & 0.86626 & 0.5190753 & 0.9701 & 0.83500682 & 0.97723333 & 0 \\
\hline $7 / 10 / 2010$ & 0.86757 & 0.55626941 & 0.9711 & 0.83920227 & 0.9756 & 0 \\
\hline $7 / 11 / 2010$ & 0.86844 & 0.62227111 & 0.9719 & 0.842725 & 0.9741 & 0 \\
\hline $7 / 12 / 2010$ & 0.86733 & 0.63719998 & 0.9638 & 0.83926364 & 0.9723 & 0 \\
\hline $7 / 13 / 2010$ & 0.867005 & 0.65433735 & 0.9675 & 0.83885909 & 0.97143333 & 0 \\
\hline $7 / 14 / 2010$ & 0.86894 & 0.65738196 & 0.9735 & 0.83978182 & 0.97096667 & 0 \\
\hline $7 / 15 / 2010$ & 0.918665 & 0.63577767 & 0.97 & 0.84434091 & 0.97056667 & 0 \\
\hline $7 / 16 / 2010$ & 0.8691 & 0.54623067 & 0.9735 & 0.8386 & 0.9702 & 0 \\
\hline $7 / 17 / 2010$ & 0.86237 & 0.53185757 & 0.9657 & 0.83225 & 0.9672 & 0 \\
\hline
\end{tabular}




\begin{tabular}{|c|c|c|c|c|c|c|}
\hline Category & Coal & Coal & NGCC & NGCC & Nuclear & Nuclear \\
\hline Cooling & $\begin{array}{c}\text { Once- } \\
\text { through }\end{array}$ & $\begin{array}{c}\text { Cooling } \\
\text { tower }\end{array}$ & $\begin{array}{c}\text { Once- } \\
\text { through }\end{array}$ & $\begin{array}{c}\text { Cooling } \\
\text { tower }\end{array}$ & $\begin{array}{c}\text { Once- } \\
\text { through }\end{array}$ & $\begin{array}{c}\text { Cooling } \\
\text { tower }\end{array}$ \\
\hline \multicolumn{7}{|l|}{ Dates } \\
\hline $7 / 18 / 2010$ & 0.81139 & 0.55892826 & 0.9622 & 0.83304546 & 0.96576667 & 0 \\
\hline $7 / 19 / 2010$ & 0.81175 & 0.53367715 & 0.9654 & 0.83790455 & 0.96806667 & 0 \\
\hline $7 / 20 / 2010$ & 0.81144 & 0.53441022 & 0.9657 & 0.83720682 & 0.96936667 & 0 \\
\hline $7 / 21 / 2010$ & 0.813275 & 0.51210265 & 0.964 & 0.77301818 & 0.9704 & 0 \\
\hline $7 / 22 / 2010$ & 0.86175 & 0.49316141 & 0.9642 & 0.84384773 & 0.97123333 & 0 \\
\hline $7 / 23 / 2010$ & 0.862865 & 0.48647248 & 0.9623 & 0.84815909 & 0.9725 & 0 \\
\hline $7 / 24 / 2010$ & 0.81463 & 0.35256904 & 0.9651 & 0.83032955 & 0.97236667 & 0 \\
\hline $7 / 25 / 2010$ & 0.809335 & 0.40661204 & 0 & 0.63468864 & 0.9683 & 0 \\
\hline $7 / 26 / 2010$ & 0.81435 & 0.52044272 & 0.9632 & 0.85448864 & 0.97133333 & 0 \\
\hline $7 / 27 / 2010$ & 0.81233 & 0.4955525 & 0 & 0.84512955 & 0.9699 & 0 \\
\hline $7 / 28 / 2010$ & 0.81106 & 0.49079389 & 0 & 0.77335909 & 0.96883333 & 0 \\
\hline $7 / 29 / 2010$ & 0.808365 & 0.43218122 & 0 & 0.57251818 & 0.9669 & 0 \\
\hline $7 / 30 / 2010$ & 0.813805 & 0.54298004 & 0 & 0.78775227 & 0.97253333 & 0 \\
\hline $7 / 31 / 2010$ & 0.864825 & 0.54332502 & 0 & 0.85778182 & 0.97606667 & 0 \\
\hline $8 / 1 / 2010$ & 0.86746 & 0.58623298 & 0 & 0.85830455 & 0.97663333 & 0 \\
\hline $8 / 2 / 2010$ & 0.866345 & 0.60067517 & 0 & 0.85404318 & 0.97596667 & 0 \\
\hline $8 / 3 / 2010$ & 0.863205 & 0.54767335 & 0 & 0.84399318 & 0.9728 & 0 \\
\hline $8 / 4 / 2010$ & 0.85741 & 0.47772146 & 0 & 0.6796 & 0.96756667 & 0 \\
\hline $8 / 5 / 2010$ & 0.80699 & 0.4222327 & 0 & 0.50185909 & 0.9663 & 0 \\
\hline $8 / 6 / 2010$ & 0.804495 & 0.43325802 & 0 & 0.50737955 & 0.96496667 & 0 \\
\hline $8 / 7 / 2010$ & 0.810245 & 0.49967172 & 0 & 0.72060909 & 0.97133333 & 0 \\
\hline $8 / 8 / 2010$ & 0.81109 & 0.47518439 & 0 & 0.71680909 & 0.9712 & 0 \\
\hline $8 / 9 / 2010$ & 0.80728 & 0.37947741 & 0 & 0.50494773 & 0.96723333 & 0 \\
\hline $8 / 10 / 2010$ & 0.802535 & 0.33676641 & 0 & 0.50400682 & 0.96423333 & 0 \\
\hline $8 / 11 / 2010$ & 0.80234 & 0.31863507 & 0 & 0.50712046 & 0.96586667 & 0 \\
\hline $8 / 12 / 2010$ & 0.80893 & 0.34207652 & 0 & 0.51267273 & 0.97073333 & 0 \\
\hline $8 / 13 / 2010$ & 0.812595 & 0.51611907 & 0 & 0.51528409 & 0.9719 & 0 \\
\hline $8 / 14 / 2010$ & 0.812665 & 0.51376204 & 0 & 0.56243636 & 0.97103333 & 0 \\
\hline $8 / 15 / 2010$ & 0.863345 & 0.54794189 & 0 & 0.7213 & 0.9727 & 0 \\
\hline $8 / 16 / 2010$ & 0.864625 & 0.53513574 & 0 & 0.84588636 & 0.97316667 & 0 \\
\hline $8 / 17 / 2010$ & 0.855635 & 0.47569822 & 0 & 0.77226818 & 0.96626667 & 0 \\
\hline $8 / 18 / 2010$ & 0.80408 & 0.52004965 & 0 & 0.57703864 & 0.9647 & 0 \\
\hline $8 / 19 / 2010$ & 0.79946 & 0.4330495 & 0 & 0.35769546 & 0.96353333 & 0 \\
\hline $8 / 20 / 2010$ & 0.51894 & 0.43390585 & 0 & 0.36183864 & 0.96453333 & 0 \\
\hline $8 / 21 / 2010$ & 0.805765 & 0.43345159 & 0 & 0.54390909 & 0.97063333 & 0 \\
\hline $8 / 22 / 2010$ & 0.860825 & 0.55594637 & 0 & 0.78397273 & 0.97593333 & 0 \\
\hline $8 / 23 / 2010$ & 0.92366 & 0.60473365 & 0.9657 & 0.85714773 & 0.98066667 & 0 \\
\hline $8 / 24 / 2010$ & 0.93243 & 0.71658767 & 0.9667 & 0.85948409 & 0.982 & 0.9328 \\
\hline $8 / 25 / 2010$ & 0.934925 & 0.71559441 & 0.9699 & 0.85712727 & 0.98296667 & 0.9346 \\
\hline $8 / 26 / 2010$ & 0.932155 & 0.71634726 & 0.9709 & 0.85719546 & 0.9817 & 0.9321 \\
\hline
\end{tabular}




\begin{tabular}{|c|c|c|c|c|c|c|}
\hline Category & Coal & Coal & NGCC & NGCC & Nuclear & Nuclear \\
\hline Cooling & $\begin{array}{c}\text { Once- } \\
\text { through }\end{array}$ & $\begin{array}{c}\text { Cooling } \\
\text { tower }\end{array}$ & $\begin{array}{c}\text { Once- } \\
\text { through }\end{array}$ & $\begin{array}{c}\text { Cooling } \\
\text { tower }\end{array}$ & $\begin{array}{c}\text { Once- } \\
\text { through }\end{array}$ & $\begin{array}{c}\text { Cooling } \\
\text { tower }\end{array}$ \\
\hline \multicolumn{7}{|l|}{ Dates } \\
\hline $8 / 27 / 2010$ & 0.930855 & 0.71713498 & 0.971 & 0.90528636 & 0.98093333 & 0.9308 \\
\hline $8 / 28 / 2010$ & 0.92885 & 0.69536837 & 0.9716 & 0.90551136 & 0.97993333 & 0.9302 \\
\hline $8 / 29 / 2010$ & 0.921175 & 0.69411611 & 0.965 & 0.84865682 & 0.97206667 & 0 \\
\hline $8 / 30 / 2010$ & 0.912825 & 0.60156165 & 0.9586 & 0.84405682 & 0.9662 & 0 \\
\hline $8 / 31 / 2010$ & 0.808955 & 0.48941257 & 0.9548 & 0.59497727 & 0.95793333 & 0 \\
\hline $9 / 1 / 2010$ & 0.52131 & 0.36052883 & 0 & 0.48149318 & 0.95076667 & 0 \\
\hline $9 / 2 / 2010$ & 0.51638 & 0.27523311 & 0 & 0.41454546 & 0.9475 & 0 \\
\hline $9 / 3 / 2010$ & 0.516005 & 0.29887372 & 0 & 0.30757955 & 0.9521 & 0 \\
\hline $9 / 4 / 2010$ & 0.518805 & 0.60866996 & 0 & 0.35886818 & 0.95953333 & 0 \\
\hline $9 / 5 / 2010$ & 0.860665 & 0.73908037 & 0.9676 & 0.65357273 & 0.97436667 & 0 \\
\hline $9 / 6 / 2010$ & 0.866495 & 0.76079352 & 0.9675 & 0.85870227 & 0.9762 & 0 \\
\hline $9 / 7 / 2010$ & 0.866975 & 0.75996663 & 0.9677 & 0.85415 & 0.97356667 & 0 \\
\hline $9 / 8 / 2010$ & 0.863925 & 0.7163377 & 0.9683 & 0.84831818 & 0.96986667 & 0 \\
\hline $9 / 9 / 2010$ & 0.919205 & 0.78247867 & 0.9702 & 0.85939318 & 0.97816667 & 0 \\
\hline $9 / 10 / 2010$ & 0.92659 & 0.78255228 & 0.9733 & 0.90601818 & 0.98323333 & 0 \\
\hline $9 / 11 / 2010$ & 0.9294 & 0.80433474 & 0.976 & 0.92928182 & 0.98453333 & 0 \\
\hline $9 / 12 / 2010$ & 0.98263 & 0.84782609 & 0.9788 & 0.99722727 & 0.9882 & 0.9324 \\
\hline $9 / 13 / 2010$ & 0.985235 & 0.84782609 & 0.9814 & 0.99761364 & 0.9893 & 0.9378 \\
\hline $9 / 14 / 2010$ & 0.983645 & 0.84760357 & 0.984 & 0.99708636 & 0.98873333 & 0.9389 \\
\hline $9 / 15 / 2010$ & 0.988385 & 0.84782609 & 0.9867 & 0.99792955 & 0.99246667 & 0.9432 \\
\hline 9/16/2010 & 0.989175 & 0.82608696 & 0.9888 & 0.99811136 & 0.99316667 & 0.9442 \\
\hline $9 / 17 / 2010$ & 0.986825 & 0.82567504 & 0.9936 & 0.99666364 & 0.992 & 0.9536 \\
\hline $9 / 18 / 2010$ & 0.987705 & 0.84777802 & 0.9959 & 0.99744546 & 0.9938 & 0.9542 \\
\hline $9 / 19 / 2010$ & 0.98549 & 0.82608696 & 0.9953 & 0.99734318 & 0.99416667 & 0.9492 \\
\hline $9 / 20 / 2010$ & 0.98887 & 0.82608528 & 0.9967 & 0.99761136 & 0.99786667 & 0.9504 \\
\hline $9 / 21 / 2010$ & 0.99184 & 0.82608696 & 0.9976 & 0.99817273 & 0.9991 & 0.952 \\
\hline $9 / 22 / 2010$ & 0.98701 & 0.82475659 & 0.9977 & 0.99589546 & 0.99513333 & 0.9537 \\
\hline 9/23/2010 & 0.980495 & 0.78165794 & 0.998 & 0.99537046 & 0.99323333 & 0.95 \\
\hline $9 / 24 / 2010$ & 0.980595 & 0.752664 & 0.9994 & 0.99066136 & 0.9945 & 0.9508 \\
\hline $9 / 25 / 2010$ & 0.97167 & 0.76004957 & 0.9996 & 0.98475909 & 0.98723333 & 0.9487 \\
\hline $9 / 26 / 2010$ & 0.979745 & 0.78225387 & 1 & 0.99558636 & 0.9978 & 0.9491 \\
\hline $9 / 27 / 2010$ & 0.988185 & 0.84714498 & 1 & 0.99642273 & 1 & 0.9563 \\
\hline $9 / 28 / 2010$ & 0.98731 & 0.86519276 & 1 & 0.98995455 & 0.99973333 & 0.9593 \\
\hline $9 / 29 / 2010$ & 0.981605 & 0.95593424 & 1 & 0.99169318 & 0.99426667 & 0.9579 \\
\hline $9 / 30 / 2010$ & 0.98172 & 0.99825839 & 1 & 0.98983636 & 0.99543333 & 0.9588 \\
\hline $10 / 1 / 2010$ & 0.985195 & 0.99909326 & 1 & 0.99040682 & 0.99526667 & 0.9669 \\
\hline $10 / 2 / 2010$ & 0.99566 & 1 & 1 & 0.99892955 & 1 & 0.9919 \\
\hline $10 / 3 / 2010$ & 0.999395 & 1 & 1 & 0.99971364 & 1 & 1 \\
\hline $10 / 4 / 2010$ & 0.999865 & 0.99981909 & 1 & 0.99923636 & 1 & 1 \\
\hline $10 / 5 / 2010$ & 1 & 0.9998118 & 1 & 0.99922955 & 1 & 1 \\
\hline
\end{tabular}




\begin{tabular}{|c|c|c|c|c|c|c|}
\hline Category & Coal & Coal & NGCC & NGCC & Nuclear & Nuclear \\
\hline Cooling & $\begin{array}{c}\text { Once- } \\
\text { through }\end{array}$ & $\begin{array}{c}\text { Cooling } \\
\text { tower }\end{array}$ & $\begin{array}{c}\text { Once- } \\
\text { through }\end{array}$ & $\begin{array}{c}\text { Cooling } \\
\text { tower }\end{array}$ & $\begin{array}{c}\text { Once- } \\
\text { through }\end{array}$ & $\begin{array}{c}\text { Cooling } \\
\text { tower }\end{array}$ \\
\hline \multicolumn{7}{|l|}{ Dates } \\
\hline 10/6/2010 & 1 & 1 & 1 & 0.99955682 & 1 & 1 \\
\hline $10 / 7 / 2010$ & 1 & 1 & 1 & 1 & 1 & 1 \\
\hline 10/8/2010 & 1 & 1 & 1 & 1 & 1 & 1 \\
\hline 10/9/2010 & 1 & 1 & 1 & 1 & 1 & 1 \\
\hline $10 / 10 / 2010$ & 1 & 1 & 1 & 1 & 1 & 1 \\
\hline $10 / 11 / 2010$ & 1 & 1 & 1 & 0.99997273 & 1 & 1 \\
\hline $10 / 12 / 2010$ & 1 & 0.99995957 & 1 & 0.99975455 & 1 & 1 \\
\hline $10 / 13 / 2010$ & 1 & 1 & 1 & 1 & 1 & 1 \\
\hline $10 / 14 / 2010$ & 1 & 1 & 1 & 1 & 1 & 1 \\
\hline $10 / 15 / 2010$ & 1 & 1 & 1 & 1 & 1 & 1 \\
\hline $10 / 16 / 2010$ & 1 & 1 & 1 & 1 & 1 & 1 \\
\hline $10 / 17 / 2010$ & 1 & 1 & 1 & 1 & 1 & 1 \\
\hline $10 / 18 / 2010$ & 1 & 1 & 1 & 1 & 1 & 1 \\
\hline $10 / 19 / 2010$ & 1 & 1 & 1 & 1 & 1 & 1 \\
\hline $10 / 20 / 2010$ & 1 & 1 & 1 & 1 & 1 & 1 \\
\hline $10 / 21 / 2010$ & 1 & 1 & 1 & 1 & 1 & 1 \\
\hline $10 / 22 / 2010$ & 1 & 1 & 1 & 1 & 1 & 1 \\
\hline $10 / 23 / 2010$ & 1 & 1 & 1 & 1 & 1 & 1 \\
\hline $10 / 24 / 2010$ & 1 & 1 & 1 & 1 & 1 & 1 \\
\hline $10 / 25 / 2010$ & 1 & 1 & 1 & 0.99991136 & 1 & 1 \\
\hline $10 / 26 / 2010$ & 1 & 0.99996126 & 1 & 0.99976818 & 1 & 1 \\
\hline $10 / 27 / 2010$ & 1 & 0.99954628 & 1 & 0.99964546 & 1 & 1 \\
\hline $10 / 28 / 2010$ & 1 & 0.99994859 & 1 & 0.99965227 & 1 & 1 \\
\hline $10 / 29 / 2010$ & 1 & 1 & 1 & 1 & 1 & 1 \\
\hline 10/30/2010 & 1 & 1 & 1 & 1 & 1 & 1 \\
\hline $10 / 31 / 2010$ & 1 & 1 & 1 & 1 & 1 & 1 \\
\hline $11 / 1 / 2010$ & 1 & 1 & 1 & 1 & 1 & 1 \\
\hline $11 / 2 / 2010$ & 1 & 1 & 1 & 1 & 1 & 1 \\
\hline $11 / 3 / 2010$ & 1 & 1 & 1 & 1 & 1 & 1 \\
\hline $11 / 4 / 2010$ & 1 & 1 & 1 & 1 & 1 & 1 \\
\hline $11 / 5 / 2010$ & 1 & 1 & 1 & 0.99979546 & 1 & 1 \\
\hline $11 / 6 / 2010$ & 1 & 1 & 1 & 1 & 1 & 1 \\
\hline $11 / 7 / 2010$ & 1 & 1 & 1 & 1 & 1 & 1 \\
\hline $11 / 8 / 2010$ & 1 & 1 & 1 & 1 & 1 & 1 \\
\hline $11 / 9 / 2010$ & 1 & 1 & 1 & 1 & 1 & 1 \\
\hline $11 / 10 / 2010$ & 1 & 1 & 1 & 1 & 1 & 1 \\
\hline $11 / 11 / 2010$ & 1 & 1 & 1 & 1 & 1 & 1 \\
\hline $11 / 12 / 2010$ & 1 & 1 & 1 & 1 & 1 & 1 \\
\hline $11 / 13 / 2010$ & 1 & 1 & 1 & 1 & 1 & 1 \\
\hline $11 / 14 / 2010$ & 1 & 1 & 1 & 1 & 1 & 1 \\
\hline
\end{tabular}




\begin{tabular}{|c|c|c|c|c|c|c|}
\hline Category & Coal & Coal & NGCC & NGCC & Nuclear & Nuclear \\
\hline Cooling & $\begin{array}{c}\text { Once- } \\
\text { through }\end{array}$ & $\begin{array}{c}\text { Cooling } \\
\text { tower }\end{array}$ & $\begin{array}{c}\text { Once- } \\
\text { through }\end{array}$ & $\begin{array}{c}\text { Cooling } \\
\text { tower }\end{array}$ & $\begin{array}{c}\text { Once- } \\
\text { through }\end{array}$ & $\begin{array}{c}\text { Cooling } \\
\text { tower }\end{array}$ \\
\hline \multicolumn{7}{|l|}{ Dates } \\
\hline $11 / 15 / 2010$ & 1 & 1 & 1 & 1 & 1 & 1 \\
\hline $11 / 16 / 2010$ & 1 & 1 & 1 & 1 & 1 & 1 \\
\hline $11 / 17 / 2010$ & 1 & 1 & 1 & 1 & 1 & 1 \\
\hline $11 / 18 / 2010$ & 1 & 1 & 1 & 1 & 1 & 1 \\
\hline $11 / 19 / 2010$ & 1 & 1 & 1 & 1 & 1 & 1 \\
\hline $11 / 20 / 2010$ & 1 & 1 & 1 & 1 & 1 & 1 \\
\hline $11 / 21 / 2010$ & 1 & 1 & 1 & 1 & 1 & 1 \\
\hline $11 / 22 / 2010$ & 1 & 1 & 1 & 1 & 1 & 1 \\
\hline $11 / 23 / 2010$ & 1 & 1 & 1 & 1 & 1 & 1 \\
\hline $11 / 24 / 2010$ & 1 & 1 & 1 & 1 & 1 & 1 \\
\hline $11 / 25 / 2010$ & 1 & 1 & 1 & 1 & 1 & 1 \\
\hline $11 / 26 / 2010$ & 1 & 1 & 1 & 1 & 1 & 1 \\
\hline $11 / 27 / 2010$ & 1 & 1 & 1 & 1 & 1 & 1 \\
\hline $11 / 28 / 2010$ & 1 & 1 & 1 & 1 & 1 & 1 \\
\hline $11 / 29 / 2010$ & 1 & 1 & 1 & 1 & 1 & 1 \\
\hline $11 / 30 / 2010$ & 1 & 1 & 1 & 1 & 1 & 1 \\
\hline $12 / 1 / 2010$ & 1 & 1 & 1 & 1 & 1 & 1 \\
\hline $12 / 2 / 2010$ & 1 & 1 & 1 & 1 & 1 & 1 \\
\hline $12 / 3 / 2010$ & 1 & 1 & 1 & 1 & 1 & 1 \\
\hline $12 / 4 / 2010$ & 1 & 1 & 1 & 1 & 1 & 1 \\
\hline $12 / 5 / 2010$ & 1 & 1 & 1 & 1 & 1 & 1 \\
\hline $12 / 6 / 2010$ & 1 & 1 & 1 & 1 & 1 & 1 \\
\hline $12 / 7 / 2010$ & 1 & 1 & 1 & 1 & 1 & 1 \\
\hline $12 / 8 / 2010$ & 1 & 1 & 1 & 1 & 1 & 1 \\
\hline $12 / 9 / 2010$ & 1 & 1 & 1 & 1 & 1 & 1 \\
\hline $12 / 10 / 2010$ & 1 & 1 & 1 & 1 & 1 & 1 \\
\hline $12 / 11 / 2010$ & 1 & 1 & 1 & 1 & 1 & 1 \\
\hline $12 / 12 / 2010$ & 1 & 1 & 1 & 1 & 1 & 1 \\
\hline $12 / 13 / 2010$ & 1 & 1 & 1 & 1 & 1 & 1 \\
\hline $12 / 14 / 2010$ & 1 & 1 & 1 & 1 & 1 & 1 \\
\hline $12 / 15 / 2010$ & 1 & 1 & 1 & 1 & 1 & 1 \\
\hline $12 / 16 / 2010$ & 1 & 1 & 1 & 1 & 1 & 1 \\
\hline $12 / 17 / 2010$ & 1 & 1 & 1 & 1 & 1 & 1 \\
\hline $12 / 18 / 2010$ & 1 & 1 & 1 & 1 & 1 & 1 \\
\hline $12 / 19 / 2010$ & 1 & 1 & 1 & 1 & 1 & 1 \\
\hline $12 / 20 / 2010$ & 1 & 1 & 1 & 1 & 1 & 1 \\
\hline $12 / 21 / 2010$ & 1 & 1 & 1 & 1 & 1 & 1 \\
\hline $12 / 22 / 2010$ & 1 & 1 & 1 & 1 & 1 & 1 \\
\hline $12 / 23 / 2010$ & 1 & 1 & 1 & 1 & 1 & 1 \\
\hline $12 / 24 / 2010$ & 1 & 1 & 1 & 1 & 1 & 1 \\
\hline
\end{tabular}




\begin{tabular}{|c|c|c|c|c|c|c|}
\hline Category & Coal & Coal & NGCC & NGCC & Nuclear & Nuclear \\
\hline Cooling & $\begin{array}{c}\text { Once- } \\
\text { through }\end{array}$ & $\begin{array}{c}\text { Cooling } \\
\text { tower }\end{array}$ & $\begin{array}{c}\text { Once- } \\
\text { through }\end{array}$ & $\begin{array}{c}\text { Cooling } \\
\text { tower }\end{array}$ & $\begin{array}{c}\text { Once- } \\
\text { through }\end{array}$ & $\begin{array}{c}\text { Cooling } \\
\text { tower }\end{array}$ \\
\hline \multicolumn{7}{|l|}{ Dates } \\
\hline $12 / 25 / 2010$ & 1 & 1 & 1 & 1 & 1 & 1 \\
\hline $12 / 26 / 2010$ & 1 & 1 & 1 & 1 & 1 & 1 \\
\hline $12 / 27 / 2010$ & 1 & 1 & 1 & 1 & 1 & 1 \\
\hline $12 / 28 / 2010$ & 1 & 1 & 1 & 1 & 1 & 1 \\
\hline $12 / 29 / 2010$ & 1 & 1 & 1 & 1 & 1 & 1 \\
\hline $12 / 30 / 2010$ & 1 & 1 & 1 & 1 & 1 & 1 \\
\hline $12 / 31 / 2010$ & 1 & 1 & 1 & 1 & 1 & 1 \\
\hline
\end{tabular}

NGCC=natural gas combined cycle 


\section{Appendix C. Annual Generation Results}

\section{No-Curtailment Scenarios}

Table C - 1. Annual Generation from Technologies under Scenarios with No Curtailments (GWh)

\begin{tabular}{|l|l|l|l|l|l|l|l|l|l|}
\hline & NGCC & Coal & NGCT & DR & Hydro & Nuclear & Other & Solar & Wind \\
\hline Baseline (No DR) & 23,421 & 31,820 & 859 & & 4,190 & 10,483 & 281 & 1,939 & 5,546 \\
\hline $\mathbf{0 \%}$ OT (No DR) & 23,298 & 32,006 & 870 & & 4,184 & 10,449 & 281 & 1,939 & 5,545 \\
\hline $\mathbf{0 \%}$ OT (DR) & 23,058 & 32,296 & 910 & 108 & 4,233 & 10,288 & 281 & 1,947 & 5,503 \\
\hline $\mathbf{2 0} \%$ OT (No DR) & 24,430 & 31,055 & 907 & & 4,216 & 10,325 & 281 & 1,933 & 5,391 \\
\hline $\mathbf{2 0 \%}$ OT (DR) & 22,452 & 32,746 & 938 & 110 & 4,242 & 10,325 & 281 & 1,975 & 5,544 \\
\hline $\mathbf{4 0 \%}$ OT (No DR) & 24,063 & 31,441 & 810 & & 4,178 & 10,363 & 281 & 1,922 & 5,485 \\
\hline $\mathbf{4 0 \%}$ OT (DR) & 22,190 & 32,868 & 1,003 & 108 & 4,226 & 10,363 & 281 & 1,981 & 5,548 \\
\hline $\mathbf{6 0} \%$ OT (No DR) & 23,637 & 31,633 & 934 & & 4,163 & 10,400 & 281 & 1,929 & 5,517 \\
\hline $\mathbf{6 0} \%$ OT (DR) & 22,877 & 32,305 & 906 & 109 & 4,215 & 10,400 & 281 & 1,959 & 5,551 \\
\hline $\mathbf{8 0} \%$ OT (No DR) & 24,597 & 30,865 & 919 & & 4,311 & 10,431 & 281 & 1,935 & 5,384 \\
\hline $\mathbf{8 0 \%}$ OT (DR) & 22,710 & 32,402 & 917 & 111 & 4,188 & 10,437 & 281 & 1,962 & 5,554 \\
\hline $\mathbf{1 0 0} \%$ OT (No DR) & 23,128 & 32,062 & 916 & & 4,207 & 10,474 & 281 & 1,960 & 5,509 \\
\hline $\mathbf{1 0 0 \% ~ O T ~ ( D R ) ~}$ & 22,260 & 32,759 & 947 & 107 & 4,265 & 10,474 & 281 & 1,983 & 5,552 \\
\hline
\end{tabular}

OT=once-through cooling; NGCC=natural gas combined cycle; NGCT=natural gas combustion turbine; $\mathrm{DR}=$ demand response

\section{Curtailment Scenarios}

Table C - 2. Annual Generation from Technologies under Scenarios with Curtailments (GWh)

\begin{tabular}{|l|l|l|l|l|l|l|l|l|l|}
\hline & NGCC & Coal & NGCT & DR & Hydro & Nuclear & Other & Solar & Wind \\
\hline Baseline (no DR) & 23,421 & 31,820 & 859 & & 4,190 & 10,483 & 281 & 1,939 & 5,546 \\
\hline $\mathbf{0 \%}$ OT (No DR) & 23,298 & 32,006 & 870 & & 4,184 & 10,449 & 281 & 1,939 & 5,545 \\
\hline $\mathbf{0 \%}$ OT (DR) & 23,058 & 32,296 & 910 & 108 & 4,233 & 10,288 & 281 & 1,947 & 5,503 \\
\hline $\mathbf{2 0} \%$ OT (No DR) & 24,424 & 31,473 & 721 & & 4,226 & 10,008 & 281 & 1,941 & 5,534 \\
\hline $\mathbf{2 0 \%}$ OT (DR) & 22,808 & 32,719 & 908 & 110 & 4,228 & 10,025 & 281 & 1,983 & 5,550 \\
\hline $\mathbf{4 0 \%}$ OT (No DR) & 24,719 & 31,959 & 762 & & 4,204 & 9,207 & 281 & 1,957 & 5,498 \\
\hline $\mathbf{4 0 \%}$ OT (DR) & 23,774 & 32,258 & 869 & 108 & 4,238 & 9,601 & 281 & 1,966 & 5,550 \\
\hline $\mathbf{6 0} \%$ OT (No DR) & 25,410 & 31,097 & 864 & & 4,132 & 9,209 & 281 & 1,929 & 5,540 \\
\hline $\mathbf{6 0} \%$ OT (DR) & 24,254 & 32,205 & 930 & 110 & 4,210 & 9,128 & 281 & 1,963 & 5,553 \\
\hline $\mathbf{8 0 \%}$ OT (No DR) & 25,648 & 31,380 & 826 & & 4,145 & 8,753 & 281 & 1,929 & 5,532 \\
\hline $\mathbf{8 0 \%}$ OT (DR) & 24,452 & 32,269 & 905 & 111 & 4,227 & 8,818 & 281 & 1,983 & 5,559 \\
\hline $\mathbf{1 0 0} \%$ OT (No DR) & 25,394 & 31,933 & 929 & & 4,182 & 8,247 & 281 & 1,979 & 5,551 \\
\hline $\mathbf{1 0 0} \%$ OT (DR) & 25,274 & 31,829 & 967 & 110 & 4,206 & 8,383 & 281 & 1,966 & 5,544 \\
\hline
\end{tabular}

OT=once-through cooling; NGCC=natural gas combined cycle; NGCT=natural gas combustion turbine; $\mathrm{DR}=$ demand response 


\section{Appendix D. Daily Generation Results during Summer Months}

\section{No-Curtailment Scenarios}

Considering the different impacts that cooling systems can have on the deployment of generators, especially during summer months, Figure D - 1 highlights how the baseline scenario compares with $100 \%$ recirculating cooling and $100 \%$ once-through cooling.
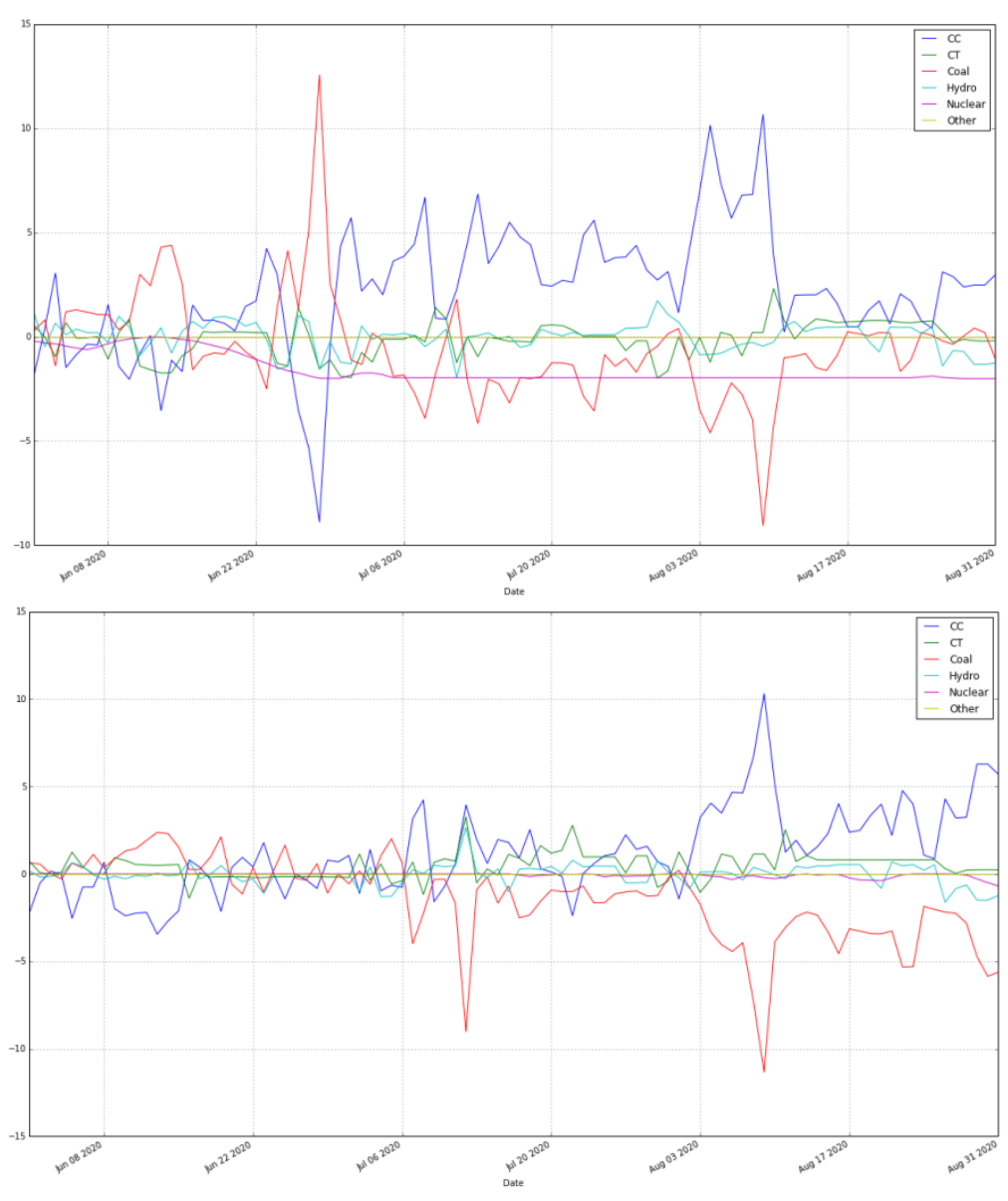

Figure D - 1. Comparison of generation mixes on an hourly basis for summer months (June, July, and August) for $100 \%$ recirculating cooling thermal systems (top) and $100 \%$ once-through cooling systems (bottom) with no curtailments compared with the baseline scenario

$$
\mathrm{CC}=\text { combined cycle; } \mathrm{CT}=\text { combustion turbine }
$$

Although there are some similar trends between the two scenarios on an annual basis and during some summer time periods, there are noticeable differences between the performance and dispatch of the system, especially at the end of June and the middle of July, when the two systems show contrasting trends in coal and natural gas combined cycle generation. 


\section{Curtailment Scenarios}

Considering the different impacts that cooling systems can have on the deployment of generators for curtailment scenarios, especially during summer months, Figure D - 2 highlights how the baseline scenario compares with $100 \%$ recirculating cooling and 100\% once-through cooling.
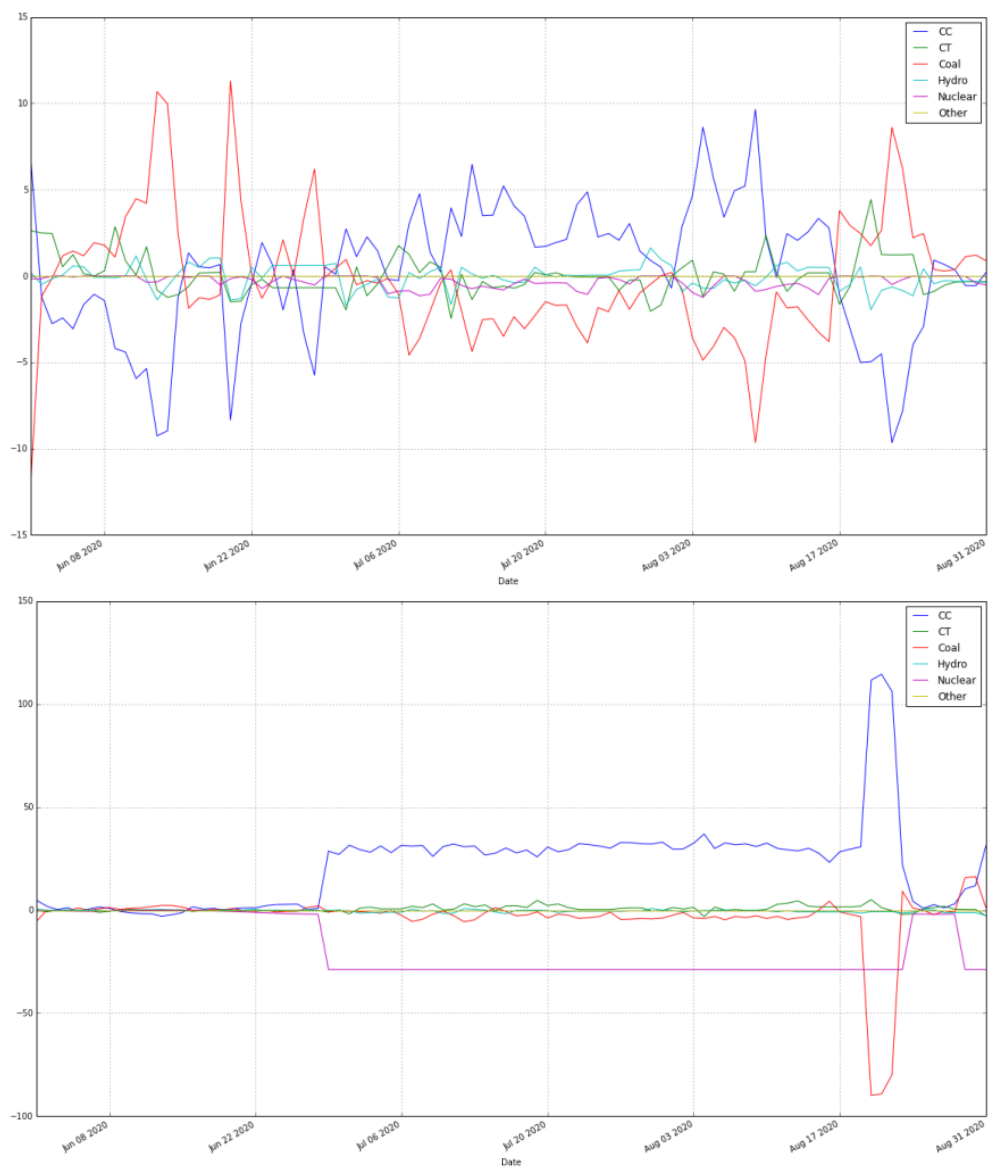

Figure D - 2. Comparison of generation mixes on an hourly basis for summer months (June, July, and August) for $100 \%$ recirculating cooling thermal systems (top) and $100 \%$ once-through cooling systems (bottom) with curtailments compared with the baseline scenario

$$
\mathrm{CC}=\text { combined cycle; } \mathrm{CT}=\text { combustion turbine }
$$

When curtailments are included, summer month generation mixes look substantially different. Under the $100 \%$ recirculating cooling scenario, generation swings alternate between coal and natural gas combined cycle generators. Under the $100 \%$ once-through cooling scenario, it is evident when curtailments start affecting both nuclear and coal-fired generation, with natural gas combined cycle generators meeting the lost generation for both technologies. 